\title{
Revisión de las especies de Hymenophyllum (Hymenophyllaceae) del sur de Argentina y Chile
}

\section{Revision of Hymenophyllum (Hymenophyllaceae) of Southern Argentina and Chile}

\author{
Cristian Larsen, M. Mónica Ponce \& M. Amalia Scataglini \\ Instituto de Botánica Darwinion (CONICET y ANCEFN), Casilla de Correo 22, B1642HYD San Isidro, Buenos Aires, Argentina. \\ clarsen@darwin.edu.ar
}

\begin{abstract}
RESUMEN
Se presenta la revisión del género Hymenophyllum (Hymenophyllaceae) para la región templada de Argentina y Chile. El estudio contiene una clave para las 22 especies reconocidas dentro de la actual definición del género, incluye descripciones enmendadas, ilustraciones y mapas de distribución geográfica. Se establecen los nombres aceptados y sinónimos nuevos de los taxones, incluyendo a Serpyllopsis caespitosa e Hymenoglossum cruentum dentro del género Hymenophyllum. Se designaron lectotipos para 21 nombres. Se incluye una filogenia, basada en secuencias del gen de cloroplasto $r b c L$, en donde se corroboran las posiciones de especies no muestreadas hasta el momento en los subgéneros correspondientes.
\end{abstract}

Palabras clave: Hymenophyllum, América austral-templada, taxonomía, filogenia.

\begin{abstract}
We present a revision of the genus Hymenophyllum (Hymenophyllaceae) for temperate regions of Argentina and Chile. The study contains a key for the 22 species recognized within the current delimitation of the genus, including descriptions amended, illustrations and distribution maps. Serpyllopsis caespitosa and Hymenoglossum cruentum are included within the genus Hymenophyllum, and new synonyms are considered for other taxa. Lectotypes were designated for 21 names. We include a phylogeny using $r b c L$ sequences, corroborating the positions of non-sampled taxa in the corresponding subgenera.
\end{abstract}

KeYwords: Hymenophyllum, austral-temperate America, taxonomy, phylogeny.

\section{INTRODUCCIÓN}

El género Hymenophyllum comprende alrededor de 250 especies distribuidas en todo el mundo (Ebihara et al. 2006), que crecen principalmente en bosques tropicales y templado-húmedos. La forma del indusio ha sido el carácter que históricamente ha definido los géneros dentro de las Hymenophyllaceae: Hymenophyllum, caracterizado tradicionalmente por la presencia de indusios bivalvos, y su género hermano Trichomanes, por sus indusios tubulares. La taxonomía entre estos dos géneros, y en general de la familia, ha sufrido varias interpretaciones a lo largo de su historia debido a que la forma de los indusios es relativamente constante en Trichomanes, mientras que no sucede lo mismo en Hymenophyllum, cuyos indusios pueden tener una continuidad de formas, desde bivalvos hasta tubulares.

El número de géneros aceptados dentro de la familia
Hymenophyllaceae varía ampliamente según los tratamientos: Christensen (1938) aceptó cuatro géneros; Copeland $(1938,1947)$ amplió la clasificación a 34 géneros, basando su trabajo en observaciones in situ y de herbario con material procedente de Asia. Morton (1968), dividió a Hymenophyllum en 5 subgéneros, 10 secciones, y 7 subsecciones y a Trichomanes en 4 subgéneros, 24 secciones y 4 subsecciones, y reconoció cuatro géneros monotípicos: Cardiomanes, Hymenoglossum, Rosenstockia y Serpyllopsis. Debido a que su estudio abarcó un análisis exhaustivo de los taxa del Nuevo Mundo, su sistema por lo general se sigue en los trabajos florísticos de América (De la Sota 1977, Kramer 1978, Proctor 1985, 1989, Mickel \& Smith 2004, Lellinger 1989, Tryon \& Stolze 1989, Rodríguez 1995, Pacheco 1995, Baksh-Comeau 2000, Sánchez 2000). Otras propuestas sistemáticas fueron realizadas por Pichi Sermolli (1977) quien consideró 42 géneros para la familia, e Iwatsuki (1984, 1990) que propuso un nuevo sistema 
jerárquico en el que incluyó sólo ocho géneros.

Los recientes estudios de filogenia molecular han esclarecido la historia evolutiva del género (Pryer et al.2001, Hennequin 2003, Hennequin et al. 2006a, 2006b, 2010). Como resultado de estas contribuciones se han incluido en Hymenophyllum a especies típicamente consideradas dentro del género hermano Trichomanes, y las pertenecientes a géneros monotípicos (e.g. Cardiomanes, Serpyllopsis, Rosenstockia, Hymenoglossum). Ebihara et al. (2006) en su revisión de la familia, realizó un análisis exhaustivo de filogenia molecular, y además completó la clasificación de la familia con el uso de caracteres morfológicos macroscópicos, proponiendo dividirla en 9 géneros, diferenciados por: la longitud del rizoma; la densidad y el color de los pelos del rizoma; la presencia o ausencia, densidad y grosor de las raíces; la venación de sus frondes (catádroma o anádroma); la presencia de falsas venillas en las láminas; el grado de división de las láminas; la simetría de las pinnas; la presencia o ausencia de tricomas en el margen de las láminas; la presencia de frondes abortivas, la presencia o no de pelos claviformes sobre pecíolos y raquis, el tipo de involucro, bivalvo o tubular, y el grosor de la lámina. En este trabajo Hymenophyllum, fue dividido en 10 subgéneros: Hymenophyllum, Mecodium, Globosa, Sphaerocionium, Pleuromanes, Hymenoglossum, Fuciformia, Cardiomanes, Diploöphyllum y Myrmecostylum; siendo el subgénero Hymenophyllum el que posee mayor número de especies, y mayores dificultades para delimitarlas, debido a su gran variabilidad morfológica y citológica.

En América del Sur se encuentran representados dentro de Hymenophyllum, los subgéneros Hymenophyllum, Sphaerocionium, Mecodium y Globosa, siendo característicos de los bosques andino-patagónicos los subgéneros Myrmecostylum, que posee cuatro especies locales (una de ellas también en Brasil) de un total de ocho (el resto crece en Nueva Zelanda y Nueva Caledonia), Fuciformia, que cuenta con una especie en el área de estudio y otra en Nueva Zelanda; e Hymenoglossum, que cuenta con un total de tres especies, de las cuales una se encuentra en el área de estudio, otra en la parte tropical de Sudamérica y Centroamérica, y la restante en Madagascar. Para la región austral de América del Sur, Diem \& Lichtenstein (1959) estudiaron las Hymenophyllaceae de los bosques subantárticos de Argentina y Chile, considerando 21 especies para el género Hymenophyllum, 3 especies para el género Trichomanes, y 1 para Serpyllopsis.

Posteriormente la familia fue tratada para la Flora de Chile (Rodríguez 1995) y Flora Patagónica (De la Sota et al. 1998), y en exploraciones más recientes se ampliaron las distribuciones de varias especies (Vidoz et al. 1999, Cassá de Pasos et al. 2010).

La actual delimitación de los géneros y subgéneros, el reagrupamiento de las especies dentro de ellos, y la reevaluación de los caracteres morfológicos para identificar los taxones, además del requerimiento permanente de la actualización florística, plantearon la necesidad de una revisión sistemática de estos helechos. El presente trabajo forma parte del estudio del género Hymenophyllum en América del Sur subtropical y templada. El tratamiento taxonómico incluye una clave, descripciones, ilustraciones y mapas de distribución para todas las especies de la región sur-templada de Chile y Argentina. Se reconocieron 22 especies, se actualizó con criterio tipológico los nombres aceptados y los sinónimos, se esclareció la identidad de taxones confusos, se realizaron lectotipificaciones para 21 nombres, y se delimitaron taxones infraespecíficos poco claros. Además se presenta un análisis fillogenético basado en secuencias del gen $r b c L$, a fin de evaluar las posiciones de las especies de Hymenophyllum muestreadas por primera vez para la región andino-patagónica, dentro de la filogenia propuesta para la familia.

Como resultado de la actual revisión se describen en la región andino-patagónica 17 taxones endémicos: Hymenophyllum caespitosum Gaudich., H. cruentum Cav., H. cuneatum Kunze, $H$. darwinii Hook. f. ex Bosch, $H$. dentatum Cav., H. dicranotrichum (C. Presl) Hook. ex. Sadeb., H. falklandicum Baker, H. fuciforme Sw., $H$. krauseanum Phil., H. nahuelhuapiense Diem \& J. S. Licht., $H$. pectinatum Cav., H. plicatum Kaulf., H. quetrihuense Diem \& J. S. Licht., H. rugosum C. Chr. ex Skottsb., $H$. secundum Hook. \& Grev., H. tortuosum Hook. \& Grev., H. umbratile Diem \& J. S. Licht. Dos especies con distribución disyunta entre el bosque valdiviano y el bosque atlántico: Hymenophyllum magellanicum (Desv.) Willd. ex Kunze e H. caudiculatum Mart., y tres con amplio rango de distribución: H. ferrugineum Colla, se halla también en Australia y Nueva Zelanda; H. peltatum (Poir.) Desv., se encuentra en África y Madagascar, e H. tunbrigense (L.) Sm., en Europa y Oceanía.

\section{ÁREA DE ESTUDIO}

El área de estudio corresponde al Dominio Subantártico sensu Cabrera \& Willink (1973), incluyendo la totalidad de sus provincias (Subantártica, Insular y de Juan Fernández). En Chile coincide casi exclusivamente con el área al sur del río Maule, aproximadamente sobre el paralelo $35^{\circ}$, con la excepción de un pequeño relicto situado $500 \mathrm{~km}$ al norte de este punto, los Bosques de Talinay y Fray Jorge, y del archipiélago de Juan Fernández. En la Argentina el límite norte se encuentra mucho más hacia el sur, aproximadamente en $39^{\circ} 40^{\prime}$, en cercanías del Lago Huechulaufquen (Diem \& Lichtenstein, 1959), y se extiende hacia el sur de manera restringida a ciertas áreas más o menos puntuales en general muy cerca o lindantes con Chile, hasta Tierra del Fuego, Isla de los Estados, Georgias del Sur e Islas Malvinas (Fig. 1). 


\section{Provincias de Argentina}

NQN: Neuquén

RN: Rio Negro

$\mathrm{CHU}$ : Chubut

SC: Santa Cruz

TF: Tierra del Fuego

Islas

IM: Islas Malvinas (Falkland)

MAf: Mas Afuera (Juan Fernández)

MAt: Mas a Tierra (Juan Fernández)

$\mathrm{G}$ : Islas Georgias

\section{Regiones de Chile}

IV: Coquimbo

V: Valparaíso

M: Metropolitana

VI: O'Higgins

VII: Maule

VIII: Bío-Bio

IX: Araucanía

XIV: de los Ríos

$X$ : de los Lagos

XI: Aisén del Gral. C.I. del Campo

XII: Magallanes
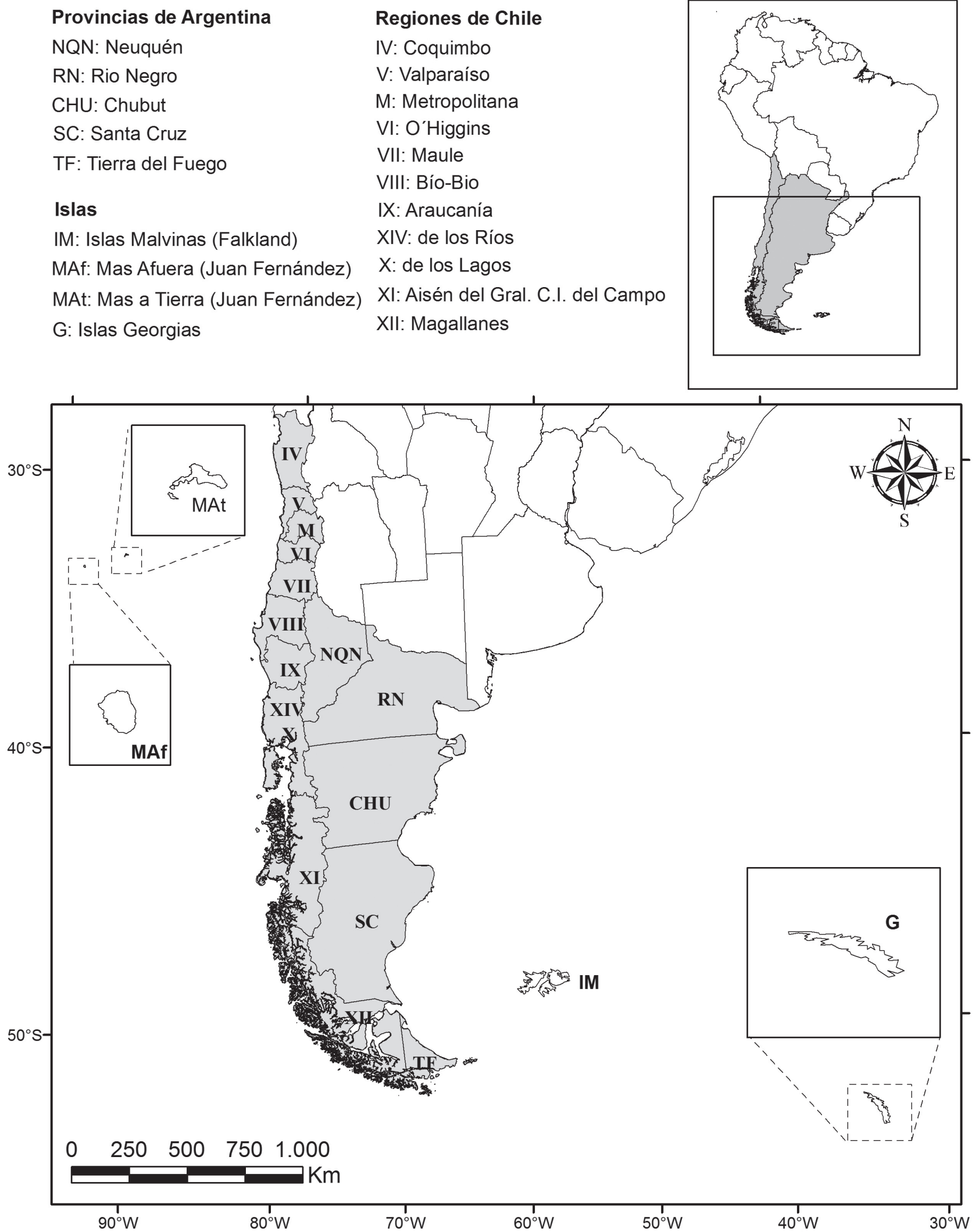

Figura 1. Área de estudio.

Figure 1. Area of study. 


\section{MATERIALES Y MÉTODOS}

ESTUDIO TAXONÓMICO

Se analizaron alrededor de 1.000 ejemplares depositados en los herbarios BA, BAB, BCRU, CONC, CORD, CTES, LIL, LP, SI (Thiers [continuously updated]). Una parte importante de los especímenes estudiados fueron recolectados en el área de estudio en exploraciones recientes, realizándose fijación de muestras, observaciones de las plantas a campo y de sus ambientes.

Para la aplicación de los nombres correctos, sus sinónimos y para resolver problemas de taxones poco claros, se examinaron ejemplares de 70 tipos nomenclaturales, depositados en los herbarios B, BA, BM, BAB, BR, E, GB, GH, K, LE, LINN, OXF, LP, MA, P, PR, S, SGO, SI, TO, UPS, US, W.

Para las descripciones morfológicas se siguió la terminología propuesta por Lellinger (2002). Las descripciones se basaron en caracteres vegetativos y reproductivos: tipo de rizoma, pelos rizomáticos, longitud, sección y presencia de alas en el pecíolo, disposición de las frondes; contorno y división de la lámina, margen, tipo y posición de los tricomas; color, pilosidad y tipo de alas de los ejes; forma, división y tamaño de las pinnas; forma, ancho y ápice de los segmentos; número y posición de los soros en la pinna y con respecto al plano de la lámina; forma e inmersión en la lámina de los involucros; y forma y posición de los receptáculos. Muchos de estos caracteres fueron usados para separar géneros (Copeland 1938) y en la clasificación actual para diferenciar subgéneros (Ebihara et al. 2006, Hennequin et al. 2006b).

ESTUDIO FILOGENÉTICO

Selección de taxones: se obtuvieron 9 secuencias del gen de cloroplasto rbcL para 7 especies de Hymenophyllum del Cono sur no analizadas hasta el momento con datos moleculares. Las mismas se analizaron junto a una selección de 39 secuencias de Hymenophyllum obtenidos de Hennequin et al. (2010), representando los diferentes subgéneros presentes en el área de estudio. Trichomanes rigidum Sw. fue utilizado para enraizar el árbol. El detalle de las especies secuenciadas en este trabajo y de las obtenidas en el Genbank se muestra en el Apéndice.

Extracción, amplificación y secuenciación del ADN: las extracciones de los ejemplares colectados en silicagel, se realizaron siguiendo el protocolo de "total CTAB" propuesto por Doyle \& Doyle (1987). Para las extracciones de ejemplares de herbario se utilizó el DNeasy Plant Mini Kit (Qiagen). El gen de $r b c L$ fue amplificado en dos mitades utilizando los cebadores específicos 1F-675R y 660F-1351R (Gastony \& Rollo 1995). Las condiciones de amplificación utilizadas fueron: un primer período de desnaturalización a $94^{\circ} \mathrm{C}$ durante 5 , , seguido de 35 ciclos de desnaturalización a $94{ }^{\circ} \mathrm{C}$ por $30^{\prime \prime}$, pegado del cebador a $48^{\circ} \mathrm{C}$ durante 1 ', y extensión a $72^{\circ} \mathrm{C}$ durante 1 ' 30 '. Un ciclo de $6^{\prime}$ de extensión final a $72{ }^{\circ} \mathrm{C}$ durante 6 ' finaliza las reacciones. Los fragmentos obtenidos se secuenciaron automáticamente en Macrogen Inc. La edición y alineamiento de las secuencias obtenidas se realizó con el programa Bioedit.

Análisis de datos: el análisis filogenético se realizó bajo el criterio de parsimonia utilizando el programa TNT (Goloboff et al. 2008). La estrategia de búsqueda consistió en 1.000 secuencias de adición seguidas por rearreglos de ramas del tipo TBR, reteniendo 10 árboles por réplica con una memoria total de 20.000 árboles. Se realizaron árboles de consenso estricto y se estimaron los soportes de rama por el método de Bootstrap.

\section{ANÁLISIS MOLECULAR}

Resultados

La matriz utilizada en el análisis filogenético constó de 49 taxones y 1.206 caracteres, de los cuales 119 resultaron informativos. Se obtuvieron 14 árboles más parsimoniosos de 332 pasos $(\mathrm{CI}=0,45$ y $\mathrm{RI}=0,65)$. $\mathrm{El}$ árbol de consenso estricto se muestra en la Figura 2.

Cinco de los subgéneros presentes en el área resultaron monofiléticos, corroborando lo obtenido por Hennequin et al. (2010): Fuciformia, Myrmecostylum, Hymenoglossum, Mecodium y Sphaerocionium. Los otros dos subgéneros resultaron polifiléticos: Hymenophyllum, ya que $H$. dicranotrichum apareció como especie hermana del subgénero Sphaerocionium; y Globosa, que se mostró dividido en tres clados consecutivos, hermanos del resto de las especies analizadas. Estas dos diferencias con respecto a Hennequin et al. (2010) no presentan soporte y se deben probablemente al uso de un único marcador en el presente trabajo en lugar del dataset completo utilizado por Hennequin et al. (2010).

Las nuevas especies secuenciadas para este trabajo se ubicaron con buenos soportes dentro de los subgéneros esperados. $H$. darwinii se ubicó con $100 \%$ de soporte en Mecodium, cuya sinapomorfía es un número cromosómico base de $\mathrm{x}=28$, $\mathrm{y}$ se caracteriza por los márgenes de la fronde enteros.

Los dos vouchers de $H$. peltatum y los dos de $H$. falklandicum analizados, al igual que $H$. umbratile quedaron incluidos en uno de los clados del subgénero Hymenophyllum con $91 \%$ de soporte. Este subgénero es uno de los más diversos y las principales características son la denticulación del margen de los segmentos, y la posición de los soros, en general en el extremo de segmentos acroscópicos (Hennequin et al. 2010).

Hymenophyllum krauseanum e $H$. magellanicum se ubican en el clado correspondiente al subgénero Myrmecostylum con $100 \%$ de soporte, junto a las 2 especies locales $H$. plicatum e $H$. tortuosum. Se conocen al menos 8 especies de este subgénero, que posee pelos multicelulares en los ejes y alternativamente pelos o dientes en los márgenes de las frondes (Ebihara et al. 2006).

La especie $H$. capurroi que habita el noroeste de Argentina resultó hermana de $H$. hirsutum con 99\% de soporte y 


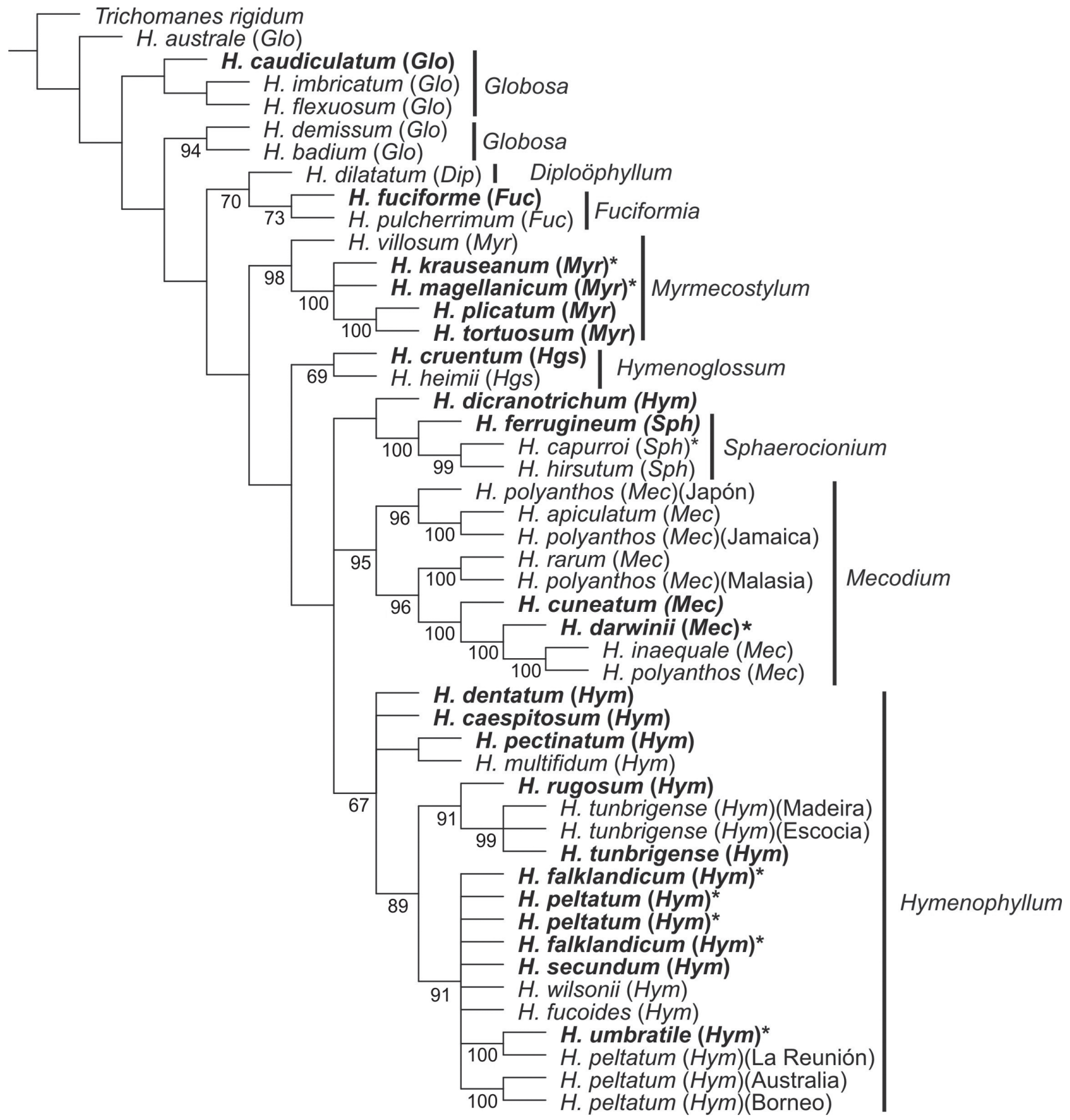

FIgURA 2. Consenso estricto de los 14 árboles más parsimoniosos obtenidos del análisis de las secuencias de $r b c L$. Los soportes de Bootstrap se muestran debajo de cada rama. En negrita se destacan las especies que habitan el área de estudio. Los asteriscos indican las secuencias generadas para el presente trabajo. Entre paréntesis se indican los subgéneros sensu (Ebihara et al. 2006): Glo: Globosa; Dip: Diploöphyllum; Fuc: Fuciformia; Myr: Myrmecostylum; Hgs: Hymenoglossum; Sph: Sphaerocionium; Mec: Mecodium; Hym: Hymenophyllum. Las barras de la derecha indican los subgéneros obtenidos. Las especies ampliamente distribuidas están representadas por más de una localidad, indicada entre paréntesis.

FIGURE 2. Strict consensus of the 14 most parsimonious trees obtained from the analysis of the $r b c L$ sequence. Bootstrap supports are shown below each branch. Bold highlights indicates species inhabiting the study area. Asterisks indicate sequences generated for this study. In each taxa parentheses indicate the subgenera sensu (Ebihara et al. 2006): Glo: Globosa; Dip: Diploöphyllum; Fuc: Fuciformia; Myr: Myrmecostylum; Hgs: Hymenoglossum; Sph: Sphaerocionium; Mec: Mecodium; Hym: Hymenophyllum. The bars on the right indicate the subgenera obtained. The widespread species are represented by more than one location listed in parentheses. 
ambas formando el clado hermano de $H$. ferrugineum, las 3 pertenecientes al subgénero Sphaerocionium, que se caracteriza por poseer pelos estrellados en sus frondes.

\section{TRATAMIENTO TAXONÓMICO}

Hymenophyllum Sm., Mem. Acad. (Turin) 5: 418, pl. 9, f. 8 . 1793. Especie tipo: H. tunbrigense (L.) Sm. (= Trichomanes tunbrigense L.).

Helechos epífitos, raramente terrestres; rizoma largamente rastrero, piloso, los tricomas castaños o rojizos; frondes delgadas y delicadas, en general pequeñas, hasta de 60 cm, [según Tryon \& Tryon (1982) cerca de $2 \mathrm{~m}$ en $H$. speciosum] monomorfas, distantes; pecíolos generalmente más cortos que la lámina, delicados, teretes, sin alas o alados, glabros a pilosos; láminas simples o lobadas a varias veces divididas, determinadas o indeterminadas, lineares a subflabeladas, planas, onduladas o crespadas, glabras o pilosas, cuando pilosas con los tricomas simples, bifurcados o estrellados; últimos segmentos con los márgenes enteros a aserrados; nervación libre, anádroma, generalmente pinnada o subflabelada, sin venillas falsas; soros marginales con involucro 2-valvado, parcialmente inmerso en la lámina a ligeramente pedunculado, orbiculares a elípticos u obovados; receptáculo filiforme a engrosado, cilíndrico a angostamente turbinado (obcónico), rudimentario o corto, hasta algo exerto en la madurez; $x=11,13,18,21,22,28,36$.

Este género posee alrededor de 250 especies en todo el mundo, y se distribuye en regiones tropicales y también en regiones templado-húmedas principalmente del hemisferio sur, con algunos representantes en la región holártica.

Estos helechos han desarrollado una estrategia higrófila, por lo que se limitan a ambientes húmedos. Son mayormente epífitos sobre troncos de árboles, en bosques húmedos, más raro terrestres o epipétricos. En sitios en donde son abundantes pueden tapizar la superficie, abarcando distintos sustratos, desde raíces y troncos de árboles vivos o muertos, troncos de helechos arborescentes hasta sobre rocas o suelo del bosque en descomposición, entremezclándose con musgos y otros helechos. En zonas tropicales, ya sea en selvas o bosques de montaña, pueden llegar hasta los 3.600 $\mathrm{m}$ s.m. En las latitudes más elevadas, pueden ser epipétricos, viviendo refugiados en "microhábitats" a la entrada de las cuevas o pozos, en los acantilados y en las matas cerca de fuentes o cascadas (Hennequin 2004).

\section{Clave de las especies de Hymenophyllum del sur de Argentina y Chile}

1. Frondes enteras (Subgén. Hymenoglossum).

3. H. cruentum

1'. Frondes pinnatífidas, pinnado-pinnatífidas o más divididas .

2. Rizomas erectos o decumbentes; frondes aglomeradas en el ápice del rizoma, valvas indusiales reducidas, dejando los esporangios a la vista (Subgén. Fuciformia) 10. H. fuciforme

2'. Rizomas rastreros o largamente rastreros; con frondes más o menos remotas a lo largo del rizoma, valvas indusiales desarrolladas, cubriendo los esporangios

...9. H. ferrugineum

3. Frondes pilosas, pelos estrellados (Subgén. Sphaerocionium)

3'. Frondes glabras, glabrescentes o si pilosas con pelos simples o bifurcados .......

4. Indusios orbiculares; receptáculos obovados u orbiculares. Rizomas gruesos (en general > 0,4 mm diám.), glabros o con escasos pelos castaños (Subgén. Globosa)

2. H. caudiculatum

4'. Indusios de formas variadas pero nunca orbiculares; receptáculos filiformes, fusiformes o claviformes. Rizomas filiformes $(<0,4$ mm diám.) pilosos, pelos castaños a ferrugíneos

5. Margen de los segmentos entero, sin pelos sobre las nervaduras y/o márgenes. Costas y nervaduras verdes, no lignificadas (Subgén. Mecodium)

6. Indusios de base y ápice agudos. Láminas pequeñas, de 1-4 cm long., de margen ondulado o algo plegado, raramente plano ...

6'. Indusios de base subaguda y ápice redondo a obtuso. Láminas mayores, de 3,5-9,5 cm long., de margen generalmente plano 4. H. cuneatum

5'. Margen de los segmentos aserrado, dentado a ciliado, si enteros, entonces con pelos sobre las nervaduras y/o márgenes. Costas y nervaduras parduscas u oscuras, lignificadas

7. Follaje plano o con el margen recurvado, margen entero o dentado; pecíolos no alados (Subgén. Hymenophyllum) ................8 8. Frondes pinnadas de margen entero; pinnas simples, pecíolos y raquis pilosos, involucros obcónicos ........1. H. caespitosum 8'. Frondes pinnatífidas, pinnado-pinnatífidas o más divididas, margen entero, dentado o aserrado, pecíolos y raquis pilosos o glabros; involucros orbiculares, ovados o elípticos...

9. Láminas con pelos bifurcados sobre su superficie 7. H. dicranotrichum

9'. Láminas generalmente glabras o con pelos simples sólo sobre los ejes

10. Soros sobre ambos lados de las pinnas

10'. Soros sólo sobre el lado acroscópico de las pinnas ......

11. Pinnas flabeladas a falcadas o trapeciformes, con la nervadura primaria o costa en la parte inferior de la pinna, recta o arqueada, dividiéndose acroscópicamente, dando lugar a segmentos simples o más divididos, paralelos o no..........12 12. Soros generalmente sobre segmentos no reducidos, del mismo ancho o levemente más angostos que el indusio, no arqueados en la base, en el mismo plano que la lámina. Indusios lanceolados. Segmentos paralelos .....................13 13. Pecíolo y base del raquis con pelos parduscos, escasos. Plantas de $3-10 \mathrm{~cm}$ alt. 
12'. Soros generalmente sobre segmentos reducidos, angostamente alados a lobulados, mas o menos arqueados en la base o arqueándose a la madurez, en el mismo plano que la lámina o no. Indusios ovados a oblongos. Segmentos no paralelos entre sí .....

14. Todas las pinnas 2-3-furcadas, las basales raramente 4-furcadas. Láminas angostas, de 0,5-1,5 cm lat., 1 indusio por pinna, raramente más

8. H. falklandicum

14'. Pinnas basales y/o medias en general 4-furcadas o más. Láminas más anchas, de 0,9-5 cm. Generalmente más de 1 indusio por pinna, hasta 4

15. Costas, cóstulas y últimos segmentos fuertemente arqueados o reflexos, segmentos generalmente angostos (menos de $1 \mathrm{~mm}$ ), con márgenes recurvados

19. H. secundum

15'. Costas y últimos segmentos rectos o arqueados, segmentos más anchos (más de $1 \mathrm{~mm}$ ), con márgenes planos o levemente recurvados

16. Ápice de los indusios entero, agudo o redondeado. Soros arqueados, frecuentemente en un plano perpendicular al plano de la lámina, sobre un pedicelo relativamente corto hasta del largo del indusio y angostamente alado. Pinnas fértiles terminadas en 2-4 lacinias de ancho normal

16'. Ápice de los indusios irregularmente dentado, redondeado. Soros levemente arqueados en la base, en el mismo plano de la lámina, sobre segmentos de longitud desigual, con alas más angostas o en ocasiones lobuladas, más anchas que el indusio. Pinnas fértiles terminadas generalmente en una lacinia alargada y ensanchada

22. H. umbratile

11'. Pinnas rómbicas, o lanceoladas a ovado-lanceoladas (por lo menos las basales), con la nervadura primaria o costa central o generando segmentos hacia ambos lados, tomando en ocasiones un aspecto simpodial

17. Todas las pinnas con segmentos hacia ambos lados, lanceoladas. Plantas endémicas de Juan Fernández. Frondes medianas (hasta $15 \mathrm{~cm}$ ) 18. H. rugosum

17'. Sólo las pinnas basales con segmentos hacia ambos lados, las demás sólo, o más desarrolladas acroscópicamente.

Plantas no endémicas de Juan Fernández. Frondes pequeñas (hasta $10 \mathrm{~cm}$ ) . ....18

18. Pecíolos y raquis con pelos rojizos. Frondes en general densas, con pinnas imbricadas. Plantas formando cojines tupidos, densos, de color verde oscuro. Margen del indusio en general eroso o dentado, receptáculo cilíndrico .........

.21. H. tunbrigense

18'. Pecíolos y raquis glabros. Frondes en general elongadas, con pinnas distanciadas. Plantas delicadas, no en cojines, de color verde claro a amarillento. Margen del indusio entero o levemente eroso, receptáculo algo engrosado, claviforme o fusiforme

13. H. nahuelhuapiense

7'. Follaje levemente ondulado, crespo o plegado, margen eroso, dentado-ciliado a ciliado. Pecíolos con alas onduladas, crespas o plegadas, por lo menos en la planta joven (Subgén. Myrmecostylum)

19. Indusios con ápice entero, cuspidado, valvas indusiales frecuentemente 3-4-partidas a la madurez. Follaje densamente plegado, margen irregular a dentado

19'. Indusios con ápice dentado o ciliado, valvas indusiales siempre 2-partidas, Follaje levemente ondulado a crespo, margen con dientes o cilias . .20

20. Indusios elípticos de ápice leve o fuertemente acuminado, terminado en un extremo angostado y trunco, entero o apenas dentado. Margen de la lámina dentado. Pecíolos con ala plana a ondulada, caediza a la madurez...........11. H. krauseanum

20'. Indusios oblongos de ápice redondeado, ocasionalmente acuminado, con dientes más o menos desarrollados. Margen de la lámina dentado a ciliado. Pecíolos con ala crespa, persistente.

21. Indusios con ápice agudo, dentados a serrados, sin pliegues laterales y/o dorsales ciliados. Margen de los segmentos fuertemente dentado-aserrado. Follaje plano o levemente ondulado

12. H. magellanicum

21'. Indusios con ápice redondeado, ciliado, con pliegues foliares laterales y dorsales, ciliados. Margen de los segmentos ciliado. Follaje muy ondulado

20. H. tortuosum

1. Hymenophyllum caespitosum Gaudich., Ann. Sci. Nat. (Paris) 5: 99. 1825. Trichomanes caespitosum (Gaudich.) Hook., Sp. Fil. 1: 132, lám. 40 B. 1846. Serpyllopsis caespitosa (Gaudich.) C. Chr., Ark. Bot. 10(2): 29, fig. 4. 1910. TIPO: Argentina, "Iles Malouines" (Islas Malvinas), I-1823, C. Gaudichaud s.n. (holotipo, P no visto; isotipo K000589552!). Fig. 3.

Hymenophyllum densifolium Phil., Linnaea 29: 108. 1857. Serpyllopsis caespitosa (Gaudich.) C. Chr. var. densifolia (Phil.) C. Chr., Ark. Bot. 10(2): 30. 1910. TIPO: Chile, "In insuli archipielagi Chonos" F. Fonck 36 (holotipo no localizado; isotipo SI!).
Hymenophyllum dusenii Christ, in Dusén, Svenska Exped. till Magellansl. 3(5): 242. 1899 (1900). Serpyllopsis caespitosa var. dusenii (Christ) C. Chr., Ark. Bot. 10(2): 31. 1910. TIPO: Chile, "Fretum magellanicum: insula Desolación, in truncis arborum”, 27/03/1896, P. Dusén 671 (lectotipo, aquí designado [anotado por Cremers in sched. in herb., 2006] K00622072!; isolectotipos S, UPS, fotos SI!). SINTIPO: Chile, "Fuegia australis: Río Azopardo, in terra ca. $500 \mathrm{~m}$ supra mare", 29/02/1896, P. Dusén 602 (P00622071!, S12-15372, S12-15376, fotos SI!).

Trichomanes caespitosum var. elongatum Hook., Sp. Fil. 1: 132, lám. 40 B, fig. 3, 4. 1846. Serpyllopsis caespitosa var. 
elongata (Hook.) C. Chr., Ark. Bot. 10 (2): 30. 1910. TIPO: Chile, "Chiloé", H. Cuming 14 (holotipo, K000589557!).

Serpyllopsis caespitosa (Gaudich.) C. Chr. var. fernandeziana C. Chr. \& Skottsb., Nat. Hist. Juan Fernández 2: 5. 1920. TIPO: Chile, Juan Fernández, "Más Afuera: Heath above Quebrada del Mono", ca. $850 \mathrm{~m}, C$. Skottsberg 421 (lectotipo, aquí designado, UPS, foto SI!; isolectotipos, GB-0047824!, S, foto SI!). SINTIPOS: Chile: "Más a Tierra: Cordón Chifladores, in the innermost part of the Frances valley, on Drimys winteri", ca. $500 \mathrm{~m}, C$. Skottsberg 1128 (sintipo, S, foto SI!); "ridge between Quebrada Laura and Quebrada Piedra agujereada", ca. 650 $\mathrm{m}$, C. Skottsberg 1129 (sintipo, S, foto SI!); "on the main crest of the island, above Pangal, on Drimys", ca. $800 \mathrm{~m}, C$. Skottsberg 1127 (no localizado); "Valle Colonial, along the road to Portezuelo, on Drimys", ca. 450 m, C. Skottsberg 136 (GB, foto SI!, S, foto SI!, UPS, foto SI!, BM, foto SI! ); "Cordón Salsipuedes, brushwood on the ridge", $615 \mathrm{~m}$, and in Quebrada Helechos, on Drimys, $660 \mathrm{~m}$, C. Skottsberg 284 (GB-0047823!, S, foto SI!, UPS, foto SI!); "rocks at Las Torres", 1350 -1370 m, C. Skottsberg 421 b (sintipos GB0047821!, UPS, foto SI!, S, foto SI!, BM, foto SI!); "South slope of Los Inocentes, in Dicksonia-forest on the trunks, ca. 950 m", C. Skottsberg s.n. (no localizado); "also near the highest summit, $1450 \mathrm{~m}$ in moss mats", C. Skottsberg 381 (S, foto SI!).

Rizomas filiformes, ramificados, castaños oscuros, de 0,2 $\mathrm{mm}$ de diám., con pelos castaños, simples, paucicelulares, de 0,3-0,7 mm long., adpresos o patentes, cubriendo densamente las partes jóvenes; frondes distantes, de crecimiento indeterminado, de 0,5-4 (7,5) cm long.; pecíolos castaño oscuros, teretes, de aprox. $0,3 \mathrm{~cm}$ long., no alados, densamente cubiertos de pelos castaños similares a los del rizoma; láminas lineares, oblongas, pinnadas o pinnatisectas, de 0,5-5 x 0,5-1,3 cm, textura membranácea, muy pilosas sobre la parte abaxial de las nervaduras y sobre el raquis, pelos paucicelulares, castaños, simples, adpresos en su base y luego reflexos con el ápice agudo; raquis castaño oscuro, terete, no alado, densamente piloso; pinnas oblongas, simples, de margen entero, raramente pinnatífidas, de 0,3-0,7 x 0,1-0,2 cm, subalternas, imbricadas o no, dispuestas de forma oblicua, hasta perpendicular con respecto al raquis y en el mismo plano que éste o no, con la base angostada a dos pequeñas alas adnatas al raquis, la abaxial mayormente más desarrollada o simétricas, la cara adaxial glabra, la cara abaxial con pelos castaños sobre las nervaduras, paucicelulares, recurvados; soros en número de 1 a 7 , agrupados en la parte apical de la fronde, pudiendo originarse nuevos en el siguiente período vegetativo, terminales sobre segmentos modificados, en el mismo plano que la lámina; involucros obcónicos, inmersos hasta más de la mitad en el segmento, de base cuneada, de ápice entero a ondulado o denticulado, con alas más o menos desarrolladas, ambas valvas cubiertas por pelos castaños similares a los del raquis, en ocasiones con crestas longitudinales terminadas en dientes; receptáculo claviforme, exerto a la madurez, continuando su crecimiento luego de liberar los esporangios.

Distribución y eCOLOGía. Especie endémica, distribuida en toda el área de estudio, desde Neuquén hasta Tierra del Fuego e Isla de Los Estados en Argentina, incluso en las Islas Malvinas, y desde la Región de los Lagos hasta la Región de Magallanes en Chile y en Juan Fernández, llegando hasta los $1.600 \mathrm{~m} \mathrm{s.m}$. (Fig. 3G). Se la puede hallar epífita sobre troncos, terrestre o epipétrica. En general crece en ambientes sombríos y húmedos, aunque se la puede hallar también en sitios más desprotegidos. Es una de las especies más abundantes y comunes del género.

ESPECÍMENES EXAMINADOS.

ARGENTINA, Chubut, Futaleufú, Parque Nacional Los Alerces, sendero entre pasarela Río Arrayanes y Puerto Chucao, 611 m, 26-X-2008, Biganzoli 1807 (SI); Parque Los Alerces, en el alerzal extremo oeste del brazo sud del Lago Menéndez, 11-X-1953, Burkart 19165 (SI). Neuquén, Lácar, Río Huahum, 630 m, 29-III-1952, Diem 2101 (SI; BAB). Los Lagos, Península Quetrihué, Parque Nacional Arrayanes, laguna Huahuan, costa norte, 22-II-2011, Larsen 169 (SI); Lago Nahuel Huapi, Península Panguinal, 31-III-1940, Diem 61P (BAB; SI); Rincón, camino al paso Puyehue, 24-IV-1943, Diem 609 (BAB; SI); Parque Nacional Nahuel Huapi, Laguna Las Monjas al pie del Cerro Tres Lagunas, 1.600 m, 22-III-1951, Diem 1883 (SI); Lago Nahuel Huapi, Isla Victoria, Punta Norte, 25-V-1944, Diem 805 (SI). Río Negro, Bariloche, Puerto Blest, 04-VII1941, Diem 597 (BAB; SI); Puerto Blest, camino al Puerto Alegre (Laguna Frías), 800 m, 23-X-1947, Diem 1059 (BAB; SI); Lago Nahuel Huapi, Brazo Tristeza, salto arroyo Raquiduanco, 780 m, 04-V-1952, Diem 2152 (BAB). Tierra del Fuego, Ushuaia, Isla de los Estados, Bahía York, 30X-1971, Dudley 1138 (BAB); San Juan del Salvamento (Isla de los Estados), 18-IV-1896, Alboff 924 (SI). Islas del Atlántico Sur, Islas Malvinas, 1850, W. J. Hooker s.n. (SI 19303) (SI). CHILE, Región de Los Lagos, Llanquihue, bajando el volcán Osorno, 1056 m, 23-II-2012, Larsen 261 (SI); Peulla, Laguna El Encanto, 200 m, 29-X-1947, Diem 1092 (BAB; SI); Puerto Varas, 26-I-1909, Hicken 5 (SI 18466) (SI). Chiloé, Buaún, 30-I-1937, Barros 197 (SI). Región de Aisén, Aisén, Ruta 7 entre Santa Lucía y La Junta, 94 m, 26-XI-2009, Biganzoli 2222 (SI); Laguna San Rafael, 28-XII-1952, Neumeyer s.n. (Diem 2259) (BAB); Istmo de Ofqui, Punta Leopardo, 12-I-1921, Hicken 85 (SI 16546). Coihaique, Ruta de Puerto Tranquilo pasando el Ventisquero Río Exploradores, km 65, fin del camino, 73 m, 29-XI-2009, Biganzoli 2261 (SI). Región de Magallanes, 

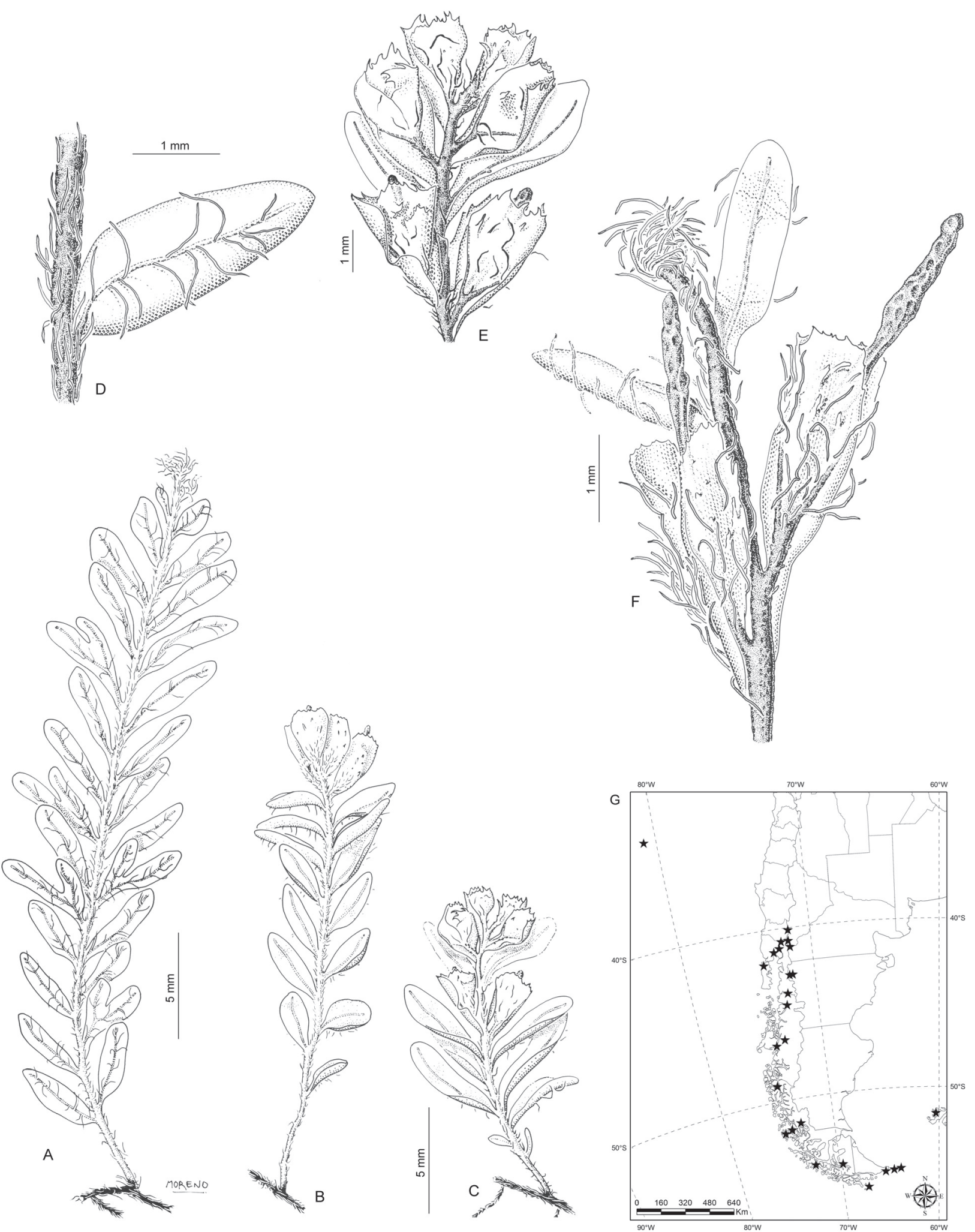

Figura 3. Hymenophyllum caespitosum. A-C, aspecto general. D, detalle del raquis y del envés de una pinna. E, detalle del ápice de una fronde fértil. F, detalle del ápice de una fronde fértil donde se pueden observar los receptáculos exertos. G, mapa de distribución de la especie.

Figure 3. Hymenophyllum caespitosum. A-C, habit. D, detail of the rachis and the underside of a pinna. E, detail of apex of a fertile frond. F, detail of apex of a fertile frond where it exserted receptacles. G, distribution map of the species. 
Última Esperanza, Isla Piazzi, Caleta Ocasión, Abra Leackey's Reatreat, 17-I-1976, Dollenz s.n. (TBPA 1046) (BAB); Isla Vidal Gormaz, Seno Nantuel, Bahía María Angélica, 03-II-1976, Dollenz s.n. (TBPA 1302) (BAB); Seno Última Esperanza, Puerto Toro, 18-I-1977, Moore s.n. (TBPA 1844) (BAB). Magallanes, Isla Santa Inés, 13-I1950, sin colector s.n. (SI 21677) (SI).

\section{OBSERVACIONES}

Especie fácilmente reconocible principalmente por su pequeño tamaño, sus pinnas simples, sus indusios obcónicos característicos y su hábito cespitoso. Presenta indusios agrupados generalmente en el ápice de la fronde, reemplazando a las pinnas en su posición, aunque se pueden hallar ejemplares que continúan su crecimiento vegetativo luego de desarrollarlos, quedando los indusios agrupados en la mitad de la fronde.

Este taxón fue originalmente descrito por Gaudichaud bajo el género Hymenophyllum, luego en 1861 Van den Bosch lo utilizó para describir un género nuevo, Serpyllopsis. Sin embargo Hooker (1844-1846) lo ubicó en el género Trichomanes, posición que fue la más utilizada por los autores. En 1910, Christensen realiza la nueva combinación bajo el género Serpyllopsis, señalando que $S$. caespitosum presenta características intermedias entre los 2 géneros clásicos de la familia, los indusios lo acercan al género Trichomanes y su hábito y características generales lo asemejan más a Hymenophyllum. Los estudios recientes de Ebihara et al. (2006), que incluyen análisis moleculares, han propuesto ubicar a Serpyllopsis dentro del género Hymenophyllum, posición que se sigue en el presente trabajo.

Posee frondes indeterminadas (Christensen 1910), lo que puede originar variaciones en su longitud (0,5-7,5 $\mathrm{cm})$. Se considera aquí que estas variaciones se relacionan con la edad de la planta, la intensidad de luz que incide directamente en sus frondes, y en general las condiciones en las que se desarrolla. De la misma manera la densidad de la pilosidad, así como el margen del labio del indusio entero o dentado, no son tomados aquí como caracteres distintivos. Por estas razones se consideran como sinónimos a las variedades densifolia, dusenii, elongata y fernandeziana, todas ellas fundadas en variaciones de los caracteres mencionados anteriormente.

2. Hymenophyllum caudiculatum Mart., Icon. P1. Crypt. 102 t. 67. 1834. Sphaerocionium caudiculatum (Mart.) C. Presl, Hymenophyllaceae: 35. 1843. Mecodium caudiculatum (Mart.) Copel., en Philip. Journ. Scien. 67 (1): 27.1938. TIPO: Brasil, "Crescit super arbores semiputridas prope Uarivaú et Manacurú pagos Indorum e tribu Jurí secundum fluvium Jarupá sitos", F.P. von Martius s.n. (holotipo, BR0000006966133!; isotipo, P00622048!). Fig. 4.

Sphaerocionium productum C. Presl, Hymenophyllaceae:
35, 61. 1843. Hymenophyllum productum (C. Presl) J. W. Sturm, Abh. Naturhist. Ges. Nürnberg 2: 193. 1858. non Kunze 1848. Hymenophyllum caudatum Bosch, Ned. Kruidk. Arch. 4 (4): 394. 1859. nom. nov. para H. productum (C. Presl) J. W. Sturm. Hymenophyllum caudiculatum Mart. var. caudatum (Bosch) Hook. \& Bak., Syn. Fil.: 61. 1874. Hymenophyllum caudiculatum Mart. var. productum (C. Presl) C. Chr., Ind. Fil.: 366. 1906. Mecodium caudiculatum (Mart.) Copel. f. productum (C. Presl) G. Kunkel, Nova Hedwigia 13: 324. 1967. TIPO: Chile, "Habitat in Chile", H. Cuming s.n. (lectotipo, aquí designado, W, foto SI!).

Hymenophyllum martii Sturm, en Martius, Fl. Bras. 1(2): 287. 1859. TIPO: Brasil, "Habitat in arboribus prope Rio de Janeiro", F.P. von Martius s.n. (holotipo, M-0186873, foto SI!).

Hymenophyllum patagonicum Gand., Bull. Soc. Bot. France 60: 28. 1913. TIPO: Chile, "Chile: Patagonia occid., ad Puerto Chacabuco", C. Skottsberg 376 (holotipo S, foto SI!; isotipos UPS, foto SI!, BM, foto SI!).

Mecodium caudiculatum (Mart.) Copel. f. nanum G. Kunkel, Nova Hedwigia 13: 324. 1967. TIPO: Chile, "Isla Mocha, Cerro Pastene, 250 m", X-1958, G. Kunkel 6405 (no localizado).

Rizomas filiformes, ramificados, de color pardo claro hasta gris oscuro, de 0,2-0,8 $\mathrm{mm}$ de diám.; pelos del rizoma castaños, simples, pluricelulares, de 0,2-1,1 mm long., escasos, caedizos a la madurez; frondes remotas, de (14)19$31 \mathrm{~cm}$ long.; pecíolos castaños, teretes, de 0,2-0,9 mm de diám., de (5)9-12 cm long., con alas desde la base, caedizas, delgadas, o con alas desde la parte media, ensanchándose hacia el extremo hasta $0,35 \mathrm{~mm}$ lat., de margen entero, en frondes jóvenes con escasos pelos en la base; láminas lanceoladas u ovado-lanceoladas, 3-pinnatífidas, de 10$20 \times 3-10 \mathrm{~cm}$, de textura membranácea, glabras; raquis castaño oscuro, hasta pardo o amarillo verdoso, verdes en vivo, glabros o raramente con escasos pelos multicelulares, terete, con alas de 0,7-1,1 $\mathrm{mm}$ de ancho, de margen entero, plano o levemente ondulado; pinnas ovado-lanceoladas, 2-pinnatífidas, de 1-6 x 0,6-2 cm, simétricas, nervaduras pardo claras hasta amarillo verdosas, en general con la primera pinnula acroscópica flabelada, o de otra forma, pero con divisiones dicotómicas cercanas que generan 2 ó 3 segmentos fértiles; raquis y costas notablemente más gruesos que las divisiones que generan, predominando un crecimiento simpodial con el segmento apical más desarrollado en forma de caudícula de hasta $3 \mathrm{~cm}$; segmentos lineares $u$ oblongos, de $(0,8) 1,2-2,2 \mathrm{~mm}$ lat. de ápice redondo o emarginado, de margen entero, en ocasiones algo ondulado; soros generalmente en todas las pinnas, más frecuentes sobre las pinnas medias y apicales, 
sobre segmentos cortos, más angostos que el indusio, a menudo subaxilares luego de una división de la costa, o en otra posición a ambos lados de las pinnas; involucros orbiculares a reniformes, no inmersos en la lámina, base plana, ápice redondo, en ocasiones emarginado, margen entero, abiertos hasta la base; receptáculo anchamente obovado a subflabelado, aplanado, inserto.

Distribución y ecología. En Argentina se encuentra en la provincia de Chubut, en el Parque Nacional Lago Puelo (Vidoz et al. 1999) y en el Parque Nacional Los Alerces. En Chile se distribuye en las islas Juan Fernández y Mocha, y en el continente desde Temuco, en la Región de la Araucanía, hasta la Laguna San Rafael, en la Región de Aisén (Fig. 4G). Habita en bosques maduros muy húmedos y sombríos. En general es epífito sobre troncos, más raro terrestre o epipétrico. Esta especie habita además en el sur y sudeste de Brasil.

\section{ESPECÍMENES EXAMINADOS.}

ARGENTINA, Chubut, Cushamen, Parque Nacional Lago Puelo, Arroyo Melo, 450 m, 7-VIII-1999, Vidoz 148 (LP). Futaleufú, Parque Nacional Los Alerces, sendero entre Lago Menéndez y Lago Cisne, 576 m, 30-X-2008, Biganzoli 1853 (SI). CHILE, Región de Valparaíso, Valparaíso, Juan Fernández, X-1872, R. A. Philippi s.n. (SI 16082) (SI); Juan Fernández, Más Afuera, 03-XII-1965, Meyer 9439 (LP). Región del Biobío, Arauco, Isla Mocha, camino entre el Faro Oeste y La Hacienda, Cordón Central, 14-III-1971, Weldt y Rodríguez 1075/370 (LP). Región de la Araucanía, Cautín, Temuco, 23-I-1937, Barros 272 (SI). Región de Los Ríos, Valdivia, Salto de Pilmaiquén, 19-II-1942, Kausel s.n. (Diem 627) (SI); Volcán Calbuco, 08-II-1937, Barros 271 (SI); Valdivia, Cordillera Pelada, vertiente W, 30-III1963, de la Sota 2769 (LP); Prope Corral in prov. Valdivia, Lechler 502 (P00622049); Corral, 00-I-1911, Hauman 6 (LIL 40845) (LIL). Ranco, Fundo Carrán, cerca del lago Maihué, 414 m, 20-II-2012, Larsen 234 (SI). Región de Los Lagos, Chiloé, Buaúm, 30-I-1937, Barros 270 (SI); Isla de Chiloé, Queilén, 10-VII-1942, Cárdenas s.n. (Diem 635) (SI); PN Chiloé, sendero El Tepual, 26-II-2012, Larsen 287 (SI). Llanquihue, Peulla, cascada de los helechos, $250 \mathrm{~m}$, 28-X-1947, Diem 1085 (SI); Casa Pangue, camino al Paso Pérez Rosales, 600 m, 21-X-1947, Diem 1047 (SI); Curso inferior del Río Puelo, sin colector s.n. (SI 16086); Boca Río Puelo, 00-I-1916, Espinosa 9 (SI 17448); Maullín, Las Chilcas, 29-I-1952, Klenner s.n. (LIL 391355); Río Tepu, slopes of Volcán Calbuco, ca. $2 \mathrm{~km}$ from Lago Llanquihue, ca. 6 km from Hotel Ensenada, 23-III-1939, Morrison 17608 (SI; LIL); Valle Cayutué (Lago Esmeralda), 01-I-1912, Wolffhügel 22 (SI 19949; Ensenada, Lago Llanquihue, 13I-1951, Pfister 1122 (10364); Casa Pangue, camino al Paso Perez Rosales 400-500 m, 21-X-1947, Diem 1046 (SI); Pto. Varas, 26-I-1909, Hicken 24 (SI 16567); Puerto Montt,
03-I-1951, Pfister 1104 (LIL 10252). Osorno, Termas de Puyehue, 27-I-1969, S. M. Cabrera s.n. (LP); Puyehue, in the moss on the trunks in the shady rainforest round Río Chanleufu, W the hotel, 350 m, 14-I-1947, Sparre 2101 (LIL). Palena, Ruta 231 entre Futaleufú y Puerto Ramírez, 165 m, 26-XI-2009, Biganzoli 2205 (SI). Región de Aisén, Ins. Magdalena, Calqueman, ca. 20 m, 13-X-1923, Werdermann 67 (SI; LIL); Istmo de Ofqui, San Rafael, cascada, 26-I-1921, Hicken 80 (SI 16570).

\section{OBSERVACIONES}

Hymenophyllum caudiculatum es una especie muy vistosa, de gran tamaño. Es el representante con frondes de mayor tamaño en el área de estudio, junto con $H$. fuciforme, de aspecto similar, que se diferencia por poseer las frondes cercanas entre sí, sobre un rizoma notablemente grueso y cubierto de pelos, y los esporangios visibles en el receptáculo exerto, apenas cubierto por las pequeñas valvas de borde irregular.

Esta especie fue considerada dentro del género Mecodium (Copeland 1938), por presentar el margen de los segmentos entero y frondes generalmente glabras. Recientemente, Hennequin et al. (2006b) plantearon la polifilia del grupo "Mecodium" basándose en genes del cloroplasto, separando el subgénero Globosa, que se caracteriza además por el número cromosómico $n=36$, la estela reducida o dorsiventral, y una lámina con varias capas de células. Dentro de este grupo se encuentra $H$. caudiculatum, junto con otras especies de regiones tropicales y templadas de Asia e islas del Pacífico. El subgénero Globosa cuenta con un total de 25 especies (Ebihara et al. 2006).

Algunos autores, como Sturm (1858), consideraron que el verdadero $H$. caudiculatum no se encuentra en Chile, sin justificarlo. Christensen (1910) aceptó dos formas de $H$. caudiculatum para el sur de Chile: la variedad caudiculatum, que habita también en Brasil, y la variedad productum, la que se diferenció por los pecíolos no alados hasta la base, alas del pecíolo y raquis crispadas, y segmentos fértiles muy contraídos. Los ejemplares de Brasil estudiados en esta revisión son más robustos, poseen mayor número de indusios en las frondes, y pinnas más cercanas y divididas, tal como lo mencionan Hooker (1844-1846) y Diem \& Lichtenstein (1959). Se observó además una tendencia a presentar mayor diámetro en el rizoma $(0,5-0,8 \mathrm{~mm})$, con pelos en general más largos (1-2,2 $\mathrm{mm})$, aunque similares. Sin embargo estas diferencias cuantitativas no permiten una diferenciación clara ya que los rangos de medidas se solapan, y por lo tanto en el presente trabajo no se encontraron evidencias que demuestren que las entidades de ambos países son taxones distintos.

Para sinonimizar las variedades se tuvo en cuenta que ninguna de las características como el diámetro y color del rizoma, la densidad, tipo, longitud, número de células y color de los pelos del rizoma, el largo de la fronde y del pecíolo, 


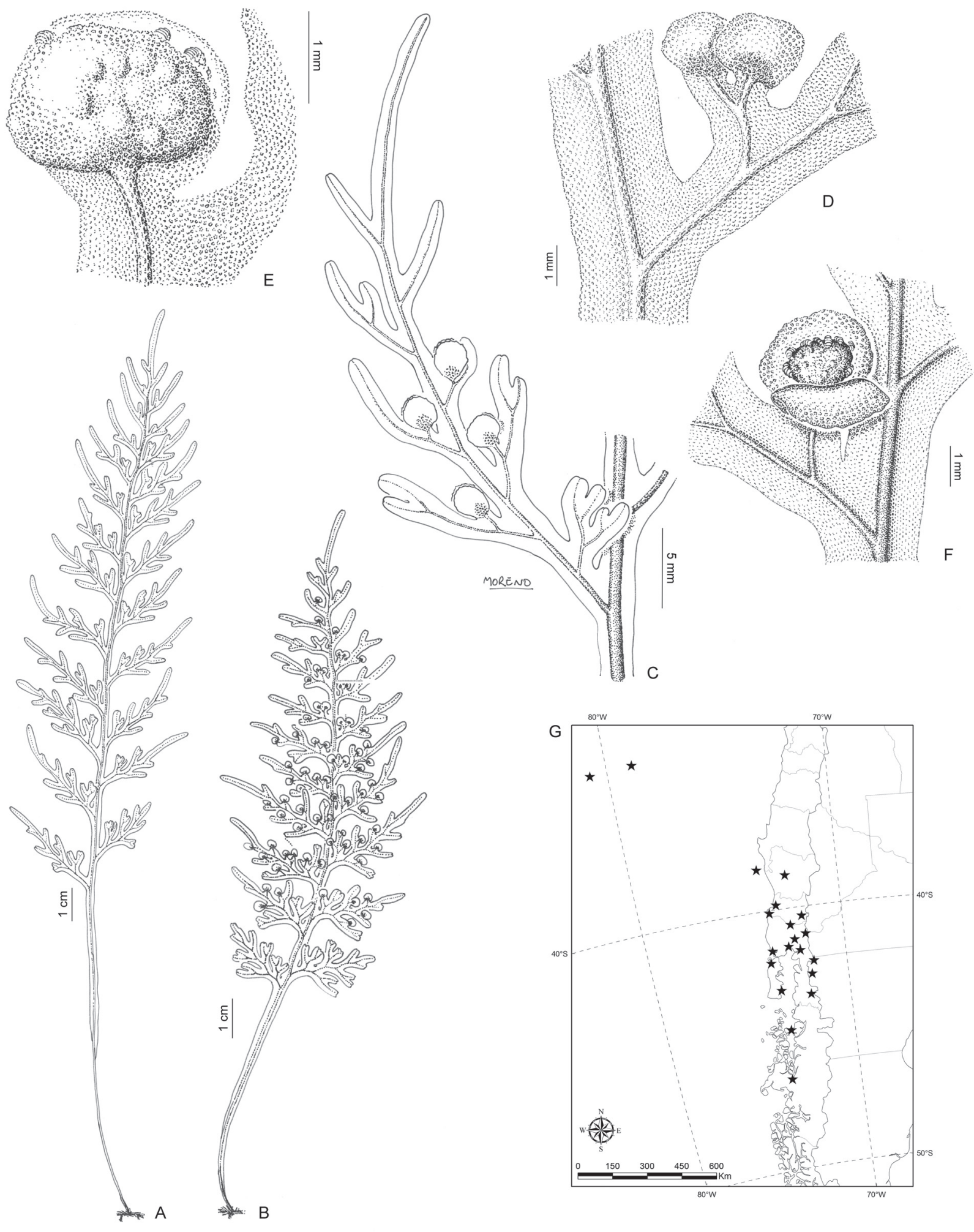

Figura 4. Hymenophyllum caudiculatum. A-B, aspecto general. C, detalle de una pinna. D-E, detalle de indusios. F, detalle del receptáculo. $\mathrm{G}$, mapa de distribución de la especie.

FIGURE 4. Hymenophyllum caudiculatum. A-B, habit. C, detail of a pinna. D-E, detail of a sorus. F, detail of a receptacle. G, distribution map of the species. 
características del ala del pecíolo, margen del raquis y segmentos, ancho del segmento que porta el indusio, forma y ancho del extremo de los segmentos estériles, la longitud del ápice de la fronde y pinnas, forma del receptáculo y número de esporangios por indusio, fueron constantes dentro de las dos áreas o se encontraron ausentes en alguna, como para determinar una diferencia morfológica que merezca asignarles nombres distintos.

Se eligió como lectotipo para Spherocionium productum el material depositado en Viena (W), debido a que no se hallaron ejemplares en los lugares donde trabajó Carl Presl (P, PCR). Por otro lado el ejemplar tipo de H. martii es una muestra de planta joven que presenta las características que definen a $H$. caudiculatum.

Se excluye de la sinonimia el nombre $H$. dilatatum (G.Forst.) Sw., citado en Martius (1859) y en Diem \& Lichtenstein (1959) como sinónimo de H. caudiculatum. Esta especie es endémica de Nueva Zelanda y muy similar morfológicamente.

3. Hymenophyllum cruentum Cav., Descr. Plant.: 275. 1802. Hymenoglossum cruentum (Cav.) C. Presl, Hymenophyllaceae: 35. 1843. TIPO: Chile, "Don Luis Née encontró esta especie sobre los troncos de los árboles en San Carlos de Chiloé", L. Née s.n. (holotipo, MA475841!; isotipo MPU018000!). Fig. 5.

Rizomas filiformes, ramificados, castaño-claros, de 0,3$0,6 \mathrm{~mm}$ de diám.; pelos del rizoma translúcidos, caedizos, uniseriados, de 0,5-1 mm long., adpresos o patentes, densos en las partes jóvenes del rizoma, glabrescentes en rizomas maduros; frondes distantes de 18-25 cm long.; pecíolos pardo claros a oscuros, hasta grisáceos, de 2 a $15 \mathrm{~cm}$ long., glabros o en ocasiones con escasos pelos blanquecinos en la base o muy dispersos en la parte media, teretes, de $0,2-$ $0,5 \mathrm{~mm}$ lat., no alados; láminas simples o en ocasiones lobuladas, ovado-lanceoladas, oblongo-lanceoladas, a lanceoladas, de 6-11 x 2-3 cm, de textura cartácea, glabras, con 10-25 pares de nervaduras, que terminan en indusios en frondes fértiles, o que llegan al margen en frondes estériles; las de la base en general opuestas volviéndose alternas hacia el ápice; raquis pardo oscuro, recto o en zig-zag; soros en los márgenes, sobre los extremos de las nervaduras, inmersos en la lámina, con su base ensanchada y venillas que rodean la base; involucros orbiculares a subovados, inmersos menos de la mitad en la lámina, base redonda a obtusa, ápice redondo, raramente agudo, margen entero, abiertos hasta la mitad; receptáculo obovado u oblongo, globoso, totalmente cubierto por esporangios, algo exerto a la madurez.

Distribución y eCOlOGía. Especie endémica de los bosques australes de Sudamérica. En la Argentina sólo ha sido coleccionada en el Parque Nacional Lago Puelo (Vidoz et al. 1999). En Chile habita en Juan Fernández, y en el continente se halla desde la Región del Maule, hasta la provincia de Magallanes, en la región homónima (Fig. 5E). En general son epífitos, en sitios muy húmedos y en bosques muy maduros, pudiendo cubrir ampliamente los troncos de los árboles, raras veces se encuentran como terrestres o epipétricos.

\section{ESPECÍMENES EXAMINADOS.}

ARGENTINA, Chubut, Cushamen, Parque Nacional Lago Puelo, Arroyo del Fuinque, 320 m, 02-VII-1999, Vidoz 136 (LP). CHILE, Región de Valparaíso, Valparaíso, Juan Fernández, 00-X-1872, Philippi 577 (SI 16179); Juan Fernández, Más a Tierra, 25-XII-1965, Meyer 9674 (LP). Región de la Araucanía, Cautín, Temuco, 23-I-1937, Barros 268 (SI). Región de los Ríos, Valdivia, Valdivia, VII-1902, Buchtien s.n. (SI 16508); Quitaluto, 23-III-1930, Gunckel 1796 (SI); Corral, 00-II-1910, Hauman 3 (LIL 40844). Región de Los Lagos, Chiloé, PN Chiloé, sendero El Tepual, 26-II-2012, Larsen 285 (SI); Ancud, El Carmelo, 27-I-1937, Barros 274 (SI); Piruquina, 31-VIII-1931, Junge 11 (SI). Llanquihue, Peulla, pasando la cascada Velo de la Novia, 22-II-2012, Larsen 250 (SI); Puerto Varas, Hicken 20 (SI 16572); River Tepu, slopes of Volcan Calbuco, ca. $2 \mathrm{~km}$ from Lago Llanquihue, 23-III-1939, Morrison 17595 (SI); Valle Cayutué, 01-I-1912, Wolffhügel 21 (SI 19956); Peulla, cascada de los helechos, 250 m, 28-X-1947, Diem 1084 (SI); Peulla, 200 m, 27-X-1947, Diem 1073 (SI); Quillagua, Maullín, 00-VII-1947, Hernández s.n. (BAB); Maullín, Las Chilcas, 29-I-1952, Klenner s.n. (LIL 391354); Cayutué, faldas del "Cerro Derrumbe", 08-II-1931, Rentzell 26 (SI). Osorno, Puyehue, in the moss on the trunks in the shady rainforest round Río Chanleufu, W the hotel, $350 \mathrm{~m}$, 14-I-1947, Sparre 2106 (LIL 245633). Región de Aisén, Aisén, Istmo de Ofqui, San Rafael, 01-II-1921, Hicken s.n. (SI 16181); Islas Guaytecas, Melinka, 00-II-1957, Ricardi 4116 (CONC); Istmo de Ofqui, Punta Leopardo, 13-I-1921, Hicken 76 (SI 16573); Ruta 7 saliendo de Puyuhuapi hacia Puerto Aisén, 10 m, 26-XI-2009, Biganzoli 2225 (SI); Puerto Chacabuco, Parque Aiken Sur, sendero del salto, 45 m, 28-XI-2009, Biganzoli 2242 (SI). Región de Magallanes, Magallanes, Caleta de las Ballenas, sur Isla Carlos III, 00-V1973, Goodall s.n. (BA).

\section{Observaciones}

Es la única especie del género con fronde entera en el área de estudio. Esta especie pertenece al subgénero Hymenoglossum, el que también comprende a $H$. asplenioides (Sw.) Sw. de Centro y Sudamérica, e H. heimii Tardieu de Madagascar, fueron incluidas aquí por Ebihara et al. (2006) basándose en similitudes morfológicas y en caracteres moleculares del cloroplasto. Las tres especies presentan la hoja entera a pinnatífida, lo que se considera como un carácter homólogo (Hennequin et al. 2006b). 

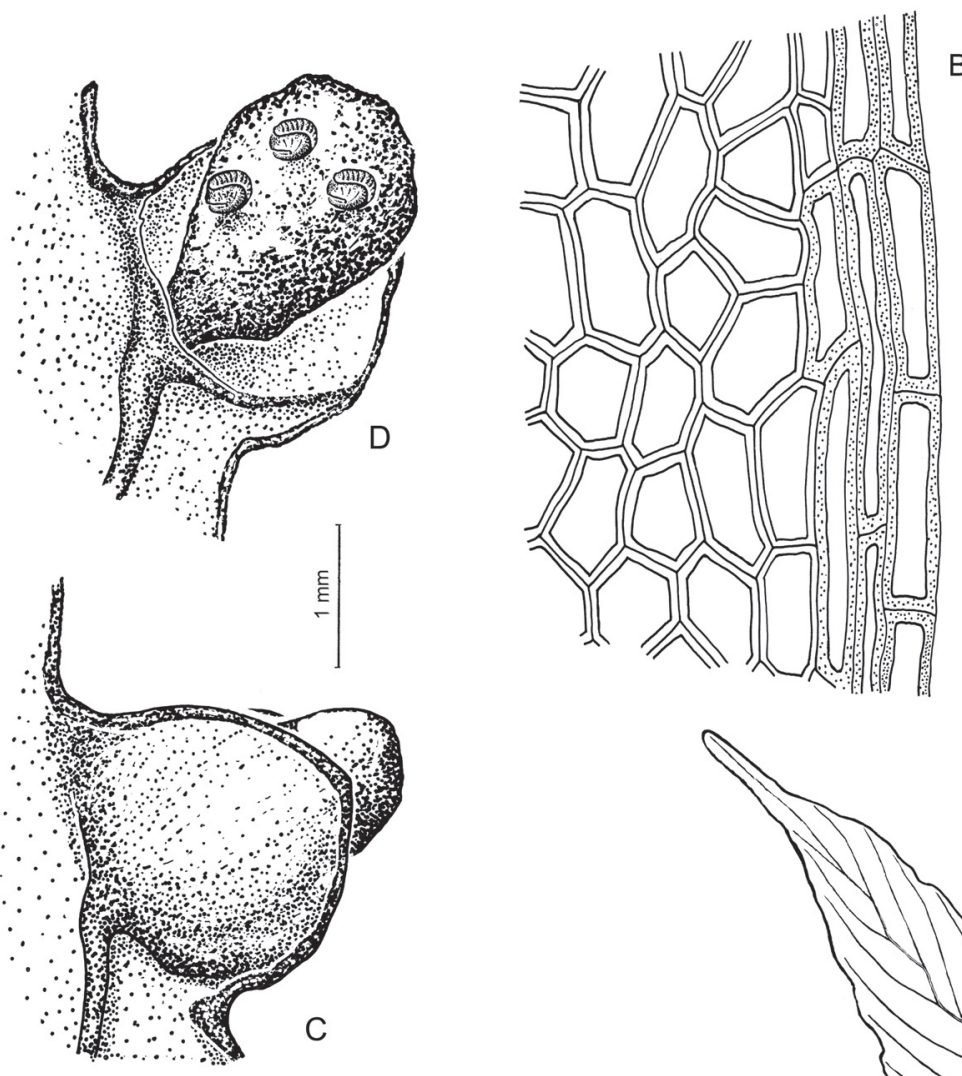

B
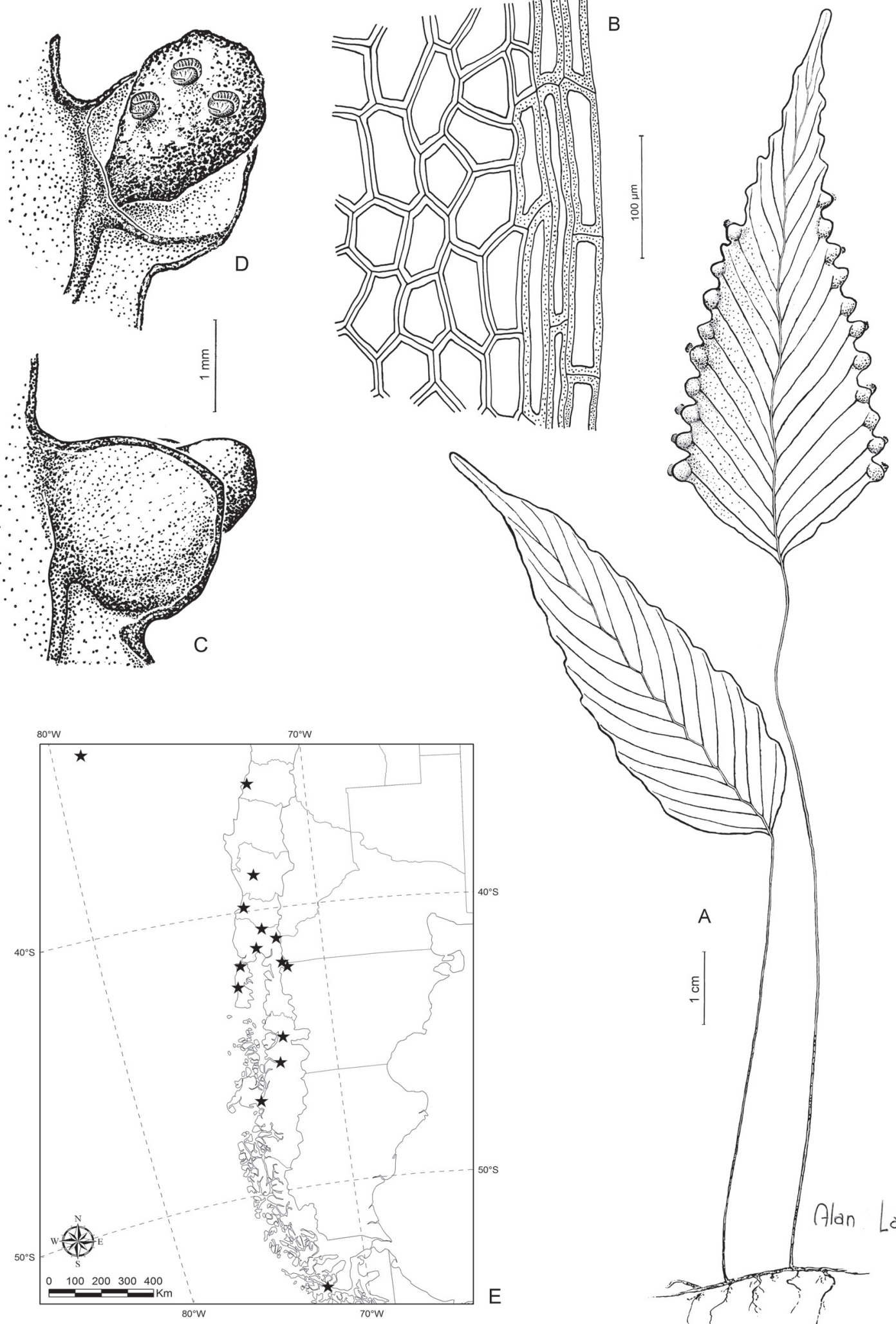
4. Hymenophyllum cuneatum Kunze, Anal. Pterid.: 50. 1837. Mecodium cuneatum (Kunze) Copel., Philipp. J. Sci. 67(1): 24. 1938. TIPO: Chile, "In insula Juan Fernández, ut videtur a Bertero (sic) lectum dedit Bory de St.-Vincent", C. Bertero s.n. (lectotipo, aquí designado, P00622194!; isolectotipo, P00622195!). SINTIPO. Chile, Isla Juan Fernández, "Ex eadem insula misit H. Cuming" (no localizado). Fig. 6 .

Hymenophyllum cumingii C. Presl, Hymenophyllaceae: 56, tab 11 A. 1843. TIPO: "Habitat in Chile" H. Cuming s.n. (OXF00003835, foto SI!).

Hymenophyllum terminale Phil., Linnaea 33: 306. 1864, nom. illeg., non Bosch 1861. Hymenophyllum parvulum C. Chr., Ind. Fil.: 365. 1905 (1906) nom. nov. para H. terminale Phil. TIPO: Chile, Valdivia, "Prope Corral”, H. Krause s.n. (holotipo SGO000000526!; isotipo K000589675!)

Hymenophyllum cuneatum Kunze. var. rariforme C. Chr. \& Skottsb., Nat. Hist. Juan Fernández 2: 8. 1922. Mecodium cuneatum (Kunze) Copel. var. rariforme (C. Chr. \& Skottsb.) Kunkel, Nova Hedwigia 9: 255. 1965. syn. nov. TIPO: Chile, "Más a Tierra: on the sharp crest separating Valle Anson from Quebrada Damajuana, on the peak", 365 m, 17/12/1916, C. Skottsberg 146 (lectotipo, aquí designado, K000589673!, isolectotipos, US00067530!, BM000936758!, S, foto SI!, UPS, foto SI!, BM, foto SI!). SINTIPO: Chile "At the road to Portezuelo", ca. $450 \mathrm{~m}, C$. Skottsberg 1143 (S, foto SI!).

Hymenophyllum cuneatum Kunze. f. imbricata C. Chr. et Skottsb, Nat. Hist. Juan Fernández 2: 8. 1922. TIPO: Chile, Juan Fernández, I. "Más a Tierra (Robinson Crusoe), Puerto Ingles, the crest of the central ridge", C. Skottsberg 1178 (holotipo S, foto SI!; isotipos UPS, foto SI!, BM, foto SI!, US, no visto).

Rizomas filiformes, ramificados, parduscos, de 0,2-0,3 mm de diám.; pelos del rizoma castaños, simples, paucicelulares de 0,3-0,6 mm long., adpresos o patentes, muy dispersos, agrupados en la base de pecíolos y raíces; frondes distantes, de 5-13(17) cm long.; pecíolos castaño-oscuros, de $(0,8) 3-5(9) \mathrm{cm}$ long., glabros o muy raramente con pocos pelos, con alas caedizas más anchas hacia el ápice, hasta de $0,3 \mathrm{~mm}$ lat.; láminas ovadas, triangulares a linearlanceoladas, 2-3-pinnatífidas, de 3,5-9,5 x 1,5-7 cm, textura membranácea, glabras, de color verdoso-amarillento in sicco; raquis castaño oscuro, glabro, terete, con alas de 0,3 $\mathrm{mm}$ lat. en todo su largo; pinnas de contorno trapeciforme o triangular, pinnatífidas a 2-pinnatífidas, de 1-3,5 x 0,5$1,2 \mathrm{~cm}$, simétricas, nervaduras, por lo menos en los ápices y las cóstulas poco lignificadas; segmentos lineares, de 1-1,3 mm lat., de ápice redondo a emarginado, de margen entero, plano o revoluto hasta algo ondulado, los fértiles en general más anchos que el indusio, o más angostos y ensanchándose notablemente en el indusio; soros en el mismo plano de la lámina, principalmente en las pinnas apicales, sobre ambos lados, terminales sobre segmentos simples o bifurcados, iguales o más anchos que el indusio; involucros suborbiculares hasta subflabelados, inmersos en la lámina hasta la mitad, de base subaguda, de ápice redondo a obtuso, el margen entero, abierto hasta la mitad o menos; receptáculo algo engrosado en el centro o en el ápice (claviforme), hasta globoso, inserto o en ocasiones levemente exerto a la madurez.

Distribución y ECOlogía. Especie hallada sólo en Chile, en las islas Juan Fernández y en el continente donde se encuentra desde Cunco, en la Región de la Araucanía, hasta la Región de Magallanes, provincia de Última Esperanza (Isla Virtudes, Isla Piazzi, etc.) (Fig. 6E). Se halla epífita, cubriendo densamente las bases de los troncos, en bosques sombríos y turberas, mezclados con musgos u otras especies del género, habitualmente especies raras, como $H$. krauseanum, $H$. cruentum, $H$. dicranotrichum, o también más comunes como $H$. pectinatum o $H$. dentatum, incluso se han observado mezcladas con plantitas de $H$. darwinii. En las islas Juan Fernández se halla epífita de otros helechos, como Blechnum cycadifolium J.W. Sturm.

\section{ESPECÍMENES EXAMINADOS.}

CHILE, Región de Valparaíso, Valparaíso, Juan Fernández Islands, Isla Más a Tierra, along the trail from Weber's house to the cordon south of El Tanque, $800 \mathrm{~m}$, 01-III1939, Morrison 17349 (SI; LIL); Juan Fernández, Más a Tierra, Quebrada Villagra, 17-II-1931, Espinosa 4 (SI 17443); Más Afuera, sin colector s.n. (SI 16516); Más a Tierra: on the sharp of crest separating V. Anson from Q. Damajuana, on the Peak, 365 m, Skottsberg 146 (SGO); Más Afuera, Quebrada Sandalo, en extensión superior, 850 m, 2001, Stuessy 9287 (CONC). Región de Los Lagos, Llanquihue, PN Vicente Pérez Rosales, 273 m, 23-II-2012, Larsen 265 (SI); Volcán Calbuco, 08-II-1937, Barros 193 (SI); Alrededores "Hotel Ensenada", 18-IX-1967, Villagrán 10253 (LP); Saltos del Río Petrohué, 21-II-1963, Diem 3333 (BAB); PN Alerce Andino, sendero hacia el Alerzal milenario, 147 m, 25-II-2012, Larsen 280 (SI). Chiloé, PN Chiloé, sendero El Tepual, 26-II-2012, Larsen 282 (SI). Región de Aisén, Aisén, Ruta 7 saliendo de Puyuhuapi hacia Puerto Aisén, 26-XI-2009, Biganzoli 2224 (SI). Región de Magallanes, Última Esperanza, Isla Virtudes, Canal Elías, Puerto Virtudes, 12-II-1976, Dollenz s.n. (TBPA 1517) (BAB); Isla Virtudes, Canal Elías, Puerto Virtudes, 09-II1976, Dollenz s.n. (TBPA 1435) (BAB); Isla Piazzi, Caleta Ocasión, Abra Leackey's Reatreat, 17-I-1976, Dollenz s.n. (TBPA 1037) (BAB). 


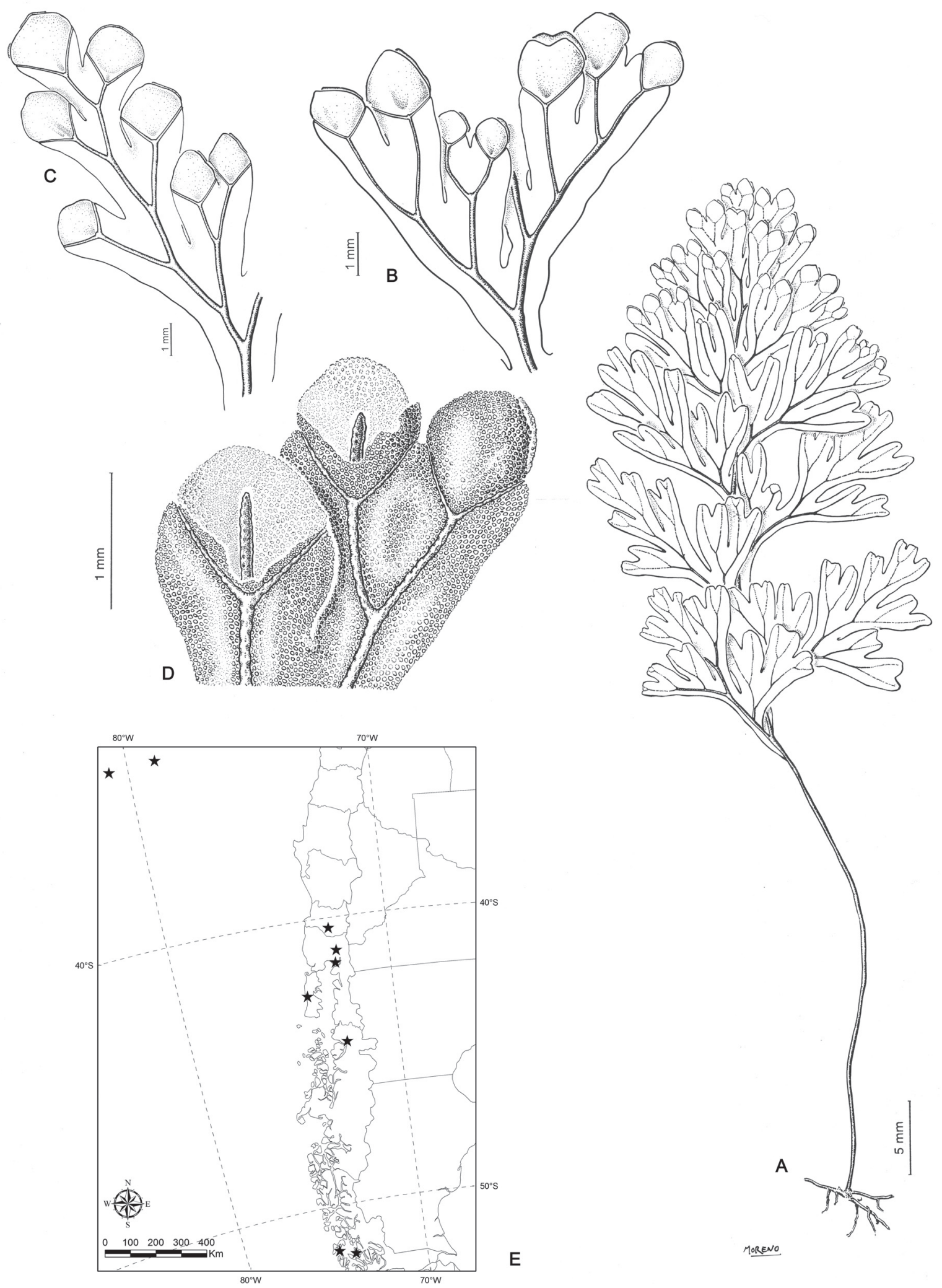

Figura 6 . Hymenophyllum cuneatum. A, aspecto general. B, C, detalle de pinnas fértiles. D, detalle de indusios y receptáculos. E, mapa de distribución de la especie.

Figure 6. Hymenophyllum cuneatum. A, habit. B, C, detail of fertile pinnae. D, detail of sori and receptacles. E, distribution map of the species. 


\section{OBSERVACIONES}

Esta especie es muy característica porque posee indusios suborbiculares hasta subflabelados, con la base subaguda u obtusa y el ápice redondo, follaje en general plano, con margen plano o revoluto hasta algo ondulado. En ocasiones puede resultar dificultosa la separación de $H$. cuneatum de ejemplares desarrollados de su especie hermana, $H$. darwinii. Ésta última se diferencia principalmente por su follaje ondulado, sus indusios lanceolados con ápice agudo, o una combinación de estos caracteres. Ambas especies se ubican en el subgénero Mecodium.

Los nombres Hymenophyllum dichotomum Cav., de Filipinas, H. polyanthos (Sw.) Sw. del Neotrópico e H. rarum R. Br., de Australia y Tasmania, fueron usados erróneamente para el material de $H$. cuneatum coleccionado en el sur Chile y en las Islas Juan Fernández, estos taxones no se encuentran en el área estudiada. En las Islas Juan Fernández pueden observarse ejemplares de $H$. cuneatum con frondes de más de $10 \mathrm{~cm}$ long. y los indusios generalmente de forma lanceolada. Esta característica lo asemeja en apariencia a $H$. polyanthos, que sin embargo se diferencia por poseer indusios ovados sobre un segmento de igual ancho o algo más angosto que éste, y una lámina de mayor tamaño (hasta de $13 \mathrm{~cm}$ long.).

Aquí se consideran a la variedad rariforme y a la forma imbricata incluidas dentro de $H$. cuneatum, sobre la base de que el tamaño de la fronde no es un carácter que tenga validez para reconocer taxones dentro de Hymenophyllum. La variabilidad de $H$. cuneatum se debe a que se distribuye ampliamente en diferentes ambientes. Entre otras cosas se han hallado en la misma cartulina muestras de diferentes tamaños, las que podrían atribuirse a distintas variedades como por ejemplo en el ejemplar tipo de $H$. terminale depositado en SGO, pero que corresponden a la misma población.

Se escogió el ejemplar de Bertero depositado en $\mathrm{P}$, código de barras P00622194, para el nombre aceptado de la especie, debido a que era el material más abundante y en mejor estado de madurez. Para el nombre H. cuneatum var. rariforme se eligió, por ser más abundante, el ejemplar con código de barras K000589673.

5. Hymenophyllum darwinii Hook.f. ex Bosch, Ned. Kruidk. Arch. 5 (3): 157. 1863. Hymenophyllum rarum R. Br. var. darwinii (Bosch) Neger, Bot. Jahrb. Syst. 23: 402. 1897. TIPO: Argentina, "Hab. Tierra del Fuego", 1833, C. Darwin 423 (holotipo, K000589674!). Fig. 7.

Hymenophyllum skottsbergii C. Chr., Ark. Bot.10 (2): 2122, fig. 2. 1910. TIPO: Argentina-Chile, "Tierra del Fuego, Lago Fagnano (Lago Cami), Bahía de la Espedición”, 2103-1908, C. Skottsberg 925 (holotipo S05-5939!; isotipos UPS, foto SI!, P00622178!, US00067703!).
Rizomas filiformes, ramificados, parduscos, de 0,15-0,25 $\mathrm{mm}$ de diám.; pelos del rizoma castaños, simples, de 0,30,5 mm long., escasos, adpresos; frondes distantes, de 2,5$12 \mathrm{~cm}$ long. o a menudo varias saliendo desde el mismo punto; pecíolos castaño-oscuros, muy delgados, de $1-9 \mathrm{~cm}$ long., glabros, teretes, no alados; láminas ovadas, ovadolanceoladas a triangulares, 2-3-pinnatífidas, de 1-4 x 0,8$2,5 \mathrm{~cm}$, de textura membranácea, glabras; raquis castaño oscuro, glabro, terete, con alas en todo su largo de aprox. 0,3 mm lat., de margen entero, ondulado; pinnas de contorno trapeciforme, compactas o no, pinnatífidas a 2-pinnatífidas, de 0,8-1 x 0,6-1,3 cm, divididas hacia ambos lados; segmentos lineares, de largo variable, fastigiados o no, de 0,8-1 mm lat., ápice redondo o emarginado, de margen entero más o menos ondulado; soros ubicados en las pinnas medias y superiores, en el mismo plano de la lámina, terminales sobre segmentos iguales o más anchos que el indusio; involucros lanceolados, inmersos en la lámina menos de la mitad, de base y ápice agudos, valvas indusiales de margen entero abiertas más de la mitad; receptáculo cilíndrico, inserto, de color oscuro a la madurez.

Distribución y ECOlOGía. Especie endémica de los bosques australes de Sudamérica. En la Argentina se la encuentra desde la provincia de Neuquén hasta Santa Cruz y Tierra del Fuego, incluida la Isla de los Estados. En Chile se la ha colectado desde la provincia de Ñuble, en la Región del Biobío, hasta la Región de Magallanes, en las provincias de Tierra del Fuego y Antártica Chilena (Fig. 7F). Ha sido más colectado del lado argentino de los Andes, y soporta una gran amplitud altitudinal, llegando hasta los $1.200 \mathrm{~m} \mathrm{s.m.} \mathrm{en}$ la provincia de Neuquén. Vive en grietas y barrancas, cerca de ríos o cauces de agua, epipétrico o sobre la hojarasca en descomposición, también es epífito, formando colonias densas, solitarios o mezclados con musgos u otras especies del género.

\section{ESPECÍMENES EXAMINADOS.}

ARGENTINA, Neuquén, Lácar, Huahum, 650 m, 30-III1952, Diem 2109 (SI); Lago Queñi, 810 m, 31-III-1952, Diem 2120 (SI). Los Lagos, Quetrihué, costa oeste Lago Nahuel Huapi, Potrero Rincón, 01-VIII-1943, Diem 740 (SI); Brazo Rincón, Península Panguinal, Cerca del camping, cruzando el río Totoral, orilla del lago, 21-II-2011, Larsen 166 (SI); Rincón, camino al paso Puyehue, 900 m, 24-IV1943, Diem 611 (BAB; SI); Quetrihué, arroyo sobre el lago Patahua, 15-X-1939, Diem 15 P (BAB); Puerto Manzano, lote 8, 800 m, 21-VI-1956, Diem 2568 (BAB); Quetrihué, Lago Escondido, 15-V-1943, Diem 638 (BAB; SI); Puerto Blest, desembocadura del Río Bravo, 800 m, 25-X-1947, Diem 1068 (SI); Puerto Blest, Laguna Ortiz-Basualdo, 1200 m, 24-X-1947, Diem 1063 (SI); Brazo Tristeza, Salto Grande de la Laguna Frey, 02-XI-1940, Diem 582 (SI); Quetrihué, arroyo al Lago Patahua, 08-X-1944, Diem 864 
(SI); Lago Nahuel Huapi, Isla Victoria, Punta Norte, 25-V1944, Diem 804 (SI); Correntoso, 05-II-1934, Burkart 6304 (SI); Subida al refugio del Cerro Colorado, sobre rocas, 1.200 m, 08-VI-1941, Diem 367 (SI); Puerto Blest, Cascada de Los Cántaros, 23-II-2011, Larsen 181 (SI). Río Negro, Bariloche, Puerto Blest, sendero que conduce a la Cascada de Los Cántaros, en el borde de un arroyito, 28-VII-2009, Zanotti 150 (SI); Puerto Blest, 27-IV-1942, Diem 353 (BAB; SI); Laguna Frías, camino entre hotel y aduana, ca. $800 \mathrm{~m}$, 30-X-1947, Diem 1098 (SI). Santa Cruz, Lago Argentino, Brazo Spegazzini: frente glaciar que baja del Cerro Heim hacia el SE, 22-III-1953, Vervoorst 4739 (LIL). Tierra del Fuego, Ushuaia, Isla de los Estados, Puerto Vancouver, ca. 360 m, 28-X-1971, Dudley 1060 B (BAB). CHILE, Región de Los Lagos, Llanquihue, Peulla, cerca del tanque de agua, 300 m, 27-X-1947, Diem 1075 (SI). Región de Aisén, Aisén, Laguna San Rafael, 00-II-1999, Teillier 4405 (CONC). Coihaique, Ruta 7 entre Villa Cerro Castillo y Puerto Tranquilo, 570 m, 28-XI-2009, Biganzoli 2253 (SI). Región de Magallanes, Antártica Chilena, Islas Wollaston: Bahía Hately, 100 m, 10-I-1949, Vervoorst 349 (LIL).

\section{OBSERVACIONES}

Hymenophyllum darwinii usualmente presenta, a pesar de ser una especie muy variable, indusios lanceolados de ápice agudo, carácter que ayuda a determinar la especie. Aunque la forma típica es de pequeño tamaño y follaje ondulado, pueden observarse ejemplares de mayor longitud, siendo estos últimos de difícil delimitación con la especie más afín, H. cuneatum (véase bajo esa especie).

Según Diem \& Lichtenstein (1959), los ejemplares que crecen a mayor altitud presentan la forma más reducida de su fronde, al igual que los que habitan a mayores latitudes (de donde procede el material tipo).

Algunos especímenes provenientes del extremo sur de América fueron erróneamente determinados como Hymenophyllum abruptum Hook., especie de Jamaica (Diem \& Lichtenstein 1959). Del mismo modo H. brevifrons Kunze [= H. abruptum var. brevifrons (Kunze.) Franch.] de Centroamérica fue un nombre erróneamente usado para la Patagonia (Hariot et al. 1889). También se excluye de la sinonimia el nombre $H$. wrightii Bosch, especie de China y Japón citada erróneamente para el área.

6. Hymenophyllum dentatum Cav., Descr. Plant.: 276. 1802. Leptocionium dentatum (Cav.) Bosch, Ned. Kruidk. Arch. 4(4): 384. 1859. TIPO: Chile, "San Carlos de Chiloé", 1801, L. Née 687 (holotipo, MA475842!; isotipo BM000936794!). Fig. 8.

Hymenophyllum bridgesii Hook., Sp. Fil. 1: 97, tab. 35 C. 1844. Sphaerocionium bridgesii (Hook.) Klotzsch, Linnaea 18: 536. 1844. TIPO: Chile, "Hab. Valdivia, on trunks of trees" T. Bridges 795 (lectotipo, aquí designado,
K000589679!; isolectotipo, E00215234!). SINTIPOS: Chile, "Hab. Valdivia, on trunks of trees" T. Bridges 796 (K000589678!, E00215233!, E00413894!); Chile, “Chiloé”, H. Cuming 9 (K000589681!, E00215229!, E00215230!).

Hymenophyllum trichocaulon Phil., Anales Univ. Chile, I, Mem. Ci. Lit. 94: 360. 1896. TIPO: "Chile austral" R. A. Philippi s.n. (holotipo SGO000000528!; isotipo SGO000000527!).

Rizomas rastreros, filiformes, ramificados, castaño-rojizos a oscuros, de 0,45-0,65 mm de diám.; pelos del rizoma castaño-rojizos, con 5-10 células, de 0,5-2 mm long., dispuestos espaciadamente sobre el rizoma, más densos en la base de los pecíolos, adnatos o adpresos, lineares, uniseriados, con las uniones entre las células engrosadas; frondes distanciadas, de (10)15-25(30) cm long.; pecíolos negros, de 3-13 cm long., con pelos en toda su longitud similares a los del rizoma, de poco más de $1 \mathrm{~mm}$ long., adpresos, ferrugíneos, no alados; láminas ovadas a subtriangulares, 3-pinnado-pinnatífidas, de 5-11 x 3-6 cm, textura membranácea, glabras; raquis negro, con pelos castaños a negros, multicelulares, uniseriados, adpresos, en forma de T, de aprox. $1 \mathrm{~mm}$ long., angostamente alados hacia el ápice, con alas de margen entero; pinnas 2-pinnadopinnatífidas, ovadas, ovado-lanceoladas a ovado-lineares, de 1-3,5 x 0,8-1,8 cm, simétricas, costas y cóstulas con pelos en su cara adaxial, angostamente aladas; segmentos oblongos, de 0,6-0,9 $\mathrm{mm}$ de ancho, con ápice redondeado, margen levemente dentado, glabros; soros en toda la lámina, a excepción de las pinnas basales, subaxilares, dispuestos a ambos lados de las pinnas, sobre un corto pedicelo arqueado, perpendiculares al plano de la lámina; involucros elípticos a suborbiculares, no inmersos en la lámina, de base aguda, engrosada, de ápice redondeado, entero o irregular, valvas abiertas hasta más de la mitad, con dientes (3) alargados en forma de crestas longitudinales sobre la superficie de una de las valvas; receptáculo filiforme, inserto, de $1 \mathrm{~mm}$ long.

Distribución Y eCología. Especie endémica. En la Argentina crece en las provincias de Neuquén, Río Negro, Chubut y también en Tierra del Fuego, incluida la Isla de los Estados. En Chile se halla desde la Región del Biobío, hasta la provincia de Capitán Prat, en la Región de Aisén; también se la ha colectado en la Región de Magallanes (Fig. 8F). Este helecho vive epífito, epipétrico, o sobre el sustrato en descomposición. Es una especie muy común, y es habitual encontrarla asociada a otras especies del género.

ESPECIMENES EXAMINADOS.

ARGENTINA, Neuquén, Lácar, Río Huahum, 630 m, 29III-1952, Diem 2103 (SI). Los Lagos, Península Quetrihué, Punta La Gaviota, 780 m, 27-VI-1948, Diem 1164 (SI); Quetrihué, 23-III-1940, Diem 126P (SI); Correntoso, 05- 

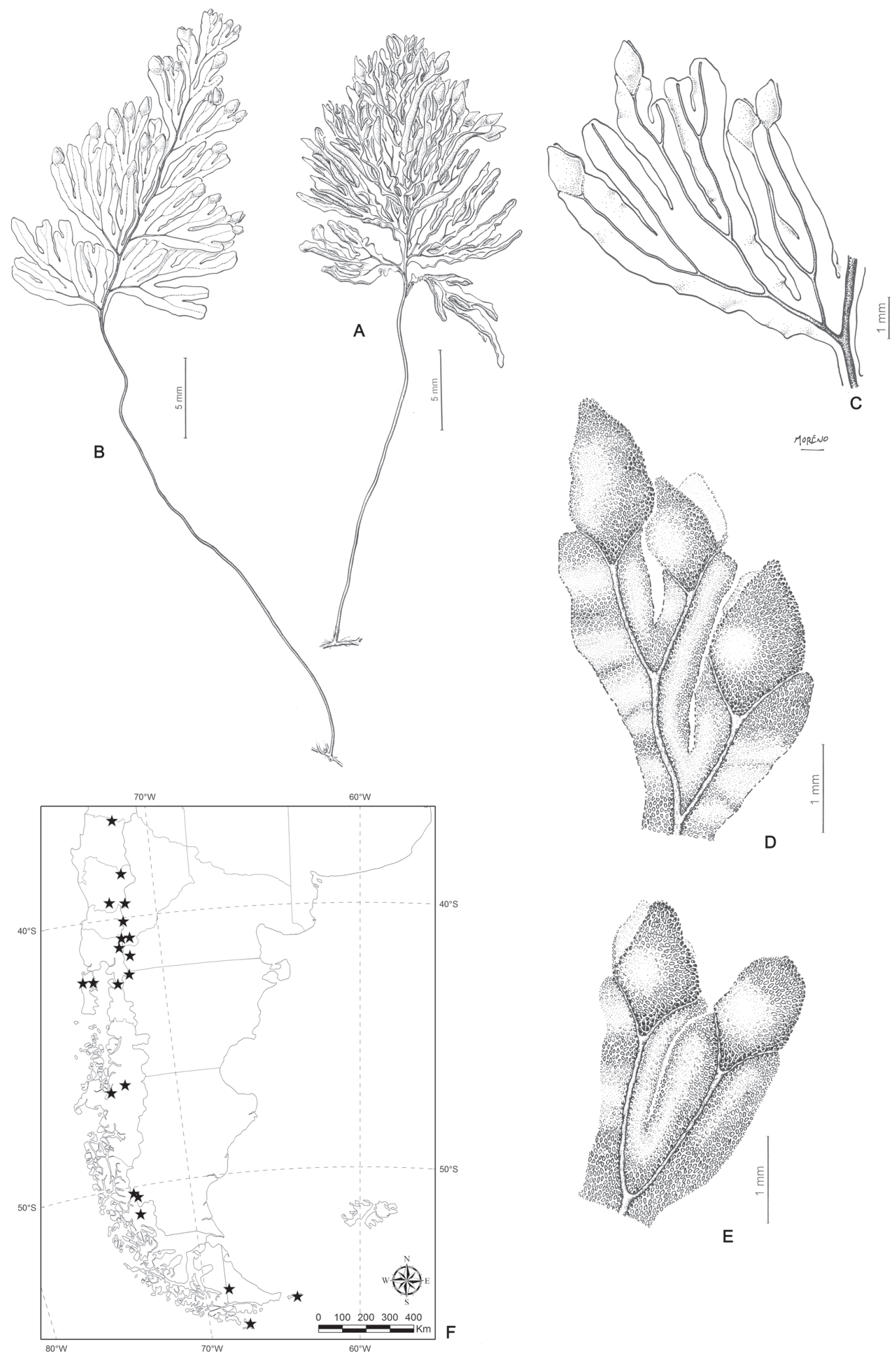

Figura 7. Hymenophyllum darwinii. A, B, aspecto general. C, detalle de una pinna fértil. D, E, detalle de los indusios. F, mapa de distribución de la especie.

Figure 7. Hymenophyllum darwinii. A, B, habit. C, detail of a fertile pinna. D, E, detail of the sorus. F, distribution map of the species. 

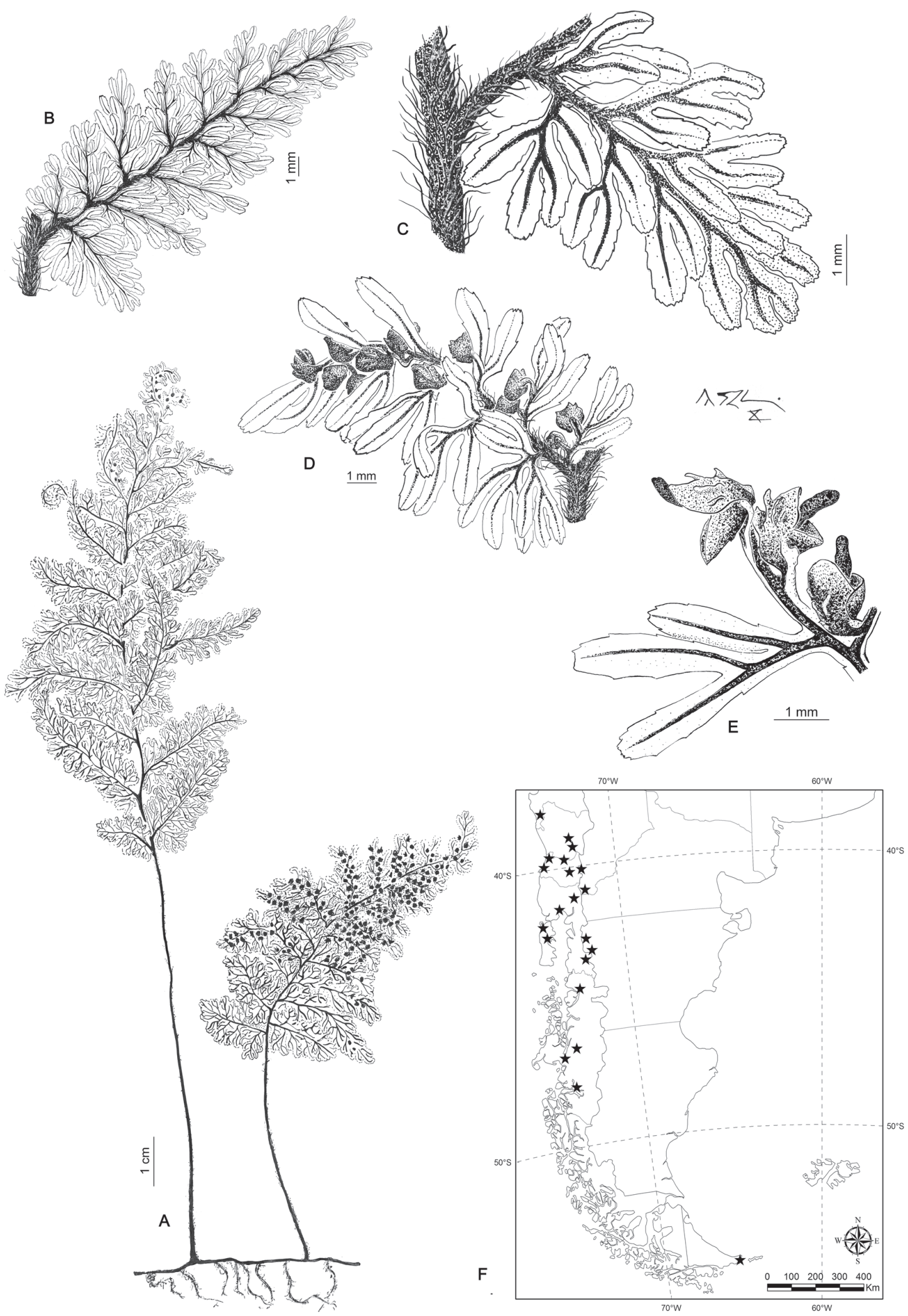

Figura 8. Hymenophyllum dentatum. A, aspecto general. B, vista de una pinna estéril. C, detalle de una pinnula. D, detalle de una pinna fértil. E, detalle de los indusios. F, mapa de distribución de la especie.

Figure 8. Hymenophyllum dentatum. A, habit. B, view of a sterile pinna. C, detail of a pinnula. D, detail of a fertile pinna. E, detail of the sori. F, distribution map of the species. 
II-1934, Burkart 6305 (SI). Río Negro, Bariloche, Puerto Blest, vertiente detrás de la Estación Biológica, 24-II2011, Larsen 188 (SI); Lago Nahuel Huapi. Pto. Blest, 19III-2008, Morero 255 (CORD). Chubut, Futaleufú, Lago Menéndez, 02-II-1945, Castellanos, s.n. (LIL150278A); Lago Menéndez, alerzales del brazo norte, 04-II-1955, Burkart 19811 (SI); Parque Nacional Los Alerces: riva orientale del Lago Situacion, 08-I-1974, Pichi-Sermolli 7413 (SI); Parque Nacional Los Alerces, sendero entre Lago Menéndez y Lago Cisne, 588 m, 30-X-2008, Biganzoli 1841 (SI). CHILE, Región del Biobío, Arauco, Contulmo, 10 m, 00-XII-1952, Gunckel 30907 (CONC). Región de la Araucanía, Cautín, Trailanqui, 10-XI-1929, Gunckel 860/3 (SI); Pucón, 08-I-1934, Barros 189 (SI); Trailanqui, 11-XI1929 Gunckel 1794 (SI). Malleco, Angol, Parque Nacional Contulmo, 24-IV-1970, De la Sota 6002 (LP). Región de Los Ríos, Valdivia, Cuyinhue, IX-1925, Werdermann 1179a (SI); Corral, Cerro de la Viga, 100 m, 24-XII-1935, Gunckel 15403 (LIL); Camino entre Dollinco y Panguipulli, bosque frente a Quilapulli, $250 \mathrm{~m}, 14-\mathrm{I}-1976$ Marticorena 330 (CTES). Ranco, Camino desde Futrono a Lago Ranco por ruta T-55, puente Caunahué, 20-II-2012, Larsen 227 (SI). Región de Los Lagos, Chiloé, Chiloé, Piruquina, 11-IX1931, Junge 21 (SI); Buaún, 30-I-1937, Barros 252 (SI 116645). Llanquihue, Volcán Calbuco, 08-II-1937, Barros 263a (SI); Cayutué, faldas del "Cerro Derrumbe", 08-II1931, Rentzell 22 (SI); Puerto Varas, 27-I-1909, Hicken 18 (SI 16578); Entre Ensenada y Petrohué, 16-II-1926, Looser 88H (SI); Puerto Montt, 24-I-1909, Hicken 19 (SI 16577); Peulla, 20-III-1959, De la Sota 2158 (LIL). Palena, Ruta 231 entre Futaleufú y Puerto Ramírez, 196 m, 26-XI-2009, Biganzoli 2200 (SI). Región de Aisén, Istmo de Ofqui, Leopardo, 13-I-1921, Hicken 84 (SI 16583); Istmo de Ofqui, San Rafael, 09-II-1921, Hicken 84 (SI 16576); Istmo de Ofqui, Leopardo, 12-I-1921, Hicken 84 (SI 16584); Ruta 7 saliendo de Puyuhuapi hacia Puerto Aisén, 10 m, 26-XI2009, Biganzoli 2227 (SI). Capitán Prat, Caleta Tortel, 5 m, 04-VIII-1976, Rodríguez R. 798 (CTES). Coihaique, Ruta de Puerto Tranquilo pasando el Ventisquero Río Exploradores, km 65, fin del camino, 73 m, 29-XI-2009, Biganzoli 2260 (SI).

\section{OBSERVACIONES}

Es una especie muy característica por sus frondes de tamaño mediano, la abundante pilosidad en los ejes y por tener todas las pinnas desarrolladas hacia ambos lados.

En su clasificación de las Hymenophyllaceae, Copeland (1938) incluye tentativamente a $H$. dentatum dentro del género Meringium por el margen dentado y la forma del involucro, aclarando que por lo demás no se circunscribe naturalmente a ningún otro género. Actualmente las especies de Meringium, incluido $H$. dentatum, se ubican dentro del subgénero Hymenophyllum (Ebihara et al. 2006).

Se escogió como lectotipo el ejemplar con código de barras K000589679, debido a su buen estado de conservación, y a que se encuentra en estado fértil.

7. Hymenophyllum dicranotrichum (C. Presl) Sadeb., Nat. Pflanzenfam.1(4): 110. 1899. Leptocionium dicranotrichum C. Presl, Hymenophyllaceae: 27, lám. XI, fig. D, 1843. Hymenophyllum chiloense Hook., Sp. Fil. 1: 90, lám. 32 A. 1844. nom. illeg. TIPO: Chile, "Chiloé", H. Cuming 8 (lectotipo, aquí designado, K000589682!; isolectotipos E00215240!, E00420016!). SINTIPO: Chile; "Chiloé”, $H$. Cuming 12 (K000589684!, E00420015!, S, foto SI!). Fig. 9.

Trichomanes spinulosum Phil., Linnaea 30: 208. 1859-60. TIPO: Chile; "Prope Corral", 1858, H. Krause s.n. (holotipo, SGO000000493!; isotipo SGO000000492!).

Rizomas filiformes, ramificados, pardo-oscuros, de 0,1-0,25 mm de diám.; pelos del rizoma translúcidos, uniseriados, adnatos, densamente dispuestos en rizomas jóvenes, caedizos a la madurez; frondes distantes, de 4,9-8 cm long.; pecíolos pardusco claros, de 0,9-3 cm long., notoriamente pilosos cuando jóvenes, con pelos traslúcidos, uniseriados, adnatos, hasta de 7 células, de 0,4-0,8 mm long. o basalmente bifurcados de $0,2 \mathrm{~mm}$; láminas lineares, lanceoladas $\mathrm{u}$ ovadas, pinnatífidas $\mathrm{a}$ 2-pinnatífidas, de 3-6 x 1-3 cm, textura membranácea, con pelos casi exclusivamente sobre el envés de la lámina, simples o basalmente bifurcados, siendo cada punta 1-2 celular, de 0,1-0,3 mm long., con pelos sobre todos sus ejes, multicelulares, uniseriados, adnatos a los ejes cerca de uno de sus extremos, con el extremo acroscópico en general más desarrollado, curvado hacia abajo, de 0,3-0,6 mm long.; raquis oscuro o pardo oscuro a verde en el extremo, anchamente alado en todo su largo, glabro en el haz, con pelos uniseriados, uni o paucicelulares, simples o connatos y en apariencia bifurcados en el envés, con el margen cubierto, al igual que el margen de los segmentos, de pelos simples o basalmente bifurcados; pinnas pinnatífidas a lobuladas, de contornos variables, lineares, obovadas, rómbicas, hasta elípticas, de 0,2-1,7 x 0,1-1,2 cm, las estériles pueden ser simétricas, o en general divididas dicotómicamente, con el segmento adaxial fértil o no, y el abaxial dividido una $\mathrm{o}$ varias veces; segmentos lineares u oblongos, simples o bifurcados, de 0,7-1,8 $\mathrm{mm}$ lat., de ápice redondo a obtuso, con pelos uni o paucicelulares, simples o bifurcados sobre el margen, idénticos a los de la lámina; soros en general subaxilares sobre el lado acroscópico, puede haber más de 1 soro por pinna, sobre todo en las pinnas basales, $y$ en ese caso, de posición alterna con respecto al eje principal de la misma, todos ellos de posición adaxial, no pedicelados; involucros suborbiculares, inmersos hasta la mitad en la lámina, de base aguda y ápice redondo de margen entero algo sinuoso, con pelos simples uni o bicelulares de 0,25 $0,35 \mathrm{~mm}$ long., abierto hasta la mitad o más; receptáculo 
filiforme, brevemente exerto a la madurez.

DistribuCión Y ECOLOGÍA. Especie endémica, hallada sólo en Chile, desde la Región del Biobío, en Concepción, hasta Laguna San Rafael, en la Región de Aisén (Fig. 9D). Vive epífita sobre troncos, solitaria o asociada a otras especies del género, en general especies raras o de ambientes muy húmedos como $H$. caudiculatum o $H$. cruentum, pudiendo formar colonias ampliamente extendidas.

ESPECÍMENES EXAMINADOS.

CHILE, Región del Biobío, Concepción, Río Chivilingo, Puentes Mellizos, 05-I-1966, Meyer 9778 (LP). Región de Los Ríos, Valdivia, camino Reyehueico y Neltume, 380 m, I-1976, Marticorena 528 (CONC). Región de Los Lagos, Osorno, Parque Nacional Puyehue, camino al volcán Casablanca, 558 m, 21-II-2012, Larsen 243 (SI). Chiloé, PN Chiloé, sendero El Tepual, 26-II-2012, Larsen 289 (SI); Chiloé, 00-I-1836, Castro s.n. (SI 16514); Chiloé, Buaún, 26-I-1937, Barros 284 (SI); Chiloé, Piruquina, 31VIII-1931, Junge 9 (SI); Chiloé, Bosque Fdo. Bellavista, Ancud, 23-I-1967, Villagrán 125 (LP). Llanquihue, Boca Río Puelo, 00-I-1916, Espinosa Bustos 10 (SI); Peulla, Cascada de los Novios, II-1947, Spinosa s.n. (SI 16831); Volcán Calbuco, 08-II-1937, Barros 196 (SI). Palena, Ruta 231 entre Futaleufú y Puerto Ramírez, 165 m, 26-XI-2009, Biganzoli 2208 (SI). Región de Aisén, Aisén, Istmo de Ofqui, Leopardo, 12-I-1921, Hicken 87 (SI 16581); Istmo de Ofqui, San Rafael, 13-II-1921, Hicken 77a (SI); Isla de los Leones, sin colector s.n. (SI 16511); Ruta 7 entre Santa Lucía y La Junta, 94 m, 26-XI-2009, Biganzoli 2221 (SI).

\section{OBSERVACIONES}

Esta especie es muy particular ya que es la única en el área de estudio que posee pelos sobre la superficie de la lámina. Posee además pelos simples o biburcados sobre el margen de la misma, y pelos simples uni o bicelulares sobre el margen del indusio, que son característicos de la especie. Otros caracteres diagnósticos son los soros subaxilares, y el receptáculo exerto.

Considerada por Morton (1968) como único representante de la sección Leptocionium dentro del subgén. Sphaerocionium, fue relacionada con Hymenophyllum por otros pteridólogos (Copeland 1938, 1947; Pichi Sermolli 1977; Iwatsuki 1984, 1990) y recientemente fue incluida dentro del subgén. Hymenophyllum por Ebihara et al. (2006).

Se designa como lectotipo de la especie el ejemplar $H$. Cuming 8 depositado en el herbario de Kew (K). Si bien este espécimen posee una sola fronde, la misma es del tamaño adulto y se encuentra en estado fértil y con rizoma.

8. Hymenophyllum falklandicum Baker, Syn. Fil. ed. 2: 68. 1874. TIPO: Argentina, "Falkland islands",
Abbott s.n. (lectotipo, aquí designado, K000214056!). SINTIPO: Argentina. "Falkland Islands", J. D. Hooker s.n. (K000214063!). Fig. 10.

Hymenophyllum caespitosum Christ, in Dusén, Svenska Exped. till Magellansl. 3(5): 242. 1899(1900). hom. illeg., non Gaudich. 1825, nec Fée 1866. Hymenophyllum glebarium C. Chr., Ind. Fil.: 362. 1906. nom. nov. para H. caespitosum Christ. TIPO: Chile, "Fuegia Australis: in valle fluminis Azopardo in terra ca. $500 \mathrm{~m}$ supra mare", $P$. Dusén 654 (lectotipo, aquí designado, UPS; isolectotipo S, fotos SI!). SINTIPO: Chile, "Pars occidentalis territorio magellanici: insula Desolacion ad Puerto Angosto in terra et in truncis arborum", P. Dusén 692 (UPS, foto SI!).

Hymenophyllum falklandicum Baker f. andinum Diem \& J. S. Licht., Darwiniana 11: 696. 1959. TIPO: Argentina, "Neuquén: Parque Nac. Nahuel Huapi, subida al Cerro Colorado, a 1.650 m, en una cueva", 18-II-1940, J. Diem P 116 (holotipo SI!; isotipos, BAB!, LIL!).

Hymenophyllum falklandicum Baker var. elongatum Diem \& J. S. Licht., Darwiniana 11: 696. 1959. TIPO: Argentina, Neuquén, Lago Nahuel Huapi, Brazo Rincón, Península Panguinal, 30-XI-1941, J. Diem 568 (lectotipo, aquí designado, SI000069!). SINTIPO: Argentina, Neuquén, Lago Nahuel Huapi, Brazo Rincón, Península Panguinal, 13VII-1941, J. Diem P114 (568) (SI000069!, BAB00000006!, BAB00000007!, LIL001942!, GH, foto SI!).

Rizomas rastreros, filiformes, ramificados, parduscos, de 0,2-0,35 mm de diám.; pelos del rizoma ferrugíneos, uniseriados, de 0,4-1 mm long., con 2-3 células, escasos, más densos cerca de la base del pecíolo; frondes distanciadas, de (2)3-7(10) cm long.; pecíolos parduscos, de $0,5-5 \mathrm{~cm}$ long., glabros o con escasos pelos ferrugíneos, similares a los del rizoma, de 2 células, de $0,5 \mathrm{~mm}$ long., teretes, levemente más delgados que el rizoma (aprox. $0,2 \mathrm{~mm}$ ), no alados; láminas lineares, linear-lanceoladas, oblongas, hasta elípticas, pinnado-pinnatífidas, de 2-6,5 x $0,5-1,5 \mathrm{~cm}$, de textura membranácea, glabras; raquis pardusco brillante, glabro, terete, en general no alado en la base y con pequeñas alas que se van ensanchando hacia el ápice; pinnas flabeladas, pinnatífidas, de 0,5-1 x 0,3-0,5 $\mathrm{cm}$, asimétricas, sólo con el lado acroscópico desarrollado, con divisiones erecto-patentes características formando un ángulo de $30^{\circ}$ entre ellas; segmentos lineares u oblongos, de 0,6-2 (2,6) $\mathrm{mm}$ de ancho, con el ápice redondeado a trunco, margen dentado, con dientes notables de más de 3 células, relativamente separados entre sí; soros subaxilares sobre las pinnas medias y apicales, en general 1 por pinna, con la base arqueada en mayor o menor grado, de manera que pueden orientarse en plano perpendicular al plano de la lámina o no, dispuestos sobre un corto pedicelo tenuemente 


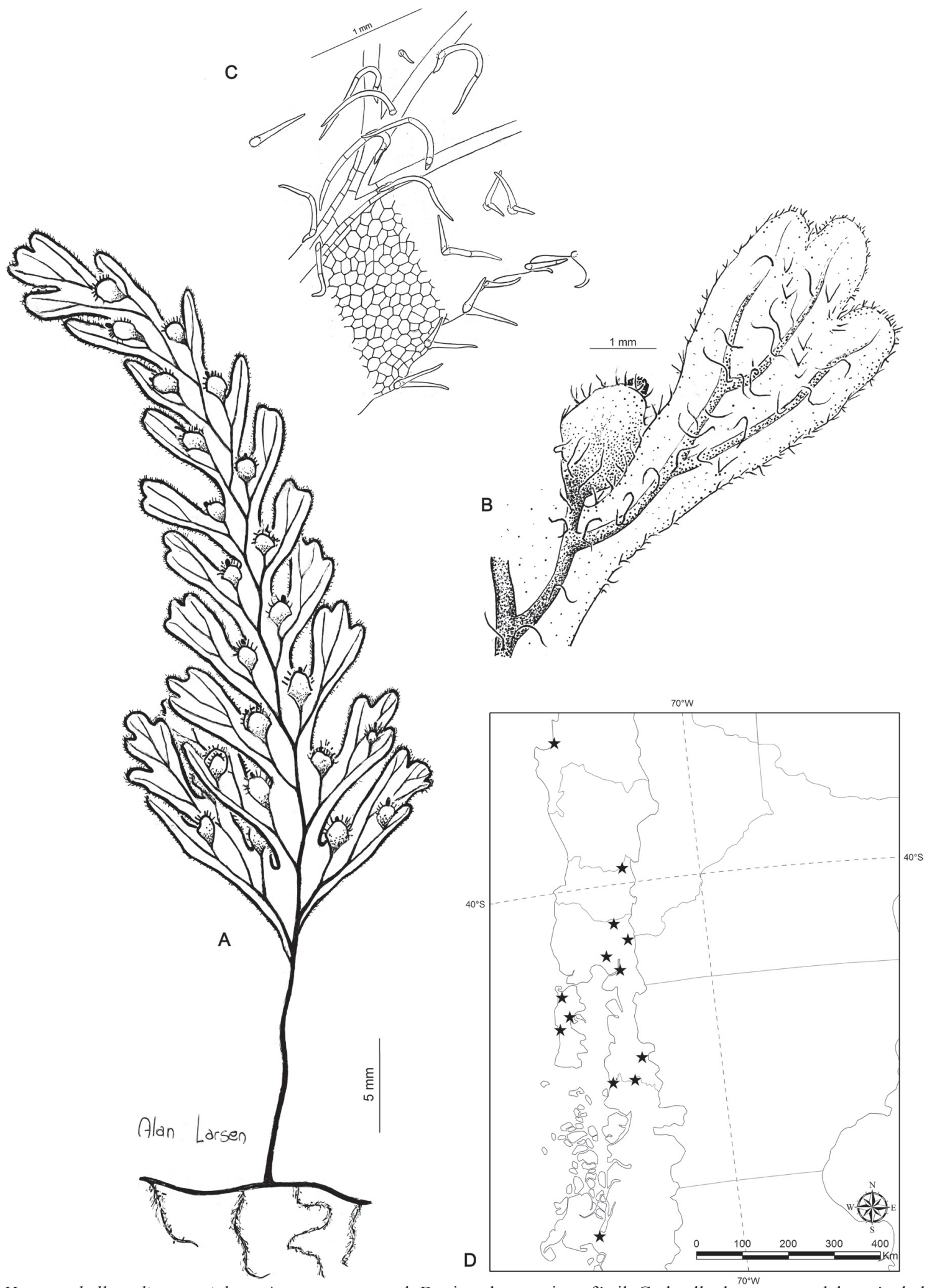

Figura 9. Hymenophyllum dicranotrichum. A, aspecto general. B, vista de una pinna fértil. C, detalle de un sector del envés de la fronde. $\mathrm{D}$, mapa de distribución de la especie.

Figure 9. Hymenophyllum dicranotrichum. A, habit. B, view of a fertile pinna. C, detail of a section of the ventral side of the frond. D, distribution map of the species. 


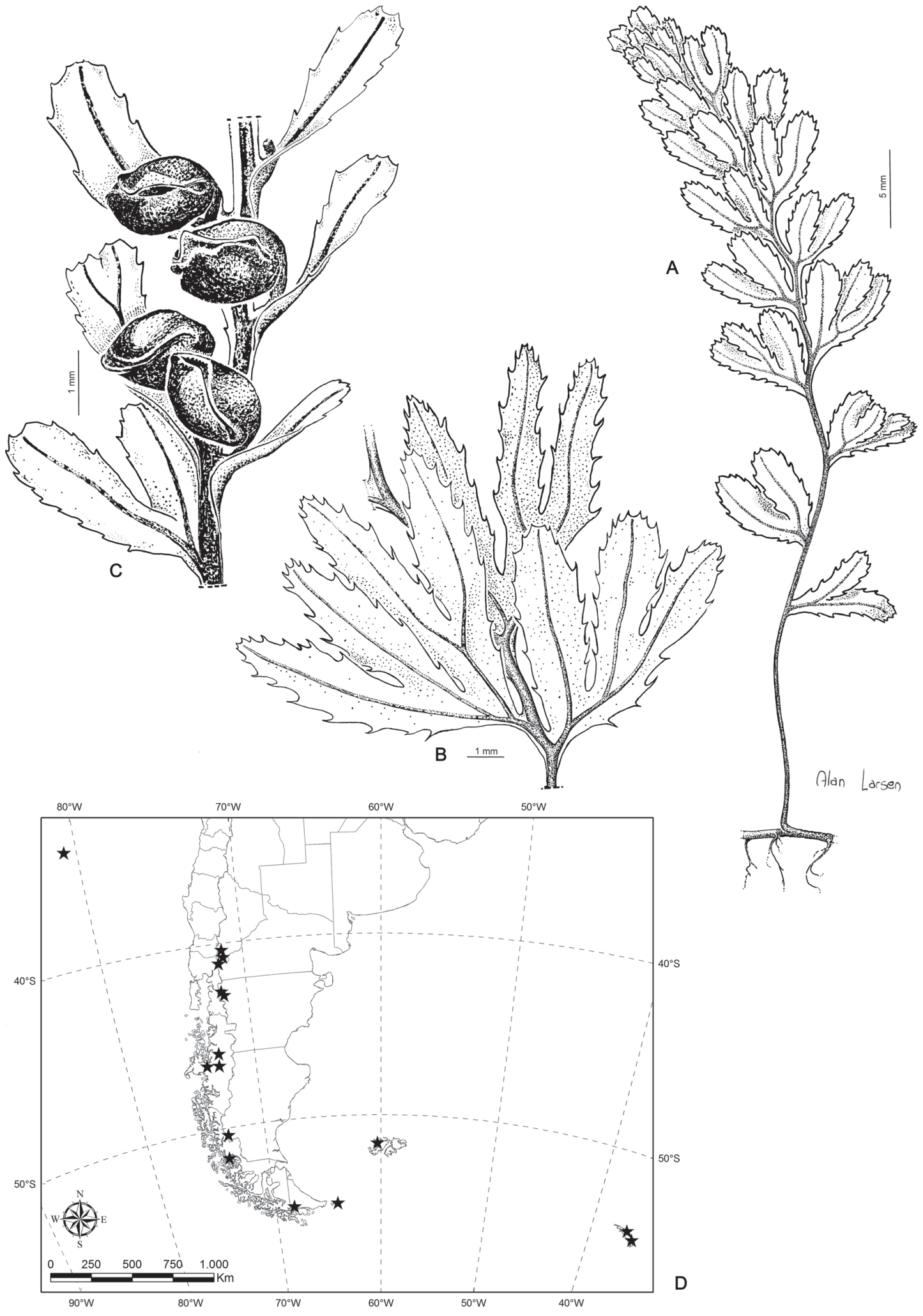

Figura 10. Hymenophyllum falklandicum. A, aspecto general. B, vista de las pinnas basales. C, vista de los indusios. D, mapa de distribución de la especie.

FIGURE 10. Hymenophyllum falklandicum. A, habit. B, view of the basal pinnae. C, view of the sori. D, distribution map of the species. 
alado; involucros ovados, ovado-lanceolados u oblongos, con la base aguda con venillas laterales engrosadas, el ápice redondeado a agudo, de margen entero, glabro, valvas abiertas un poco más de la mitad; receptáculo filiforme, delgado, inserto, de una longitud siempre menor a la del indusio.

Distribución y eCOlogía. Especie endémica de los bosques australes de Sudamérica austral-templada. En la Argentina se distribuye desde Neuquén hasta Tierra del Fuego, incluyendo a las Islas Malvinas. En Chile se halla desde la Región del Biobío hasta la Región de Magallanes y Antártica Chilena, incluyendo las islas Juan Fernández (Fig. 10D). Es una de las especies que soporta mayor rango de condiciones ambientales, llegando hasta una altitud de 1.800 m s.m. Además es la única Hymenophyllaceae que ha sido recolectada en las Islas Georgias, y se halla entre las especies raras que habitan las Islas Malvinas (Falkland Islands), lugar de hallazgo de la especie. Crece frecuentemente sobre rocas, en sitios húmedos o protegidos como grietas, sobre sustrato en descomposición o mezclado con musgos, en ocasiones epífito, en densas colonias o cojines compactos que tapizan la superficie de las raíces y bases de los árboles. También ha sido observado asociado con $H$. caespitosum e H. tortuosum.

ESPECIMENES EXAMINADOS.

ARGENTINA, Neuquén, Lácar, Lago Hermoso, 1100 m, 03-IV-1952, Diem 2126 (SI). Los Lagos, Cerro Colorado, 1800 m, 01-VI-1947, Diem 1028 (SI); Península Panguinal, Brazo Rincón, Lago Nahuel Huapi, 30-XI-1941, Diem 568 (SI); Quetrihué, Muelle bosque de los Arrayanes 18-VIII1940, Diem 946 (SI); Puerto Blest, Laguna Ortiz-Basualdo, 1200 m, 24-X-1947, Diem 1065 (SI); Puerto Blest, cascada de Los Cántaros, 23-II-2011, Larsen 178 (SI); cerca Laguna Divisoria, Río Bravo, Pto. Blest, 1400 m, 22-III-1946, Diem 957 (SI); Laguna "Las Monjas" en los nacimientos del arroyo Vinagre, debajo de una roca húmeda, $1600 \mathrm{~m}, 05$-III1945, Diem 926 (SI); Camino del Rincón al paso Puyehue, a orillas del Río Pireco, 24-IV-1943, Diem 608 (SI); Isla Victoria, Puerto Mercedes, 01-IX-1946, Diem 984 (SI); Filo Machete al $\mathrm{C}^{\mathrm{o}}$ Rothkugel, Campamento 3, $1650 \mathrm{~m}$, 27-III-1941, Diem 580 (SI). Río Negro, Bariloche, Laguna Frías, 28-IV-1942, Diem 552 (SI); Puerto Blest, Sendero entre Laguna de Los Cántaros y Laguna Ortiz Basualdo, 25-II-2011, Larsen 193 (SI); Brazo Blest, Arroyo Bravo, 09-II-1938, Capurro s.n. (LIL 102853). Santa Cruz, Lago Argentino, Lago Argentino, Puerto Ferrari, 05-III-1914, Hicken 1 (SI 16517); Lago Argentino, Puerto Ferrari, 00III-1914, Hicken 427 (SI). Tierra del Fuego, Ushuaia, Isla de los Estados, 18-XI-1903, Skottsberg s.n. (SI 16513); Rio Olivia, a NW di Ushuaia, 24-I-1974, Pichi-Sermolli 7551 (SI); Montes Martials, 15-XII-1932, Castellanos 7525 (LIL 18370). Islas del Atlántico Sur, South Georgia, Royal Bay,
Moltke Harbour, 27-IV-1902, Skottsberg s.n. (SI 16582). CHILE, Región de Valparaíso, Valparaíso, Juan Fernández, Más Afuera, 1.000 m, 30-XI-1965, Meyer 9388 (LP). Región de Aisén, Aisén, Istmo de Ofqui, Punta Leopardo, 13-I-1921, Hicken 78 (SI 19979). Coihaique, Ruta de Puerto Tranquilo al Ventisquero Río Exploradores, 320 m, 29-XI2009, Biganzoli 2254 (SI). Región de Magallanes, Última Esperanza, Canal de Las Montañas, 00-XI-1987, Pisano 6157 (CONC).

\section{OBSERVACIONES}

Esta especie es muy cercana a $H$. nahuelhuapiense, diferenciándose esta última por el follaje verde claro, las pinnas basales divididas hacia ambos lados, por las valvas de los indusios que se abren hasta la base y por el receptáculo de mayor grosor. Otro elemento afín, y en ocasiones difícil de diferenciar, es H. peltatum (véase bajo esa especie).

Hymenophyllum falklandicum se ubica dentro del subgén. Hymenophyllum (Ebihara et al. 2006), presentando las características típicas asignadas a éste: margen de los segmentos denticulados, e indusios en el extremo de segmentos acroscópicos (Hennequin et al. 2010).

$\mathrm{La}$ forma andinum y la variedad elongatum son entidades cuyos caracteres se encuentran dentro del rango de variabilidad de la especie $H$. falklandicum, incluyéndose en su sinonimia. Diem \& Lichtenstein (1959) describieron a la forma andinum como una variación de la especie que sobrevive a grandes altitudes o expuestas a fríos rigurosos. A la var. elongatum estos autores la separan por tener pinnas más remotas, mayor longitud de la lámina, segmentos más angostos (menos de $1 \mathrm{~mm}$ ), caracteres que son variables en $H$. falklandicum y que también están relacionados con las condiciones ambientales.

Para lectotipificar Hymenophyllum caespitosum Christ se escogió el ejemplar $P$. Dusén 654 depositado en UPS, por su mejor estado de conservación. Para Hymenophyllum falklandicum var. elongatum se designó lectotipo al ejemplar SI000069, debido a que es el más abundante.

9. Hymenophyllum ferrugineum Colla, Mem. Accad. Torino 39: 30. (1835) 1836. Sphaerocionium ferrugineum (Colla) Copel., Philipp. J. Sci. 67 (1): 33. 1938. Hymenophyllum subtilissimum Kunze, Anal Pteridogr.: 49. 1837. nom. illeg. Hymenophyllum berteroi Hook. Sp. Fil. 1: 93, lám. 33 C. 1844. nom. illeg. TIPO: Chile, "Ad rupes et arborum radices in sylvis umbrosis montium editiorum ins. Juan Fernández", 5-1830, C. Bertero 1540 (holotipo, TO, foto SI!; isotipos, P00622060!, P00622061!, P00622062!, US00067522!, MPU018008!). Fig. 11.

Hymenophyllum ferrugineum Colla var. donatti Looser, Physis (Buenos Aires) 15:218, fig. 1. 1939. Sphaerocionium ferrugineum (Colla) Copel. var. donatti (Looser) Kunkel, Nova Hedwigia 9(1-4): 257. 1965. TIPO: Argentina, 
"Río Negro, Arroyo Frías, 800 m" A. Donat 17 (holotipo, G00284080!).

Rizomas filiformes, ramificados, marrones, de 0,3-0,5 $\mathrm{mm}$ de diám.; pelos del rizoma simples, paucicelulares, patentes, de aprox. $2 \mathrm{~mm}$ long., cubriendo densamente el rizoma; frondes distantes, de 8-22 cm long.; pecíolos parduscos, de 1,7-10 cm long., densamente cubiertos por pelos paucicelulares, simples, bifurcados hasta estrellados, teretes, de 0,3-0,5 $\mathrm{mm}$ de diám., no alados; láminas ovado-lanceoladas u ovado-linear-lanceoladas, pinnado-2pinnatífidas, de 1,4-12 x 1,4-6,5 cm, de textura cartácea, densamente cubierta por pelos doblemente estrellados desde la base, o basalmente bifurcados y luego estrellados sobre los márgenes, y estrellados, basalmente estrellados y luego bifurcados o estrellados en una de sus ramas sobre las nervaduras; raquis oscuro, alado a partir del tercer a quinto par de pinnas, piloso; pinnas lanceoladas, 2-pinnatífidas, de 0,8-2,4 x 0,6-1,5 cm, simétricas; segmentos lineares, de aprox. $1 \mathrm{~mm}$ lat., de ápice redondeado, el margen entero; soros terminales en casi todos los segmentos a ambos lados de las pinnas medias y apicales; involucros suborbiculares, inmersos menos de la mitad en la lámina, iguales o levemente más angostos que el segmento, abierto en la mitad o menos, de ápice redondo a obtuso, la base obtusa, pilosa, el margen entero, densamente cubierto por pelos; receptáculo corto, inserto, con el ápice globoso.

DistribuCiÓn y eCOlOGía. Esta especie se encuentra, en América del Sur austral y en Nueva Zelanda. En la Argentina $H$. ferrugineum se encuentra en las provincias de Chubut, Neuquén, Río Negro y Tierra del Fuego. En Chile crece desde la Región de Los Lagos hasta la Región de Magallanes, y en las islas Juan Fernández (Fig. 11O). Terrestre, epífita o epipétrica, en barrancas, grietas, o sobre troncos en bosques húmedos. También ha sido recolectada en turbales, asociado a musgos.

\section{ESPECÍMENES EXAMINADOS.}

ARGENTINA, Chubut, Futaleufú, Parque Nacional Los Alerces, sendero entre Lago Menéndez y Lago Cisne, 576 m, 30-X-2008, Biganzoli 1849 (SI). Neuquén, Los Lagos, Península Panguinal, Brazo de Última Esperanza, 09-XI1941, Diem 563 (SI; CTES; BAB); Península Panguinal costa Lago Nahuel Huapi, Brazo Rincón, 770 m, 25-IV1943, Diem 614 (SI; BAB); Puerto Blest, a orillas del Río Bravo, 800 m, 25-X-1947, Diem 1069 (SI; BAB); Quetrihué, 06-VII-1941, Diem 125P (SI); Cuesta del Diablo, Rincón, camino al Paso Puyehue, 07-II-1940, Diem 596 (BAB). Puerto Blest, Cascada de Los Cántaros, 23-II-2011, Larsen 180 (SI); Río Negro, Bariloche, orillas de la Laguna Frías, 800 m, 01-XI-1947, Diem 1104 (SI; BAB); Camino entre Laguna y Ventisquero Frías, 31-X-1947, Diem 1103 (SI); Puerto Blest, 27-IV-1942, Diem 352 (BAB). Tierra del
Fuego, Ushuaia, Isla de Los Estados, Bahía Flinders, 07-XI1971, Dudley 1565 (BAB). CHILE, Región de Valparaíso, Valparaíso, Más Afuera, sendero monte de Quebrada VacasLas Torres, 690 m, 14-III-2002, Stuessy 5077 (CONC); Juan Fernández, Más a Tierra, Quebrada Villagra, Falda oeste de La Damajuana, 18-II-1931, Espinosa 3 (SI 17442). Región de Los Lagos, Llanquihue, Casa Pangue, camino al Paso Pérez Rosales, 600 m, 21-X-1947, Diem 1048 (SI); Peulla, cascada de los helechos, 250 m, 28-X-1947, Diem 1081 (BAB). Chiloé, PN Chiloé, sendero El Tepual, 26II-2012, Larsen 284 (SI). Región de Aisén, Aisén, Ruta 7 entre Puyuhuapi y Puerto Aisén, Parque Nacional Queulat, sendero Padre García, 135 m, 27-XI-2009, Biganzoli 2234 (SI); Istmo de Ofqui, Leopardo, 13-I-1921, Hicken 79 (SI 16544); Istmo de Ofqui, San Rafael, Playita, 04-II-1921, Hicken 79 (SI 16545). Región de Magallanes, Última Esperanza, Isla Rennel Norte, Canal Smyth, 21-I-1976, Dollenz 1107 (BAB); Península Roca, Seno Resi, ca. 175 m, 22-I-1978, Pisano 2831bis (LP); Península Roca, Seno Resi, 175 m, 22-I-1978, Pisano s.n. (TBPA 2831b) (LP).

\section{OBSERVACIONES}

Hymenophyllum ferrugineum presenta un característico follaje castaño rojizo debido a sus tricomas, que lo hacen fácil de reconocer a campo. Es el único representante del subgén. Sphaerocionium del área de estudio, caracterizado por la presencia de pelos estrellados.

Se observaron diferencias en el material de Juan Fernández, principalmente en cuanto a los pelos del margen de la lámina que son basalmente estrellados y luego tetrafurcados en la gran mayoría de los casos, además los segmentos se mantienen aproximados y paralelos luego de una división. Estas características se observaron también en el escaso material procedente de Nueva Zelanda observado, $\mathrm{y}$ todo el conjunto requiere de un mayor estudio.

Se elimina de la sinonimia a $H$. franklinianum Colenso (= H. aeruginosum var. franklinianum Hook) de Nueva Zelanda, considerada una especie distinta de H. ferrugineum en Hennequin et al. (2010).

10. Hymenophyllum fuciforme Sw., Syn. Fil.: 148. 1806. Leptocionium fuciforme (Sw.) C. Presl, Abh. Boehm. Ges. Wiss. 5(5): 336. 1848. TIPO: Chile, "Ins. St. Carlos de Chiloé” L. Neé s.n. (holotipo B-W2023, foto SI!). Fig. 12.

Hymenophyllum fucoides Cav., Descr. Plant.: 275. 1802. nom. illeg., non Swartz 1788. TIPO: Chile, "San Carlos de Chiloé”, L. Neé s.n. (holotipo B-W2023, foto SI!).

Hymenophyllum semiteres Colla, Mem. Accad. Torino 39: 32, lám. 61. (1835) 1836. TIPO: Chile, "Ins. Juan Fernández”, 4-1830, C. Bertero 1543 (holotipo, TO, foto SI!) 

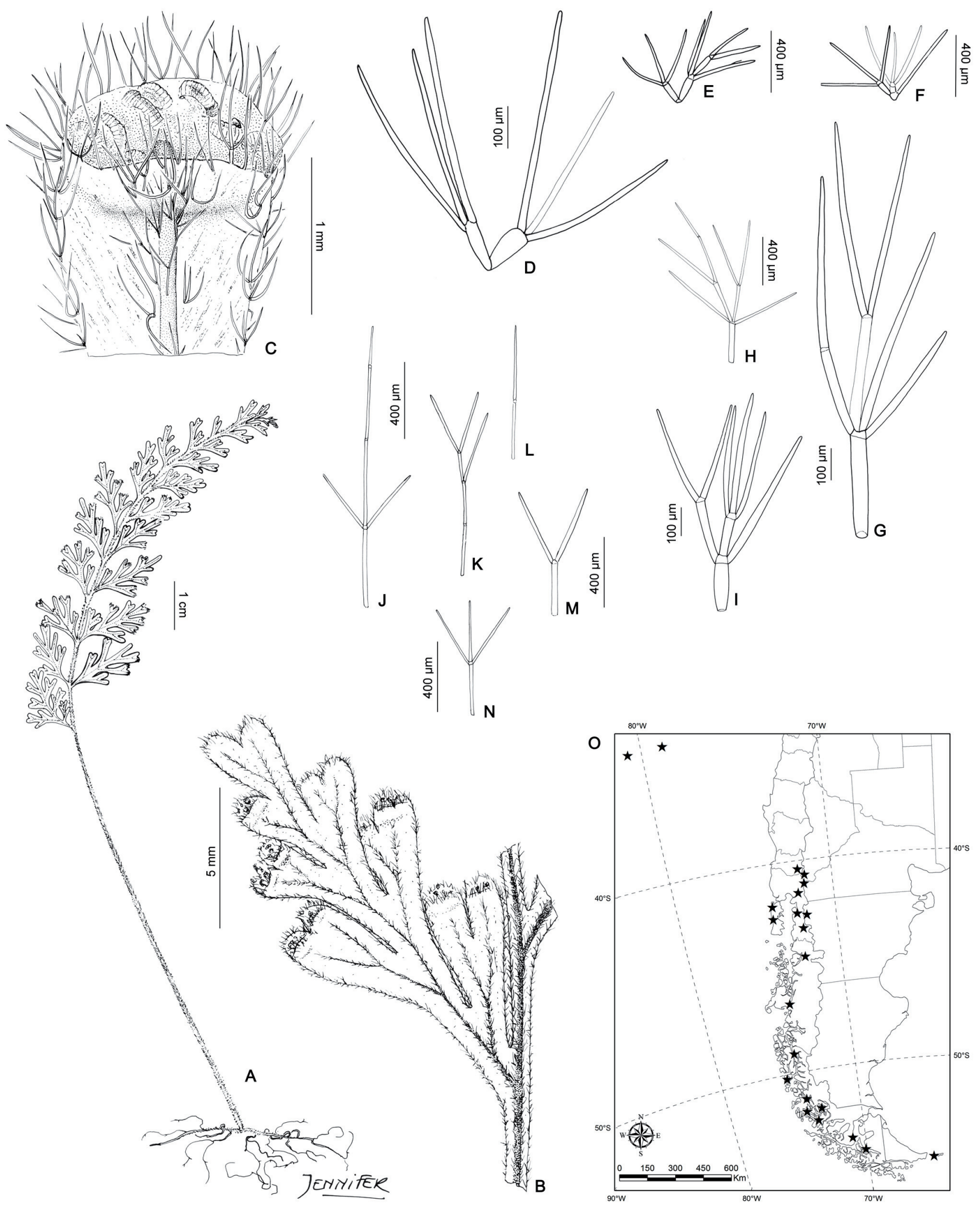

Figura 11. Hymenophyllum ferrugineum. A, aspecto general. B, detalle de una pinna. C, detalle de un indusio. D-F, pelos del margen de la lámina. G-I, pelos del raquis y nervaduras. J-N, pelos del pecíolo. O, mapa de distribución de la especie.

Figure 11. Hymenophyllum ferrugineum. A, habit. B, detail of a pinna. C, detail of a sorus. D-F, hairs of the margin of the frond. G-I, hairs of rachis and veins. J-N, petiole hairs. $\mathrm{O}$, distribution map of the species. 


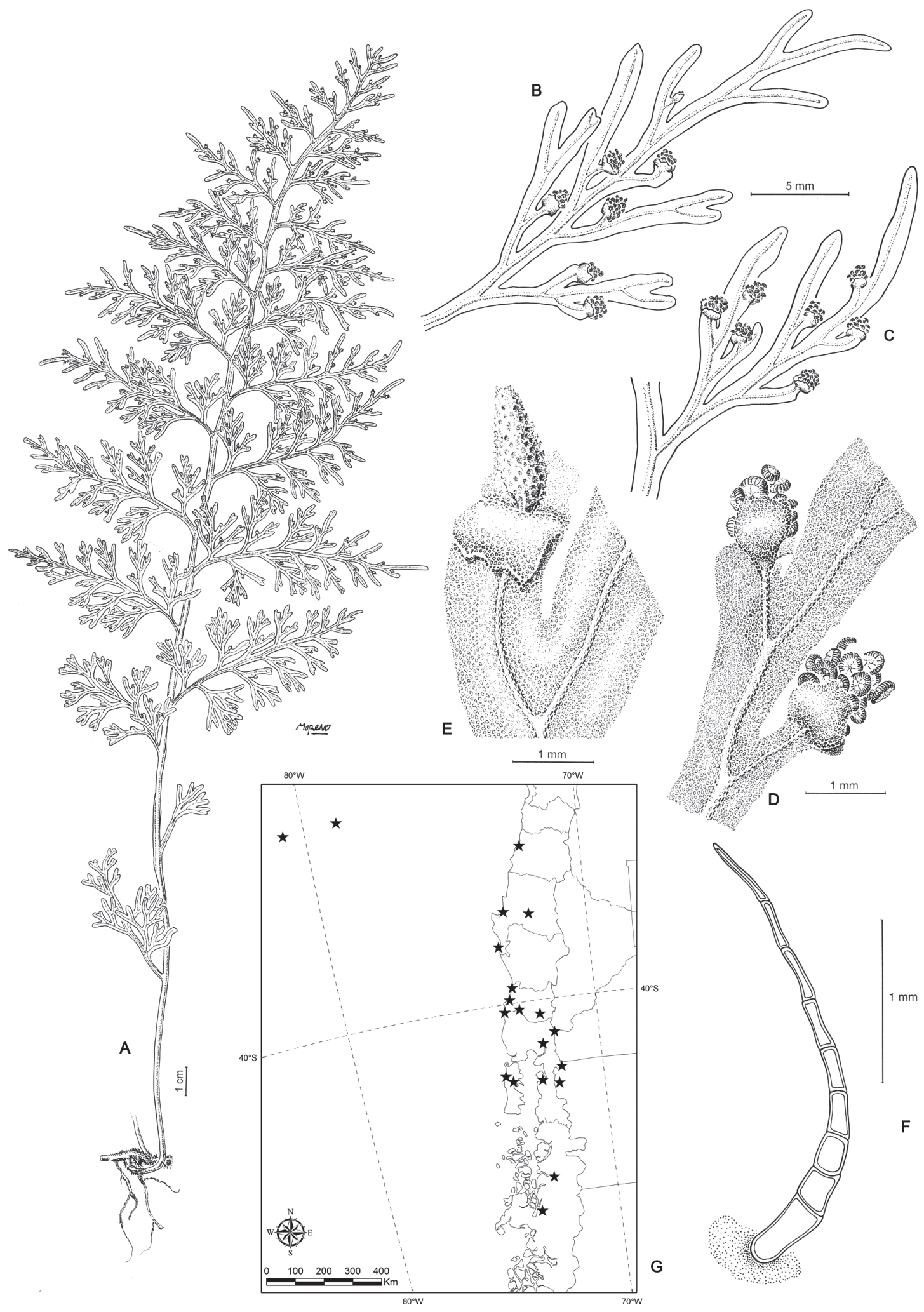

Figura 12. Hymenophyllum fuciforme. A, aspecto general. B, C, detalle de pinnas fértiles. D, detalle de indusios con esporangios. E, detalle de un receptáculo. F, detalle de un pelo del rizoma. G, mapa de distribución de la especie.

Figure 12. Hymenophyllum fuciforme. A. habit. B, C, detail of fertile pinnae. D, detail of sorus with sporangia. E, detail of a receptacle. F, detail of a rhizome hair. G, distribution map of the species. 
Rizomas rastreros, cortos o suberectos, escasamente ramificados, de color castaño oscuro, de 1,5-2,5 mm de diám.; pelos de rizoma castaño oscuros, simples, pluricelulares, de aprox. 2,5-3,5 mm long., cubriendo densamente todo su largo incluso la base de los pecíolos en donde pueden llegar a medir $6 \mathrm{~mm}$; frondes aglomeradas, fasciculadas, de 30-60 cm long.; pecíolos verde claros a parduscos en su base, de 14-26 cm long., glabros, algo aplanados en sección, con alas a partir de la mitad de su longitud o antes, que se van ensanchando hacia el ápice; láminas ovadas u ovado-lanceoladas, 4-pinnatífidas, de $15-30 \times 10-12 \mathrm{~cm}$, textura membranácea, glabras; raquis verde claro, glabro, comprimido, alado en toda su longitud, alas de 1-2 mm de ancho, de margen entero; pinnas ovado lanceoladas, 3-pinnatífidas, de 7-9 × 3-4 cm, simétricas; segmentos lineares u oblongos, de 1-1,4 mm lat., ápice redondo a subagudo, en ocasiones emarginado, margen entero, con la nervadura llegando hasta el final de este; soros distribuidos en toda la lámina, sobre ambos lados de las pinnas, levemente arqueados en la base, ubicados sobre segmentos cortos luego de una división; involucros suborbiculares a irregulares, no inmersos en la lámina, abiertos hasta la base de las valvas, ápice redondeado, el margen irregular; receptáculos subcilíndricos, algo engrosados en su parte basal o media, exertos a la madurez, rodeados hasta su base por aprox. 20 esporangios.

Distribución y eCología. Especie endémica, en la Argentina ha sido colectada en los parques nacionales Lago Puelo y Los Alerces, y recientemente en Puerto Blest, en el Parque Nacional Nahuel Huapi. En Chile crece desde la provincia

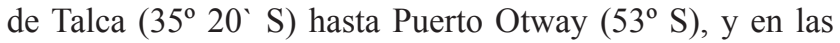
dos islas del Archipiélago Juan Fernández (Más a Tierra y Más Afuera), entre 300 y 950 m s.m. (Fig. 12G). Es una especie poco frecuente, forma colonias muy limitadas por el corto crecimiento de su rizoma, y a la vez muy vistosas por sus frondes grandes dentro del género. Puede ser epipétrico, habitando en grietas o barrancas, mezclado con sustrato, o epífito, en sitios muy húmedos, frecuentemente cerca de la influencia de cascadas, o pequeñas vertientes de agua, mezclado con musgos.

\section{ESPECÍMENES EXAMINADOS.}

ARGENTINA, Chubut, Cushamen, Parque Nacional Lago Puelo, Arroyo del Fuinque, entre Gendarmería y Los Hitos, 360 m, 28-IV-1999, Vidoz 131 (LP). Futaleufú, Parque Nacional Los Alerces, sendero entre Lago Menéndez y Lago Cisne, 588 m, 30-X-2008, Biganzoli 1840 (SI). Río Negro, Bariloche, Puerto Blest, vertiente detrás de la Estación Biológica, 24-II-2011, Larsen 185 (SI). CHILE, Región de Valparaíso, Valparaíso, Juan Fernández, Más a Tierra, 20XII-1965, Meyer 9608 (LP); Más Afuera, Quebrada Larga, por el final NE de Isla, 910 m, 2001, Stuessy 9445 (CONC); Juan Fernández, V-1830, Bertero 1541 (K000589689!).
Región del Biobío, Arauco, Laraquete, 15-XII-1963, Ricardi 757 (LIL). Región de Los Lagos, Chiloé, Piruquina, 13-IX1931, Junge 28 (SI). Llanquihue, Peulla, pasando la cascada velo de la novia, $255 \mathrm{~m}, 22-\mathrm{II}-2012$, Larsen 251 (SI); Peulla, 20-III-1959, De la Sota 2157 (BAB; LIL). Región de Los Ríos, Valdivia, Corral, Quebrada de la Aguada, 60 m, 15XII-1931, Gunckel 2876 (LIL); Barra del Río Bueno, 10X-1935, Hollermayer 1044 (LIL). Región de Aisén, Aisén, Puerto Chacabuco, Parque Aiken Sur, sendero del salto, 28XI-2009, Biganzoli 2243 (SI).

\section{OBSERVACIONES}

Especie muy vistosa y sobresaliente por su gran tamaño, sus frondes color verde oscuro y su follaje plano de margen entero. Dentro del área es similar a $H$. caudiculatum, (subgén. Globosa) que se diferencia por poseer indusios de gran tamaño, orbiculares, con receptáculo incluso, y frondes distanciadas entre sí sobre rizomas más delgados.

Copeland (1938) menciona en la lista de especies al final de su trabajo, que esta especie podría incluirse en el género Mecodium, aunque con dudas debido a su receptáculo alargado. Esto es mencionado en la sinonimia de la especie por Diem \& Lichtenstein (1959), y aquí se lo excluye definitivamente. Actualmente se considera dentro del subgén. Fuciformia (Ebihara et al. 2006), que comprende dos especies, la de Sudamérica austral, $H$. fuciforme, e $H$. pulcherrimum Colenso, de Nueva Zelanda. Este subgénero presenta hojas aglomeradas en rizomas gruesos, rastreros a suberectos, característica única en el género.

11. Hymenophyllum krauseanum Phil., Linnaea 30: 208. 1860. Hymenophyllum magellanicum (Desv.) Willd. ex Kunze var. krauseanum (Phil.) C. Chr., Ind. Fil.: 363. 1906. Hymenophyllum dichotomum Cav. var. krauseanum (Phil.) C. Chr., Ark. Bot. 10(2): 27. 1910. Hymenophyllum plicatum Kaulf. var. krauseanum (Phil.) Looser, Revista Universitaria (Santiago) 19: 271. 1934. Meringium krauseanum (Phil.) G. Kunkel, Nova Hedwigia 13: 326. 1967. TIPO: Chile, "Prope Corral, portum Valdiviae", H. Krause s.n. (holotipo, SGO000000522!; isotipo, herbario del Colegio San Pedro Nolasco, no visto). Fig. 13.

Hymenophyllum bibraianum J.W. Sturm, Flora 23: 361. 1853. TIPO: Chile, "Porto de Corral zu Valdivia", E. v. Bibra s.n. (B 200100203 , no visto, foto SI!).

Rizomas filiformes, ramificados, castaño-oscuros de 0,30,7 mm de diám., con pelos del rizoma parduscos, lineares o en forma de $\mathrm{T}$, de 0,2-1 mm, más densamente dispuestos en los rizomas jóvenes; frondes remotas (distanciadas $1 \mathrm{~cm}$ o más), de 8 a 20(22) cm long; pecíolos castaño-oscuros, 3-7 cm long., glabros, teretes, con alas en todo su largo, más o menos onduladas, de margen entero o contorto, con pelos multicelulares de $0,5 \mathrm{~mm}$ o más de largo; láminas 


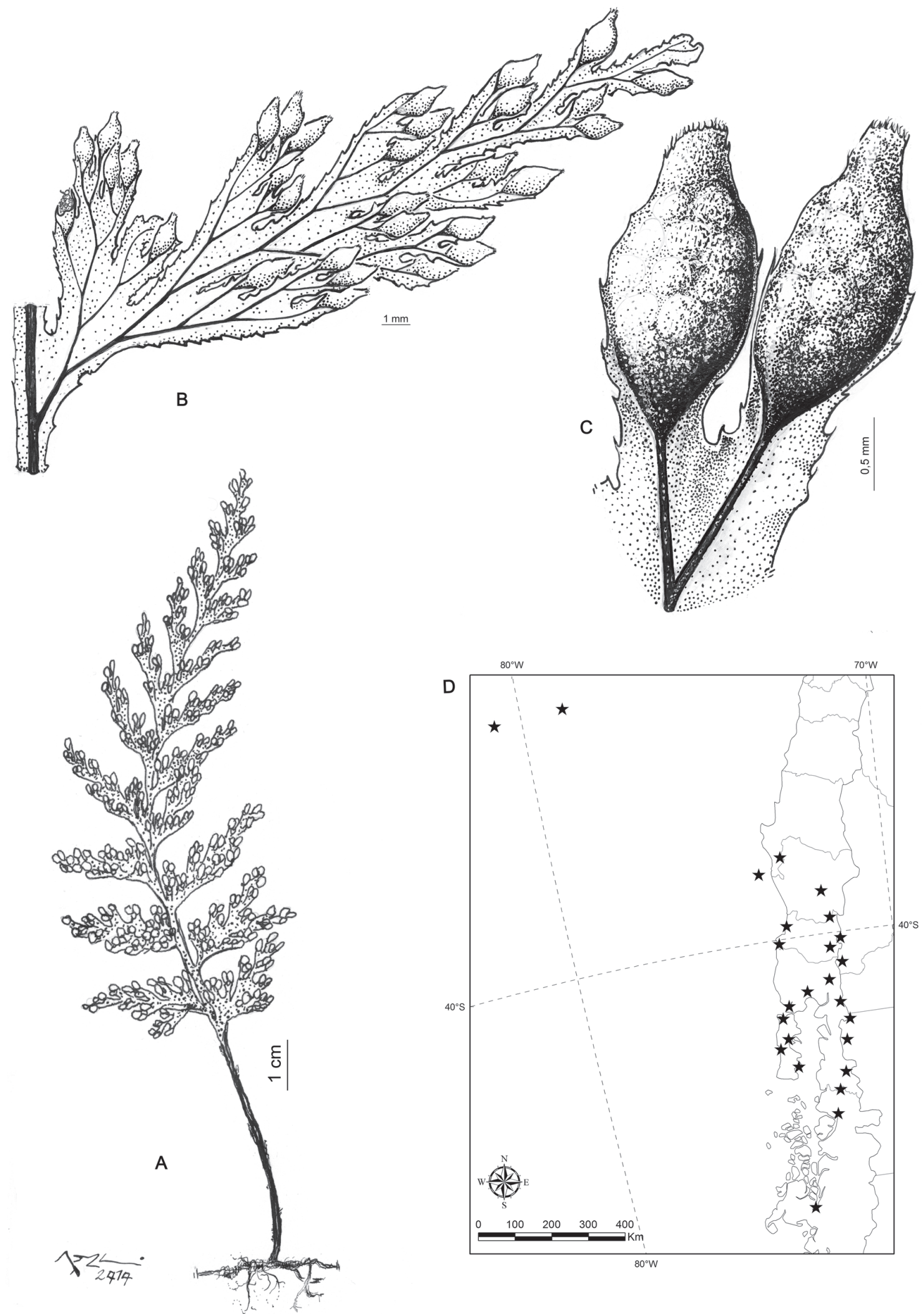

FIGURA 13. Hymenophyllum krauseanum. A, aspecto general. B, detalle de una pinna fértil. C, detalle de los indusios. D, mapa de distribución de la especie.

Figure 13. Hymenophyllum krauseanum. A, habit. B, detail of a fertile pinna. C, detail of the sori. D, distribution map of the species. 
lineares a ovado-lanceoladas, 3-pinnatífidas, de 6-13 x 4-7,5 $\mathrm{cm}$, de textura cartácea (in sicco), glabras; raquis oscuro, glabro, terete, con alas tan anchas como el raquis, planas, margen con dientes distanciados rematados en pelos uni a pluricelulares; pinnas lanceoladas u ovado-lanceoladas, las basales algo trapeziformes, pinnado-pinnatífidas, de 1-6,2 x 1-3 cm, las basales con el lado acroscópico más desarrollado; segmentos lineares a oblongos, de aprox. $1 \mathrm{~mm}$ lat., de ápice redondeado o emarginado, el margen con cortos dientes dirigidos acroscópicamente, ubicados a intervalos regulares, a veces rematados en pelos de 1 a varias células; soros terminales en casi todos los segmentos simples o bifurcados, en ambos lados de las pinnas (en ocasiones las pinnas basales estériles), en el mismo plano de la lámina; involucro oblongo o elíptico, de base aguda con venillas laterales, inmersa en el segmento, el ápice acuminado terminado en un extremo angostado, trunco, entero o levemente dentado, valvas abiertas por la mitad o más; receptáculo filiforme, exerto a la madurez.

Distribución y eCología. Endémica de la región australtemplada de América. En la Argentina se encuentra en Neuquén, en la zona de Nahuel Huapi y en Chubut. En Chile habita al sur de la Región del Biobío, hasta la Región de Aisén y en las Islas Juan Fernández (Fig. 13D). Crece en bosques, mayormente epífito, cubriendo escasamente los troncos debido a sus rizomas largos y frondes distanciadas, también terrestre. Solitario o asociado a otras especies del género.

ESPECÍMENES EXAMINADOS.

ARGENTINA, Chubut, Futaleufú, Parque Nacional Los Alerces, sendero entre Lago Menéndez y Lago Cisne, 576 m, 30-X-2008, Biganzoli 1845 (SI). Cushamen, Parque Nacional Lago Puelo, Arroyo de la toma de agua, $220 \mathrm{~m}$, 17-VI-2002, Vidoz 131 (LP). Neuquén, Lácar, Huahum, 640 m, 30-III-1952, Diem 2115 (SI). Los Lagos, Quetrihué, en un arroyo sobre Arrayán, 11-V-1943, Diem 616 (SI); Península Panguinal, Brazo Rincón, 25-IV-1943, Diem 614a (SI); Península Quetrihué, desagüe Lago Escondido, en el pequeño salto, $800 \mathrm{~m}$, 14-VIII-1942, Diem 383 (BAB). CHILE, Región del Biobío, Arauco, Isla Mocha, sin colector s.n. (SI 16519). Región de la Araucanía, Cautín, Trailanqui, 10-XI-1929, Gunckel 859/3 (SI). Malleco, Parque Nacional Contulmo, 150 m, 00-X-1974, Rodríguez R. 521 (CONC). Región de Los Ríos, Ranco, Fundo Carrán (Ganadera y Forestal), cerca del lago Maihué, 414 m, 20II-2012, Larsen 233 (SI). Región de Los Lagos, Chiloé, PN Chiloé, sendero El Tepual, 26-II-2012, Larsen 288 (SI); Queilén, 10-VII-1942, Cárdenas s.n. (SI 109984); Chiloé, Piruquina, 23-VIII-1931, Junge 7/13 (SI); Chiloé, Buaún, 30-I-1937, Barros 250 (SI); Chiloé, Bosque Fdo. Bellavista, Ancud, 23-I-1967, Villagrán 132 (LP). Llanquihue, Peulla, pasando la cascada velo de la novia, $255 \mathrm{~m}, 22-\mathrm{II}-2012$,
Larsen 255 (SI); Peulla, 200 m, 27-X-1947, Diem 1074 (SI); Casa Pangue, camino al Paso Pérez Rosales, 400-500 m, 21-X-1947, Diem 1045 (SI); Valle Cayutué, Lago Todos Los Santos, 10-III-1926, Herborn 21a (SI); Puerto Varas, sobre troncos en bosques sombríos, 26-I-1909, Hicken 10 (SI 16587); Valle del Río Manso inferior, sin colector s.n. (SI 16520); Maullín, Las Chilcas, 29-I-1952, Klenner s.n. (LIL 391359). Palena, Ruta 231 entre Futaleufú y Puerto Ramírez, 165 m, 26-XI-2009, Biganzoli 2203 (SI). Región de Los Ríos, Valdivia, Cordillera Pelada, vertiente occidental, 30-III-1963, de la Sota 2763 (LP). Panguipulli, Camino entre Coñaripe y Liquiñe, Los Añiques, 450 m, 16I-1976, Marticorena 511 (CTES); Parque Oncol, Sendero Oncol, 516 m, 22-XI-2006, Morrone 5615 (SI). Región de Aisén, Aisén, Istmo de Ofqui, Leopardo, 13-I-1921, Hicken s.n. (SI 16518); Ruta 7 entre Santa Lucía y La Junta, 94 m, 26-XI-2009, Biganzoli 2220 (SI); Ruta 7, saliendo de Puyuhuapi hacia Puerto Aisén, 26-XI-2009, Biganzoli 2228 (SI).

\section{OBSERVACIONES}

Hymenophyllum krauseanum es muy afín a H. magellanicum, separándose esta última por el margen de las frondes con dientes más largos, el color de las frondes verde intenso, y principalmente por el indusio de forma oblonga y con dientes notables en el margen.

Se ubica en el subgén. Myrmecostylum, bien representado en el área de estudio con cuatro especies, creciendo las restantes cuatro en Nueva Caledonia y Nueva Zelanda. Este subgénero se caracteriza por la presencia de pelos multicelulares sobre el pecíolo y margen de las frondes, o alternativamente por el margen dentado de las frondes (Ebihara et al. 2006).

Sadebeck (1902) y Christensen (1905-1906) ubican a Hymenophyllum bibraianum Sturm en la sinonimia de $H$. magellanicum. Sin embargo, la descripción de H. bibraianum se ajusta más a las características de $H$. krauseanum, pudiendo mencionarse entre las mismas el color de la fronde verde oliva oscuro (en seco), el raquis bordeado por un ala muy angosta y espinosamente dentada, y los involucros elípticos, de ápice angostado infrecuentemente dentado. Por lo cual aquí se incluye a $H$. bibraianum en la sinonimia de H. krauseanum.

12. Hymenophyllum magellanicum (Desv.) Willd. ex Kunze, Bot. Zeitung (Berlin) 5: 226. 1847. Didymoglossum magellanicum Desv., Prod.: 331. 1827. (= Mémoires de la Société Linnéenne de Paris 6: 331. 1827). Ptychophyllum magellanicum (Desv.) Klotzsch, Linnaea 18: 533. 1844. Leptocionium magellanicum (Desv.) Bosch, Ned. Kr. Arch. 4 (4): 384. 1859. Meringium magellanicum (Desv.) Copel., Philip. Journ. Scien. 67(1): 45, 96. 1938. TIPO: Argentina-Chile, "Habitat ad terram Magellanicam", Anon s.n. (holotipo no localizado; isotipo, B-W 20245, foto SI!). 
Hymenophyllum seselifolium C. Presl, Hymenophyllaceae: 52. 1843. TIPO: "Habitat in Chile", H. Cuming 6 (lectotipo, aquí designado, K000589692!; isolectotipos E, BM, fotos SI!). Fig. 14.

Hymenophyllum attenuatum Hook., Sp. Fil. 1: 99, lám. 36 B. 1844. nom. illeg., Leptocionium attenuatum (Hook.) v. d. Bosch, Ned. Kr. Arch. 4 (4): 384. 1859. SINTIPOS: Brasil, "Hab. Summit of the Organ Mountains", Gardner 5950 (sintipos K000589690!, BM, foto SI!). Chile, "Chiloé", $H$. Cuming 6 (sintipo K000589692!).

Rizomas rastreros, filiformes, ramificados, castaño oscuros de 0,6-0,8 $\mathrm{mm}$ de diám., con pelos delgados, uniseriados, multicelulares de 1,2-1,3 mm long.; frondes remotas, erectas, de (9)15-25 cm long.; pecíolos de 5-12 cm de largo, castaño-oscuros, glabros, de 0,9-1 mm de diám., con alas en todo su largo, caedizas a la madurez, de $1 \mathrm{~mm}$ o más de ancho, irregularmente onduladas, de margen eroso; láminas ovadas a triangulares, 3-4-pinnatífidas, de (4)11-17 x (4)7-13 $\mathrm{cm}$, textura membranácea, glabras; raquis oscuro, negruzco, glabro, terete, con alas planas a onduladas, con cilias marginales de 0,5-1 $\mathrm{mm}$ long. pinnas ovado-lanceoladas a subtriangulares, 2-3-pinnatífidas, de 2-7 x 1-4,5 cm; segmentos lineares a oblongos, de ápice redondeado, $0,7-$ $0,9 \mathrm{~mm}$ lat., margen con cilias de 0,2-0,3 mm long., en ocasiones la célula apical se elonga dando la apariencia de un pelo; soros en general subaxilares, dispuestos sobre un corto segmento, a ambos lados de las pinnas, en el mismo plano de la lámina; indusios oblongos, en ocasiones ovados, la base redondeada, inmersa en el segmento con venillas laterales, el ápice agudo a redondeado, raramente trunco o apiculado, con pequeños pelos cortos, de aprox. 0,15 $\mathrm{mm}$ long., cónicos, unicelulares, ubicados en el ápice y en menor cantidad en los costados del indusio, valvas abiertas hasta la mitad de su long. o menos; receptáculo filiforme, exerto a la madurez.

DistribuCiÓn y eCOlOGía. En Argentina se encuentra en Neuquén, Río Negro y Chubut. En Chile se encuentra al sur de la Región del Biobío hasta la Región de Magallanes y de la Antártica Chilena, y en las Islas Juan Fernández (Fig. 14E). Es una especie poco común aunque ampliamente distribuida en el área, de hábito terrestre, tapiza el sotobosque en sitios de mucha humedad, extendiéndose sobre el sustrato y la base de los troncos. Esta especie se encuentra también en el sur y sudeste de Brasil.

ESPECÍMENES EXAMINADOS.

ARGENTINA, Chubut, Futaleufú, Lago Menéndez, Brazo Norte, 02-II-1945, Castellanos s.n. (LIL 114241); Parque Los Alerces en el alerzal, extremo oeste del brazo sud del Lago Menéndez, 11-X-1953, Burkart 19097 (SI). Neuquén, Los Lagos, Quetrihué, desagüe Lago Huahuan, 800 m, 17-
V-1943, Diem 640 (BAB; SI); Lago Nahuel Huapi, camino Rincón al Paso Puyehue, cascada Sta. Ana, 900 m, 03-IV1953, Diem 2249 (SI); Correntoso, 05-II-1934, Burkart 6319 (SI); Puerto Blest, camino a cascada Los Cántaros, 784 m, 23-II-2011, Larsen 174 (SI); Puerto Blest, cascada de Los Cántaros, 23-II-2011, Larsen 176 (SI); Río Negro, Bariloche, Puerto Blest, 780-800 m, 20-X-1947, Diem 1041 (BAB; SI); San Carlos de Bariloche, 00-I-1949, Hjerting s.n. (LIL 340796); Brazo Blest, Arroyo Bravo, 09-II-1938, Capurro s.n. (LIL 18374); Pto. Blest, Laguna Frías, 800 m, 12-III-1959, de la Sota 2160 (LIL). CHILE, Región de la Araucanía, Cautín, Termas de Palguín, 750 m, 00-I-1953, Ricardi 2387 (CONC). Región de Valparaíso, Valparaíso, Juan Fernández, 00-X-1872, Philippi s.n. (SI 16058) (SI). Región de Los Ríos, Valdivia, Corral, El Bolsón, 150 m, 21-XI-1931, Gunckel 9021 (LIL). Región de Los Lagos, Chiloé, Isla de Chiloé, Queilén, 10-VII-1942, Cárdenas s.n. (Diem 630) (SI); Chiloé, Piruquina, 21-IX-1931, Junge 23/36 (SI). Llanquihue, PN Vicente Pérez Rosales, camino de Ensenada a Ralún, 122 m, 23-II-2012, Larsen 268 (SI); PN Alerce Andino, sendero hacia el Alerzal milenario, 147 m, 25-II-2012, Larsen 278 (SI); Valle Cayutué (Lago Esmeralda), 01-I-1912, Wolffhügel 25 (SI 19953); Boca Río Puelo, 00-I-1916, Espinosa 7 (SI); Casa Pangue, camino al Paso Pérez Rosales, ca. 600 m, 21-X-1947, Diem 1049 (SI). Región de Aisén, Aisén, Istmo de Ofqui, San Rafael, en el bosque, cascada, 26-I-1921, Hicken 82 (SI 16589); Isla de los Leones, Philippi s.n. (SI 16053). Región de Magallanes, Última Esperanza, Seno Última Esperanza, Puerto Bella Vista, 20 m, 11-I-1977, Moore s.n. (TBPA 1643) (LP); Skyring water, 01-III-1917, Bonarelli 26 (SI). Magallanes, Puerto Gallant, XII-1878, sin colector s.n. (SI 16521).

\section{OBSERVACIONES}

La especie más cercana a $H$. magellanicum es $H$. tortuosum, que se diferencia principalmente por su follaje, notablemente ondulado, el margen de los segmentos ciliado, y sus indusios ciliados en ápice redondeado, con pliegues foliares laterales y dorsales ciliados. Otra especies similar es $H$. krauseanum (véase observaciones bajo esta especie). Todas ellas pertenecen al subgén. Myrmecostylum.

En el presente trabajo se considera a esta especie geográficamente disyunta, ya que habita en el sur de Argentina y Chile, y en el sudeste de Brasil. Aunque los ejemplares de Brasil presentan ciertas diferencias, principalmente en el menor tamaño de la fronde $(9-18 \mathrm{~cm})$, de la lámina $(6,5-11 \mathrm{~cm})$, una menor longitud del pecíolo (3,5-5 cm), y el ápice del indusio, siempre redondeado, con pelos más delgados y delicados; son necesarios mayores estudios para corroborar estos resultados.

Sturm (1858) cita que: "de acuerdo con una nota manuscrita de Presl, bajo la colección de H. Cuming 6 se distribuirá la planta Hymenophyllum seselifolium", de acuerdo con esto se designa lectotipo de H. seselifolium al 

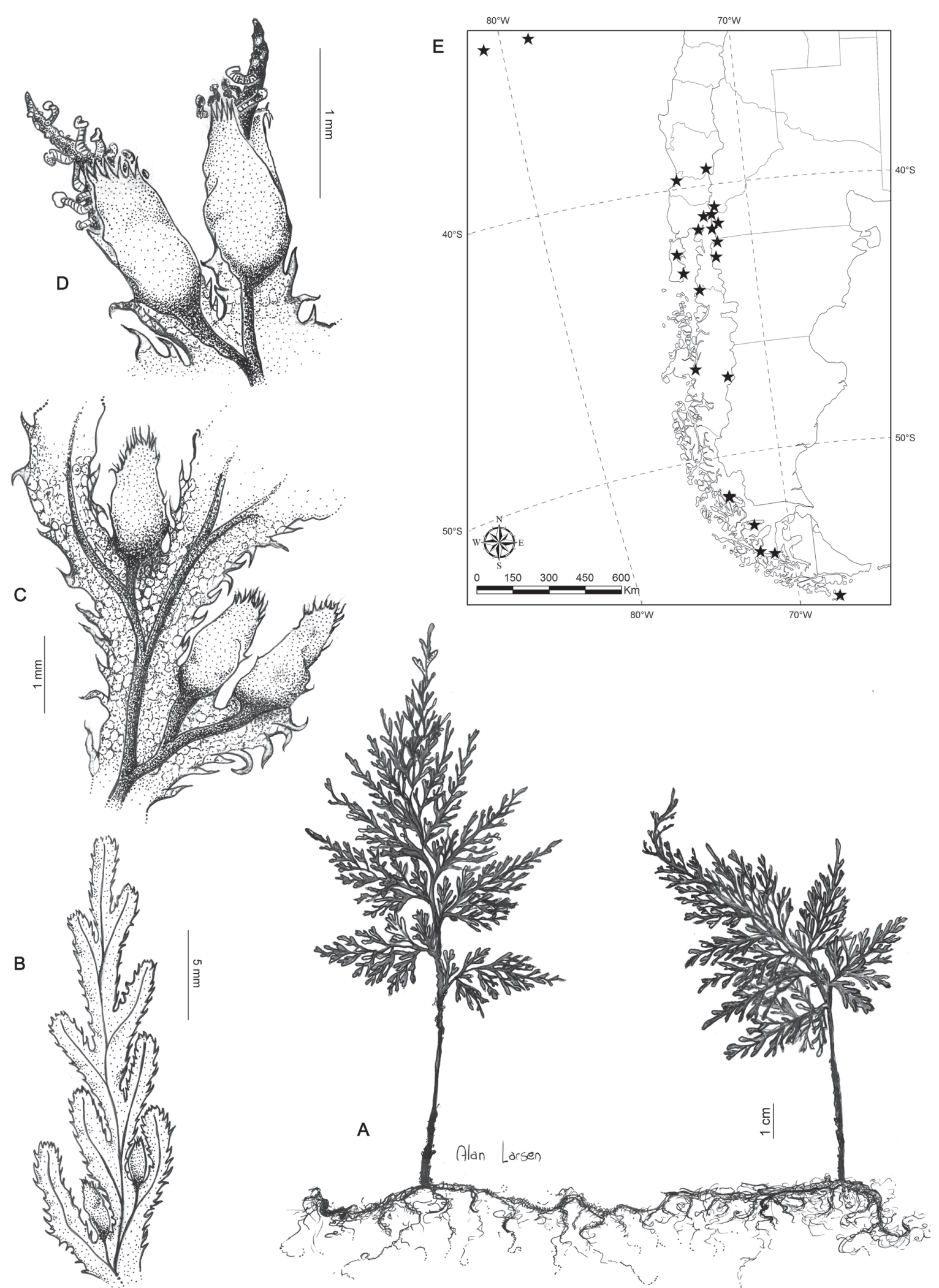

Figura 14. Hymenophyllum magellanicum. A, aspecto general. B, detalle del ápice de una fronde. C, detalle de una porción de la fronde mostrando el raquis y la inserción de los indusios. D, detalle de los indusios y receptáculos. E, mapa de distribución de la especie.

Figure 14. Hymenophyllum magellanicum. A, habit. B, detail of apex of a frond. C, detail of a portion of the frond showing the rachis and insertion of sori. D, detail of the sori and receptacles. E, distribution map of the species. 
ejemplar Cuming 6 depositado en K (K000589689), debido a que no fue hallado en PR y PRC, lugares de trabajo de C. Presl. Asimismo este duplicado fue uno de los sintipos usado por Hooker (1844-1846) para describir H. attenuatum, por lo tanto este es un nombre ilegítimo (Art. 52 CINB).

13. Hymenophyllum nahuelhuapiense Diem \& J. S Licht., Darwiniana 11 (4): 722. 1959. TIPO: Argentina. "Neuquén. Lago Nahuel Huapi, Brazo Rincón, Península Panguinal, a orillas de un arroyo", 8-VI-1945, J. Diem 612 (P109) (lectotipo, aquí designado, SI000088!; isolectotipo BAB00000008!). SINTIPOS: Argentina, "Neuquén, Lago Nahuel Huapi, Brazo Rincón, Península Panguinal, a orillas de un arroyo", 31-III-1940, J. Diem 612 (P109), (sintipos BAB00000009!, BAB00000010!, LIL001943!, US00067549!). 25-IV-1943, J. Diem 612 (P109) (sintipo, SI000073!). Fig. 15.

Rizomas muy delgados, filiformes, rastreros, ramificados, castaño claros, de 0,2-0,3 mm diám.; pelos del rizoma ausentes o muy escasos, en ocasiones sólo en la base del pecíolo, rojizos, uniseriados, cortos, de aprox. $0,25 \mathrm{~mm}$ long. formados por 3 o 4 células; frondes remotas, de 3-10 (12) $\mathrm{cm}$ long.; pecíolos parduscos a grisáceos, glabros, teretes, en general levemente más delgados que el rizoma, de $0,15-$ 0,25 mm diám., no alados; láminas de contorno elíptico, ovado-lanceoladas hasta lineares, 2-pinnatífidas, de 2,5-5,5 x 0,9-2 cm, textura membranácea, glabras; raquis parduscorojizo, glabro, terete, con alas muy angostas en su base que se ensanchan hacia el ápice, de margen entero; pinnas flabeladas, pinnatífidas, de 0,5-1,5 x 0,2-1 cm, las basales desarrolladas hacia ambos lados, a veces simpodiales, las apicales sólo con el lado acroscópico desarrollado, el margen entero a dentado en los segmentos; segmentos largamente obovados, 3 a 5 por pinna, de 0,9-3,7 $\mathrm{mm}$ lat., de ápice redondo a veces emarginado, margen con dientes pequeños formados por 1 a varias células iguales entre sí, glabros; soros en general 1 por pinna, raramente 2-3, siempre del lado acroscópico, subaxilares, sobre las pinnas medias a subapicales, con la base arqueada, perpendiculares al plano de la lámina, sobre un corto pedicelo angostamente alado, arqueado en su extremo junto con la base del involucro; involucros suborbiculares, sobre una base ensanchada, no inmersos en la lámina, ápice redondo, margen entero o raramente irregular, glabro, valvas abiertas a la madurez, hasta prácticamente la base; receptáculo inserto, algo engrosado en la mitad, elipsoide.

Distribución y eCología. Especie endémica, en la Argentina ha sido hallada en el Parque Nacional Nahuel Huapi, en la provincia de Neuquén, y en el Parque Nacional Los Alerces en la provincia de Chubut. En Chile fue recolectada en Peulla, en la Región de Los Lagos, y en la Isla Hoste, en la Región de Magallanes, sin embargo su presencia en este país debe ser confirmada (Fig. 15E). Vive sobre piedras húmedas o sobre el sustrato del sotobosque, en barrancas y cerca de arroyos o vertientes, formando pequeñas colonias.

\section{ESPECÍMENES EXAMINADOS}

ARGENTINA, Chubut, Futaleufú, Parque Nacional Los Alerces, entre río Cisne y Lago Menéndez, 12-V-1966, Eskuche 1624a (SI). Neuquén, Los Lagos, Lago Nahuel Huapi, Península Panguinal, costa S, 25-IV-1943, Diem 612 (SI 60825); Lago Nahuel Huapi, Brazo Tristeza, 09-I-1947, Diem 992 (SI). Río Negro, Bariloche, Puerto Blest, vertiente detrás de la Estación Biológica, 24-II-2011, Larsen 186 (SI); camino al ventisquero Frías, 900 m, 31-X-1947, Diem 1100 (SI); Laguna Frías, 28-IV-1942, Diem 581 (BAB); Puerto Blest, 04-VII-1941, Diem 556 (BAB). CHILE, Región de Los Lagos, Llanquihue, Peulla, 400 m, 27-X-1947, Diem 1079 (SI).

\section{OBSERVACIONES}

Hymenophyllum nahuelhuapiense es cercano principalmente a $H$. falklandicum (ver bajo esta especie), y también a $H$. peltatum, especie que se diferencia por sus frondes más robustas, de color verde intenso, con todas las pinnas desarrolladas hacia el lado acroscópico, y con 1 a 4 indusios por pinna. Al igual que sus especies afines, $H$. nahuelhuapiense se ubica en el subgén. Hymenophyllum.

Varios ejemplares que figuran como tipo de $H$. nahuelhuapiense en BAB, LIL, SI, US, fueron recolectados en fechas diferentes, aunque todos ellos poseen la misma numeración, J. Diem 612 (P109), estos ejemplares fueron considerados como sintipos, designándose como lectotipo al material depositado en SI que contiene mayor información original de los autores.

14. Hymenophyllum pectinatum Cav., Descr. Pl.: 275. 1802. TIPO: Chile,. "Isla de San Carlos de Chiloé", 1801, L. Née s.n. (holotipo MA475845!; isotipo MPU017994!). Fig. 16.

Rizomas filiformes, ramificados, pardo claros, de aprox. $0,7 \mathrm{~mm}$ de diám.; pelos del rizoma vellosos, translúcidos, pluricelulares, delgados, simples, de aprox. 1,5 mm long., ausentes a la madurez; frondes distantes, de 5-20 cm long.; pecíolos pardo-claros, de 2,5-10 cm long., glabros, teretes, de aprox. 0,4 $\mathrm{mm}$ de diám., no alados; láminas ovadolanceoladas, 2-3-pinnatífidas, de 3-12 x 1,5-4 cm, textura membranácea, glabras; raquis castaño oscuro, terete, no alado, con largos pelos paucicelulares blancuzcos sobre el lado del envés, de aprox. 1,4 mm long., adpresos en su base, de aspecto lanoso a reflexo en el ápice, y continuándose sobre la base de las nervaduras de las pinnas; pinnas subflabeladas a falcadas, pinnatífidas a 2-pinnatífidas, solo el lado acroscópico desarrollado, de 1,5-2,5 x 0,5-0,7 cm, alternas, imbricadas o no, con papilas cortas sobre las nervaduras, 

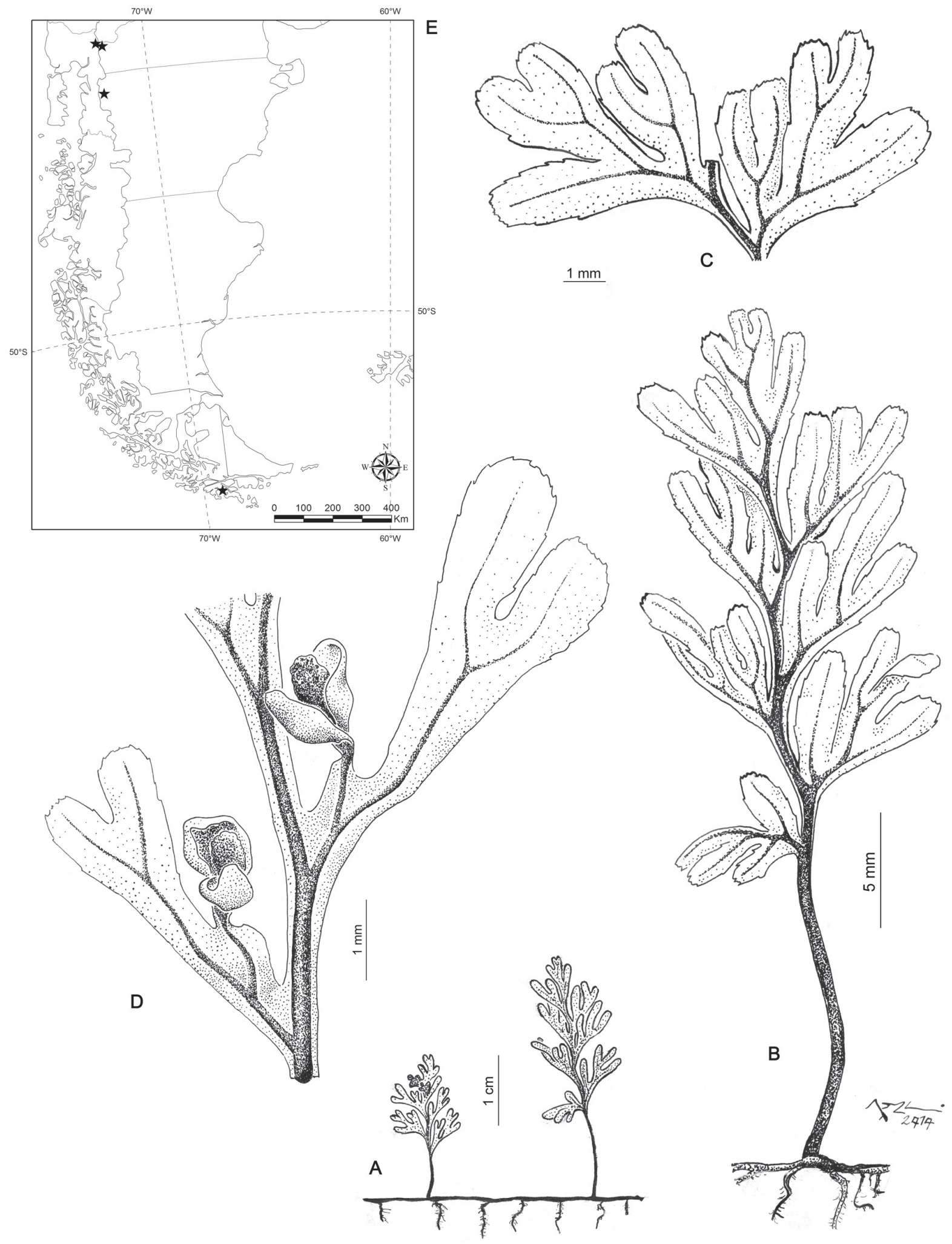

Figura 15. Hymenophyllum nahuelhuapiense. A, B, aspecto general. C, vista de las pinnas basales. D, detalle de pinnas fértiles e indusios. E, mapa de distribución de la especie.

Figure 15. Hymenophyllum nahuelhuapiense. A, B, habit. C, view of the basal pinnae. D, detail of fertile pinnae and sori. E, distribution map of the species. 


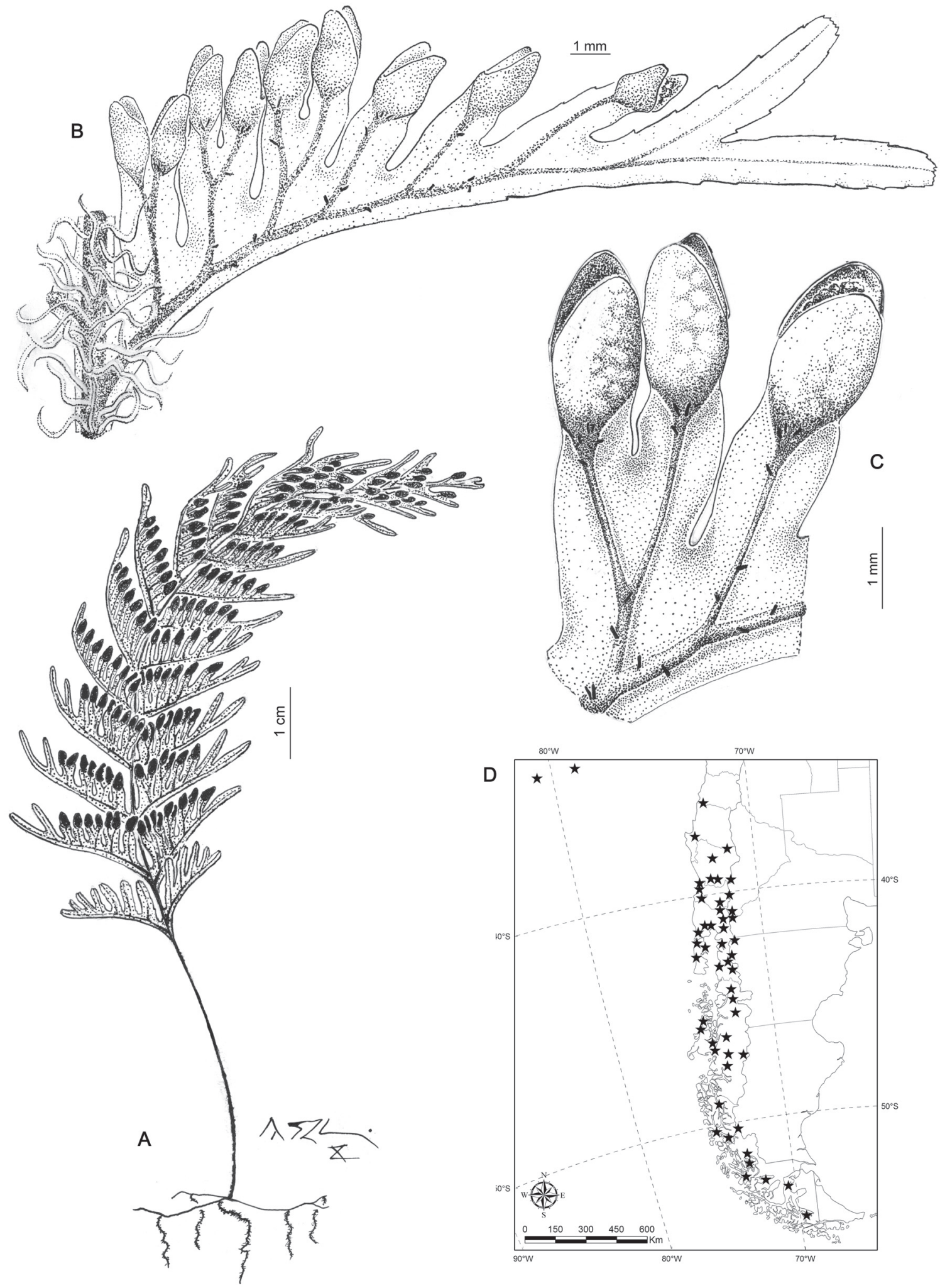

FIGURA 16. Hymenophyllum pectinatum. A, aspecto general. B, vista de una pinna fértil, en donde se pueden observar los pelos en el envés del raquis. $\mathrm{C}$, detalle de los indusios. $\mathrm{D}$, mapa de distribución de la especie.

FIGURE 16. Hymenophyllum pectinatum. A habit. B, view of a fertile pinna, where can be seen the hairs on the ventral side of the rachis. C, detail of the sori. D, distribution map of the species. 
parduscas, sobre ambos lados, dispuestas espaciadamente; segmentos lineares u oblongos, 5 a 8 por pinna, hasta de 1,5 mm lat., de ápice redondeado, margen espaciadamente aserrado; soros en todas las pinnas, en el mismo plano de la lámina, sobre segmentos simples o bifurcados, más angostos o del mismo ancho que los indusios; involucros ovados a lanceolados, inmersos menos de la mitad en la lámina, de base obtusa, ápice agudo a obtuso, margen entero, abierto más de la mitad; receptáculo cilíndrico, inserto.

Distribución Y eCología. Especie endémica, en la Argentina se halla en las provincias de Neuquén, Río Negro, Chubut y Santa Cruz. En Chile se halla desde la provincia de Malleco hasta la de Magallanes, incluido el Archipiélago Juan Fernández (Rodríguez 1995) (Fig. 16D). Es una especie común, muy abundante, con un amplio rango de distribución y hallada bajo diversas condiciones de incidencia lumínica y humedad. A menudo se la encuentra solitaria, sobre rocas o en barrancas, con sus rizomas transcurriendo entre la hojarasca en descomposición y la tierra. También se la puede hallar epífita en el bosque, con sus frondes distanciadas sobre los troncos, asociada a musgos y a especies del género como $H$. dentatum, también muy abundante, o más raras como $H$. dicranotrichum y $H$. cuneatum.

\section{ESPECIMMENES EXAMINADOS}

ARGENTINA, Chubut, Futaleufú, Parque Nacional Los Alerces, en el alerzal, extremo oeste del brazo sud del Lago Menéndez, 11-X-1953, Burkart 19098 (SI); Parque Nacional Los Alerces, sendero entre Lago Menéndez y Lago Cisne, 565 m, 30-X-2008, Biganzoli 1835 (SI); Parque Nacional Los Alerces: riva orientale del Lago Situación, 08-I-1974, Pichi-Sermolli 7411 (SI). Neuquén, Lácar, Huahum, 30-III1952, Diem 2112 (BAB). Los Lagos, Cascada Santa Ana, 1155 m, 27-I-2010, Morero 310 (CORD; SI; CTES); Brazo Rincón, Península Panguinal, cerca del camping, cruzando el río Totoral, orilla del lago, 21-II-2011, Larsen 165 (SI); Península Panguinal, Brazo Última Esperanza, 09-XI-1941, Diem 590 (BAB; SI); Quetrihué, 850 m, 29-VII-1951, Diem 1928 (BAB; LIL); Correntoso, bosque entre los Lagos Nahuel Huapi y Correntoso, 05-II-1934, Burkart 6324 (SI); Lago Nahuel Huapi, Pto. Blest, camino a la Cascada de Los Cántaros, a orillas del sendero, 19-III-2008, Morero 252 (CORD); Puerto Blest, cascada de Los Cántaros, 23-II2011, Larsen 179 (SI); Río Negro, Bariloche, Puerto Blest, 00-IV-1990, Conticello 964 (BAB); Lago Nahuel Huapi, Brazo Tristeza, Arroyo Lluvucó, 780 m, 04-V-1952, Diem 2145 (SI). CHILE, Región de Valparaíso, Valparaíso, Más Afuera, parte superior de Quebrada Varadero, 950 m, 2002, Stuessy 9571 (CONC). Región de Los Ríos, Valdivia, Parque Oncol, Sendero Oncol, 516 m, 22-XI-2006, Morrone 5611 (SI); Corral, Quitaluto, 450 m, 28-VIII-1930, Gunckel 1793 (LIL); Niebla, 10-II-1956, Garaventa 5542 (SI). Región de Los Lagos, Chiloé, PN Chiloé, sendero El Tepual, 26-II-
2012, Larsen 283 (SI); Ins. Chiloé, Castro-Piruquina, 200 m, 00-III-1924, Werdermann 307 (LIL; SI). Llanquihue, Quillagua, Maullín, 00-VII-1947, Hernández s.n. (Diem 1040) (BAB; SI); Peulla, 300 m, 27-X-1947, Diem 1076 (SI); Puerto Varas, en el bosque sobre troncos, 27-I-1909, Hicken 9 (SI 16592); Valle Cayutué (Lago Esmeralda), 00I-1912, Wolffhügel s.n. (SI 19954); Cayutué, Lago Todos Los Santos, 01-III-1926, Herborn s.n. (SI 15967); Volcán Calbuco, 08-II-1937, Barros 199 (SI). Osorno, Aguas Calientes, 26-I-1991, Debandi 10 (LP). Palena, Ruta 231 entre Futaleufú y Puerto Ramírez, 165 m, 26-XI-2009, Biganzoli 2207 (SI); Corcovado, sin colector s.n. (SI 15965) (SI). Región de Aisén, Aisén, Ruta 7 entre Puyuhuapi y Puerto Aisén, 235 m, 27-XI-2009, Biganzoli 2237 (SI); Isla Clemente, Canal Millabú, 22-VII-1970, Parra 89 (BAB); Lag. San Rafael, 31-XII-1952, Neumeyer s.n. (Diem 2255) (BAB); Istmo de Ofqui, San Rafael, 19-I-1921, Hicken 43 (SI 16591); Istmo de Ofqui, Punta Leopardo, 13-I1921, Hicken 74 (SI 16593). Región de Magallanes, Isla Drummond Hay, Puerto Molyneux, 11-XII-1977, Roig 159 (TBPA 2667) (BAB); Última Esperanza, Península Roca, seno Resi, 175 m, 21-I-1978, Pisano 2790 (TBPA 2790) (LP); Seno Última Esperanza, Puerto Toro, Costa E. del Río Serrano, 22-I-1977, Moore s.n. (TBPA 1888) (LP); Skyring water, 01-III-1917, Bonarelli 27 (SI).

\section{OBSERVACIONES}

Esta especie se caracteriza por tener pinnas desarrolladas acroscópicamente, pectinadas, los segmentos paralelos entre sí, y el extremo de la costa elongado. Las frondes son medianas a grandes y los ejemplares jóvenes o estériles se distinguen por presentar pelos blancuzcos sobre el envés del raquis. Hymenophyllum pectinatum es cercana a $H$. quetrihuense, la cual se diferencia por su menor tamaño, por la presencia de escasos pelos parduscos en el pecíolo y raquis, y por la disposición de los indusios, aislados o en bajo número por pinna, sobre segmentos en ocasiones bifurcados y subparalelos. Estas dos especies junto con H. umbratile fueron agrupadas en la sección Eupectinum por Diem \& Lichtenstein (1959), basándose en la división acroscópica de sus pinnas. En la clasificación actual se ubican dentro del subgén. Hymenophyllum.

15. Hymenophyllum peltatum (Poir.) Desv., Mém. Soc. Linn. Paris 6: 333. 1827. Trichomanes peltatum Poir., en Lam. Encycl. Bot. 8: 76. 1808. Hymenophyllum unilaterale Bory ex Willd., Sp. P1. 5: 521. 1810. nom. illeg. TIPO: Islas Mascarenas, Isla Reunion, "Bourbon", J.B. Bory de StVincent 117 (holotipo, P00477834!; isotipo B -W 20225!). Fig. 17.

Hymenophyllum meyeri C. Presl, Hymenophyllaceae: 50. 1843. TIPO: Sudáfrica, "Capite bonae spei (Cabo Buena Esperanza)", J.F. Drège s.n. (holotipo PR, foto SI!). 


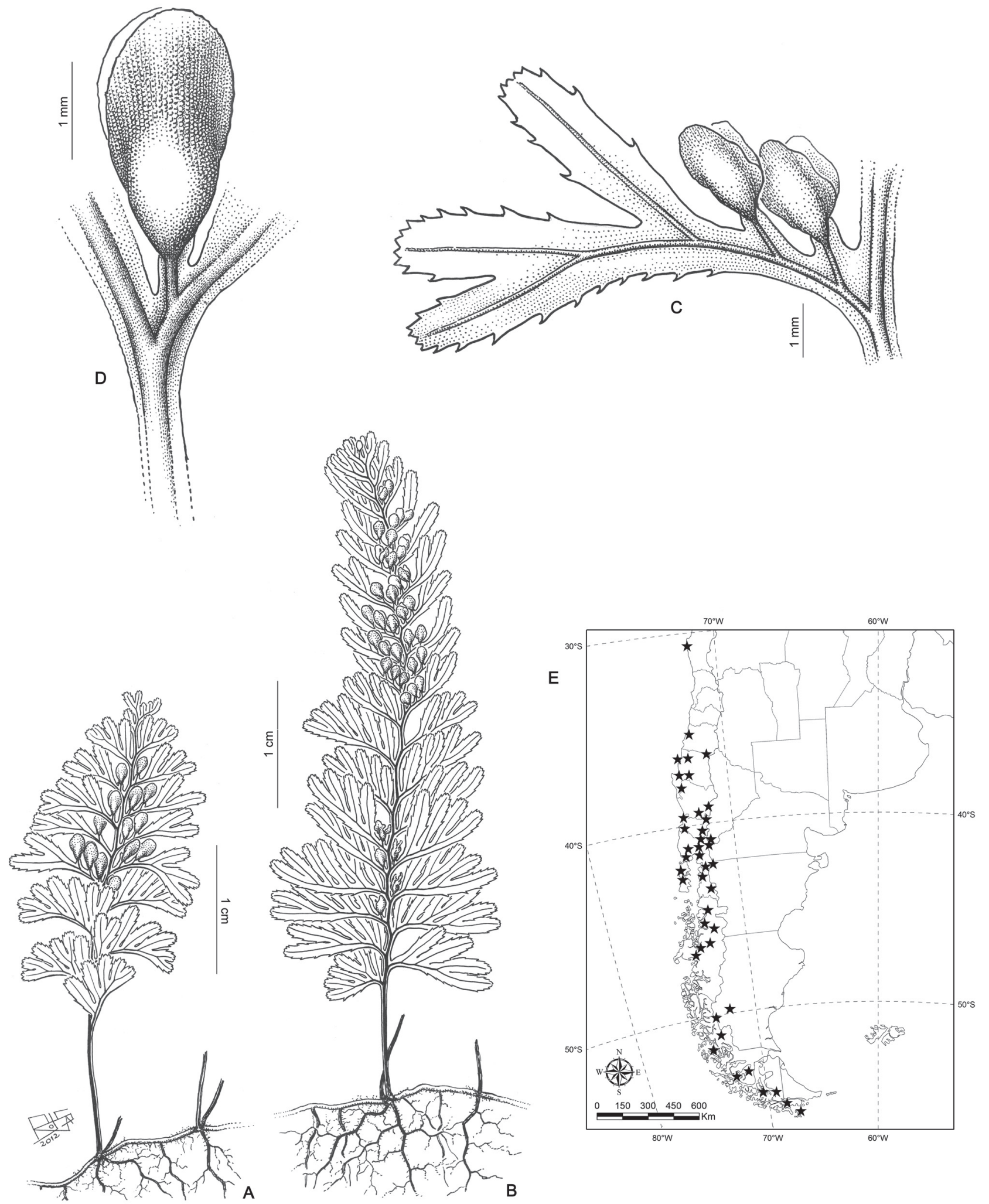

FIGURA 17. Hymenophyllum peltatum. A-B, aspecto general. C, detalle de una pinna fértil. D, detalle de un indusio. E, mapa de distribución de la especie.

Figure 17. Hymenophyllum peltatum. A-B, habit. C, detail of a fertile pinna. D, detail of a sorus. E, distribution map of the species. 
Hymenophyllum menziesii C. Presl, Hymenophyllaceae: 51.1843. TIPO: Argentina, "Habitat in Staatenland", 1787, A. Menzies s.n. (holotipo, no localizado; isotipos, E, foto $\mathrm{SI}$, OXF, foto SI!).

Hymenophyllum mettenii Bosch, Ned. Kruidk. Arch. 5(3): 171. 1863. TIPO: Chile, "Valdivia", R. A. Philippi 415 (lectotipo, aquí designado, K0000589694!). SINTIPO: "Chile”, C. Gay s.n. (no localizado).

Hymenophyllum peltatum (Poir.) Desv. var. elegans Diem \& J.S. Licht., Darwiniana 11(4): 704. 1959. TIPO: Argentina, "Neuquén: Dpto. Los Lagos, Lago Nahuel Huapi, Península Quetrihué”, 14-VIII-1942, J. Diem 380 (holotipo, SI!; isotipos LIL001944!, US00067693!, GH21379!).

Hymenophyllum peltatum (Poir.) Desv. var. elongatum Diem \& J.S. Licht., Darwiniana 11(4): 704. 1959. TIPO: Argentina, "Neuquén: Dpto. Los Lagos, Lago Nahuel Huapi, Península Quetrihué, en bosque de Nothofagus dombeyi", 30-VII-1946, J. Diem 981 (holotipo; SI!, isotipos LIL001945!, US00067692!).

Hymenophyllum peltatum (Poir.) Desv. var. imbricatum Diem \& J.S. Licht., Darwiniana 11(4): 706. 1959. TIPO: Argentina. "Neuquén: Dpto. Los Lagos, Lago Nahuel Huapi, Península Quetrihué, bosque de Arrayanes", 12-III1940, J. Diem P119 (lectotipo, aquí designado, SI000078; isolectotipos, SI000077!, BAB00000013!, US00067691, GH21379!).

Hymenophyllum peltatum (Poir.) Desv. var. patagonicum Diem \& J.S. Licht., Darwiniana 11(4): 707. 1959. TIPO: Argentina, "Neuquén: Dpto. Los Lagos, Lago Nahuel Huapi, Península Quetrihué, orilla del Lago Patahua”, J. Diem 376 (P107); 9-VIII-1942 (lectotipo, aquí designado, SI000080!; isolectotipos GH, no visto, US00067694!). SINTIPOS: Argentina, "Neuquén: Dpto. Los Lagos, Lago Nahuel Huapi, Península Quetrihué, orilla del Lago Patahua”, 28VII-1941, J. Diem 376 (P107) (LIL001947!). Argentina. "Neuquén: Dpto. Los Lagos, Lago Nahuel Huapi, Península Quetrihué, orilla del Lago Patahua", 1-X-1939, J. Diem 376 (P107) (BAB00000017!, BAB00000018!).

Hymenophyllum peltatum (Poir.) Desv. var. minor Diem \& J. S. Licht., Darwiniana 11(4): 707. 1959. TIPO: Argentina, "Neuquén: Dpto. Los Lagos, Lago Nahuel Huapi, Península Quetrihué, costa oeste, 800 m s.m.”, 28-VII-1940, J. Diem 579 (holotipo SI000079!; isotipo BAB00000015!).

Rizomas filiformes, rastreros, ramificados, parduscos claros, de 0,2-0,35 mm de diám.; pelos del rizoma translúcidos, rojizos, de 2-4 células, de 0,2-0,8 mm long., escasos, más densos en la base del pecíolo; frondes remotas, de 2-11(16) cm alt., péndulas; pecíolos castaño-oscuros, teretes, de 0,2$0,3 \mathrm{~mm}$ de diám., con pelos simples, similares a los del rizoma, de 2-3 células, muy esparcidos, de aprox. 0,4 mm long., con angostas alas caedizas desde la base, de margen entero; láminas elípticas, oblongas a ovado-lanceoladas, 2-pinnatífidas, de 1,6-9 x 0,9-2,4 cm, textura membranácea, glabras; raquis oscuro, casi negro alado en toda su longitud, en ocasiones no alado, o sólo alado en el ápice; pinnas flabeladas, con el lado acroscópico desarrollado, rectas o arqueadas, pinnatífidas, de 0,5-1,3 x 0,2-0,6 cm, asimétricas, imbricadas o no; segmentos oblongos, de 0,7-1,3 mm lat., de ápice redondeado o truncado, margen con dientes notables, de 3 o más células, glabros, con 1 ó 2 células entre el extremo de las venillas y el margen del segmento; soros 1-4 por pinna, sobre el lado acroscópico, proximales al raquis, principalmente en las pinnas medias y apicales, en un plano perpendicular al plano de la lámina, sobre un pedicelo relativamente corto hasta del largo del indusio y angostamente alado; involucros ovados, no inmersos en la lámina, de base obtusa, ápice agudo, margen entero, abierto más de la mitad, siendo frecuente encontrarlos en su madurez con las valvas abiertas; receptáculo filiforme, angosto, aguzado en el extremo, inserto.

DistribuCión Y ECOLOGíA. Esta especie de Sudamérica australtemplada se encuentra también en África y Madagascar. En la Argentina fue recolectado en los márgenes del Lago Nahuel Huapi, en las provincias de Neuquén y Río Negro y también en la provincia de Santa Cruz. En Chile se halla desde la Región del Maule, hasta la Región de Magallanes; asimismo existe una población aislada en la Región de Coquimbo, en el Parque Nacional Fray Jorge (30 40`) (Fig. 17E). Epífito sobre diversas especies de árboles de los bosques húmedos, raramente terrestre o epipétrico, a menudo mezclado con musgos, formando matas densas, o con especies del género, como $H$. caespitosum o H. tortuosum.

\section{ESPECÍMENES EXAMINADOS}

ARGENTINA, Neuquén, Los Lagos, Quetrihué, cerca del Mallín chico, 21-IV-1940, Diem 578 (SI); Península Quetrihué, Costa Oeste, Arroyo Canaleta, 14-VIII-1942, Diem 380 (SI); Quetrihué, Potrero Los Radales, 22-V1943, Diem 642 (SI); Lago Nahuel Huapi, Brazo Rincón, Península Panguinal, 13-VII-1941, Diem 1887 (SI; BAB); Lago Nahuel Huapi, Machete, desagüe Laguna Gallardo, 10-VII-1949, Diem 1187 (SI); camino del Rincón al Paso Puyehué, 24-IV-1943, Diem 607 (SI); Península Panguinal, 31-III-1940, Diem 102p (SI); Isla Victoria, en el bosque de los Arrayanes, 17-V-1942, Diem 557 (SI); Lago Nahuel Huapi, Brazo Última Esperanza, 780 m, 04-VII-1943, Diem 733 (SI; BAB). Río Negro, Bariloche, Brazo Tristeza, 09-I1947, Diem 993 (SI); Puerto Blest, 27-IV-1942, Diem 554 (SI); Puerto Blest, camino al Puerto Alegre (Laguna Frías), 800 m, 23-X-1947, Diem 1058a (SI); Laguna Frías, camino 
al Hotel, 28-IV-1942, Diem 553 (SI); Laguna Frías, camino entre hotel y aduana, 30-X-1947, Diem 1096 (SI); sendero entre Puerto Frías y Paso de las Nubes, 24-II-2011, Larsen 184 (SI). Santa Cruz, Lago Argentino, Puerto Ferrari, Lago Argentino, 05-III-1914, Hicken s.n. (SI 16543); Lago Argentino, Brazo Onelli: camino al lago Onelli, 250 m, 24-II-1943, Vervoorst 4526 (LIL). CHILE, Región de Coquimbo, Limarí, Fray Jorge, 00-IX-1904, Reiche s.n. (SI 16522); Bosque de Talinay, 08-II-1948, Jiles 579 (SI; LIL). Región de Los Ríos, Ranco, Ruta T-55 a Lago Ranco, camino de ripio hacia antiguo volcán Carrán, $221 \mathrm{~m}, 20$-II2012, Larsen 231 (SI). Región de Los Lagos, Llanquihue, Bosque límite con vegas altoandinas bajando el volcán Osorno, 1056 m, 23-II-2012, Larsen 259 (SI); PN Alerce Andino, sendero hacia el Alerzal milenario, 147 m, 25-II2012, Larsen 277 (SI); Casa Pangue, camino al Paso Pérez Rosales, ca. 650 m, 21-X-1947, Diem 1052b (SI; BAB); Peulla, Laguna El Encanto, 200 m, 29-X-1947, Diem 1093 (SI; BAB). Palena, Ruta 231 entre Futaleufú y Puerto Ramírez, 165 m, 26-XI-2009, Biganzoli 2206 (SI). Región de Aisén, Aisén, Istmo de Ofqui, Punta Leopardo, 12-I-1921, Hicken s.n. (SI 20023); San Rafael, playita, 00-II-1921, Hicken 85bis (SI); Ruta 7 entre Puyuhuapi y Puerto Aysén, Parque Nacional Queulat, desvío al Ventisquero Colgante, 26-XI-2009, Biganzoli 2229 (SI); Ruta 7 entre Puyuhuapi y Puerto Aisén, Parque Nacional Queulat, sendero Bosque Encantado, 495 m, 27-XI-2009, Biganzoli 2236 (SI); Ruta 7 de Puerto Aysén a Coihaique, puente de Las Pizarras frente a quebrada Las Pizarras, 100 m, 28-XI-2009, Biganzoli 2247 (SI). Coihaique, Ruta 7 entre Villa Cerro Castillo y Puerto Tranquilo, 570 m, 28-XI-2009, Biganzoli 2252 (SI); Ruta de Puerto Tranquilo al Ventisquero Río Exploradores, km 24, 320 m, 29-XI-2009, Biganzoli 2255 (SI). Región de Magallanes, Magallanes, Isla Piazzi, Caleta Ocasión, Abra Leackey's Reatreat, 150 m, 16-I-1976, Dollenz s.n. (TBPA 1019) (BAB).

\section{OBSERVACIONES}

Hymenophyllum peltatum es una especie muy variable, y en ocasiones resulta difícil establecer los límites entre ésta e $H$. falklandicum o $H$. secundum. De la primera se diferencia porque $H$. falklandicum es de menor tamaño, posee una fronde más frágil, delicada, y sobre todo más angosta y linear, con las pinnas divididas en 2-3 segmentos $\mathrm{y}$, en general, 1 indusio por pinna. Poseen también indusios globosos, con sus valvas que permanecen cerradas a la madurez. Sin embargo existen casos de ejemplares más desarrollados de $H$. falklandicum que portan más de 1 indusio por pinna o que poseen más de 4 segmentos por pinna (aunque son raros), y en consecuencia resulta difícil separarlo de $H$. peltatum.

Con respecto a $H$. secundum, la situación es similar, debido principalmente a la variabilidad de ambas especies; $H$. secundum se caracteriza por sus pinnas divididas en más de 4 segmentos angostos, con ejes arqueado-reflexos y últimos segmentos divididos una vez o más, que en conjunto le dan a la planta un aspecto más robusto e intrincado. Los segmentos son oblongos, pero más delgados que $H$. peltatum y se angostan hacia el ápice. Los soros, de forma romboidal a angostamente elíptica, sobre un segmento arqueado, angostamente alado o sólo alado en su parte más basal, se pueden observar frecuentemente en número de 4 o más por pinna, y en ocasiones solitarios sobre un segmento y subaxilares a la costa (véase fig. $21 \mathrm{~B}$ y C). Otros caracteres que diferencian $H$. secundum de $H$. peltatum son los dientes del margen de los segmentos, más separados y notables.

Respecto a Hymenophyllum megachilum C. Presl, que fue incluida en la sinonimia de $H$. peltatum por Diem \& Lichtenstein (1959), en esta revisión se aclara que se trata de un taxón que crece en Brasil, que se diferencia porque presenta el raquis no alado o alado sólo en el ápice, mayor división de la lámina, que es 3-4-pinnatífida; pinnas con ramificación simpodial con segmentos hacia ambos lados; soros con pedicelo alado; involucros de forma elíptica, abiertos hasta la base y receptáculo engrosado.

Se designó como lectotipo para el nombre H. mettenii, el ejemplar Philippi 415 depositado en Kew, debido a que fue el único encontrado.

Los tipos de las variedades de $H$. peltatum en varios casos poseen más de una fecha de recolección para un mismo número de colector por lo cual constituyen sintipos. Además algunas cartulinas presentan dos fechas de recolección, en éstos se decidió tomar la fecha más antigua como fecha de colecta de la totalidad del ejemplar depositado en dicha cartulina.

Para la var. imbricatum se designó como lectotipo al ejemplar con una sola fecha de recolección depositado en el herbario SI (código de barras SI000078), lugar de trabajo de J. Lichtenstein, coautora de la variedad. Para la var. patagonicum se eligió el ejemplar SI000080 por las mismas razones que la anterior.

Se excluye a $H$. wilsonii Hook. e H. tunbrigense var. wilsonii (Hook.) Hook., de la sinonimia de H. peltatum tal como se cita en Diem \& Lichtenstein (1959), porque correspondería a un sinónimo de H. tunbrigense.

16. Hymenophyllum plicatum Kaulf., Enum. Filic.: 268. 1824. Ptychophyllum plicatum (Kaulf.) C. Presl, Hymenophyllaceae: 29, pl. 11 E. 1843. Meringium plicatum (Kaulf.) Copel, Philipp. J. Sci. 67: 45. 1938. TIPO: "Habitat in Chile", L. A. Chamisso s.n. (holotipo LE, foto SI!). Fig. 18.

Hymenophyllum nigricans Colla, Mem. Reale Accad. Sci. Torino 39: 32, Tab. LXII. 1836. TIPO: Chile, "ad arborum truncos in sylvis montanis ins. Juan Fernández" C. Bertero s.n. (holotipo TO, foto SI!). 


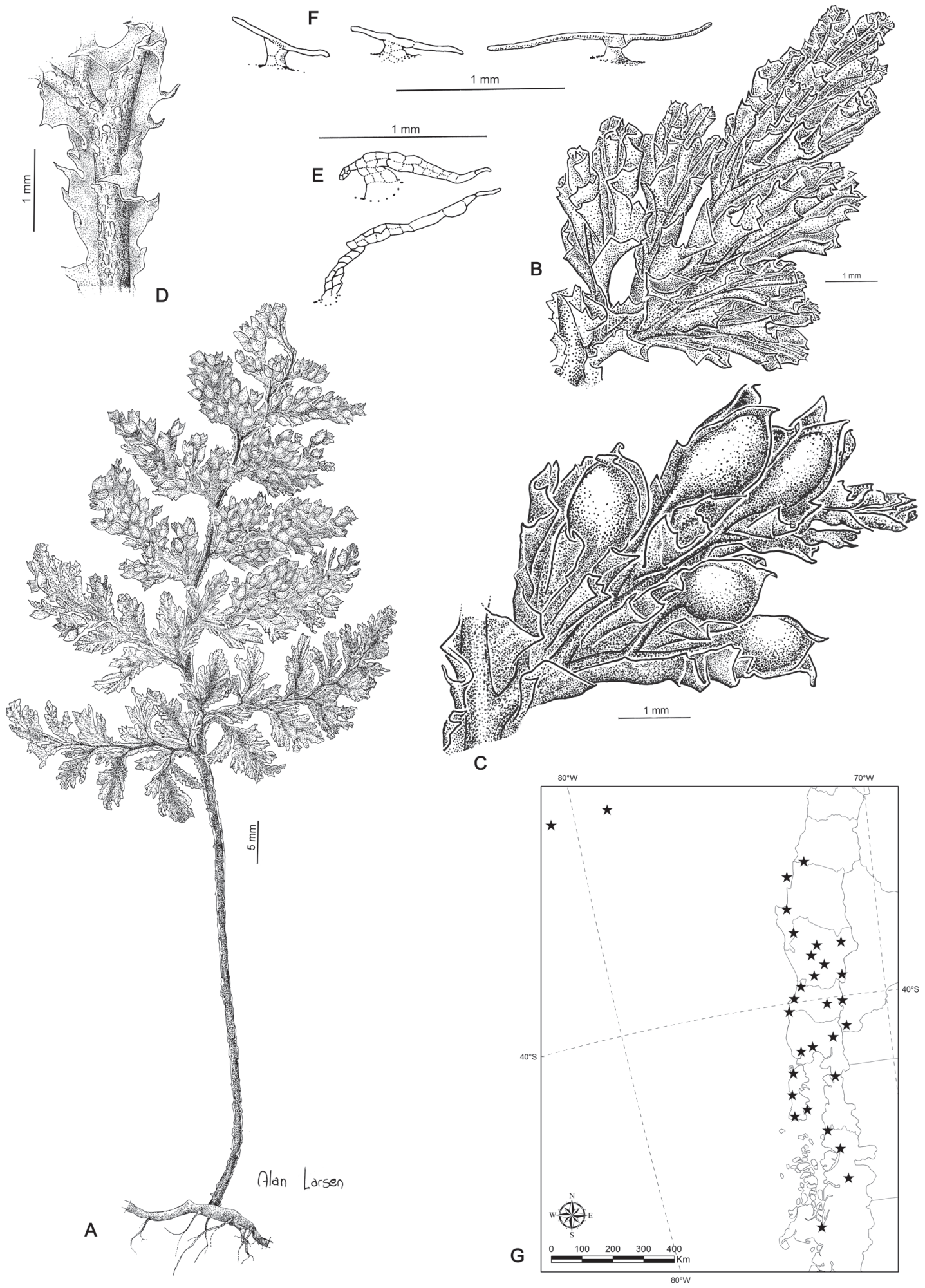

Figura 18. Hymenophyllum plicatum. A, aspecto general. B, vista de una pinna estéril. C, detalle de los indusios. D, vista en detalle del envés del pecíolo en donde se observan pequeñas expansiones. E, detalle de los pelos del pecíolo (en ejemplar joven). F, detalle de los pelos del rizoma. G, mapa de distribución de la especie.

FIGURE 18. Hymenophyllum plicatum. A, habit. B, view of a sterile pinna. C, detail of the sori. D, detailed view of the ventral side of the petiole where small expansions are observed. E, detail of the hairs of the petiole (in young specimen). F, detail of the hairs of the rhizome. $\mathrm{G}$, distribution map of the species. 
Hymenophyllum quadrifidum Phil., Linnaea 30: 208. 185960. Hymenophyllum plicatum Kaulf. var. quadrifidum (Phil.) Looser, Revista Univ. (Santiago) 22 (1): 110. 1937. TIPO: Chile, "Prope Corral", H. Krause s.n. (lectotipo, aquí designado, SGO000000525!; isolectotipo, SGO000000524!).

Rizomas ramificados, filiformes, pardo-oscuros, 0,4$1 \mathrm{~mm}$ de diám., con pelos pluricelulares (8 a 17 células), adnatos, simples, delgados, translúcidos, de 0,9-1,9 mm long., más densos en la parte inferior del rizoma, caducos a la madurez, ocasionalmente pelos adnatos con la base ensanchada; frondes de 5-18 cm long., distantes, erectas; pecíolos teretes, parduscos o negros a la madurez, de 1,5-9 $\mathrm{cm}$ long., glabrescentes, con pelos adnatos de base más o menos desarrollada sobre el lado abaxial en frondes jóvenes, que dejan un rastro al caerse, de 0,5-1 mm de diám., con alas caedizas de borde irregular muy ondulado; láminas de 3,5-13 x 1,5-5 cm, ovadas a triangular-lanceoladas, 3-4-pinnatífidas, textura membranácea, brillantes; raquis pardusco o negro a la madurez, alado, alas planas o muy onduladas, de borde irregular a laciniado; pinnas lanceoladas a ovado-lanceoladas, 2-3-pinnatífidas, 14-26 pares por fronde, de 0,4-2,5 x 0,5-1,4 cm, ascendentes, simétricas; segmentos oblongos, ápice redondo, margen irregular a dentado; soros en el mismo plano de la lámina, sobre segmentos terminales, 4-54 por pinna; involucros de 1,9-2,4 x 1,2-1,3 mm, globosos, elípticos, o elípticolanceolados, inmersos menos de la mitad en el segmento, la base aguda, el ápice agudo a cuspidado, glabro, a veces dividido en 3 o 4 valvas, abierto hasta la mitad o más; receptáculo filiforme, inserto.

Distribución Y ECOLOGÍA. Especie endémica de los bosques australes de Sudamérica. En Chile se distribuye desde la Región del Biobío hasta Isla Desolación en la Región de Magallanes y la Antártica Chilena. En Argentina se encuentra en la provincia de Neuquén, fue recolectado principalmente en Península Quetrihué y Lago Lacar (Fig. 18G). Vive en bosques muy húmedos, en general se lo ha visto epífito sobre troncos, asociado a musgos u otras especies del género, aunque también puede ser terrestre o epipétrico. Forman colonias pequeñas y definidas o también pueden extenderse, trepando por los troncos.

\section{ESPECÍMENES EXAMINADOS}

ARGENTINA, Neuquén, Lácar, Huahum, 640 m, 30III-1952, Diem 2114 (SI). Los Lagos, Quetrihué, arroyo Puente de Tierra, 28-VII-1940, Diem 122P (SI); Península Quetrihué, Costa Lago Nahuel Huapi, Pto. Ganger, 17VIII-1949, Diem 1193 (SI). CHILE, Región de Valparaíso, Valparaíso, Juan Fernández, Más a Tierra, Quebrada Villagra, 17-II-1931, Espinosa s.n. (SI 17441); Más Afuera, Quebrada de Las Casas, a lo largo De Caleta, 210 m, 12-
VIII-2002, Stuessy 5057 (CONC). Región del Biobío, Arauco, Isla Mocha, Laguna Hermosa, 15-III-1971, Weldt y Rodríguez 1139/434 (LP); Isla Mocha, camino entre La Hacienda y Laguna Hermosa, 15-III-1971, Weldt y Rodríguez 1122/417A (LP). Región de la Araucanía, Cautín, Temuco, 23-I-1937, Barros 262 (SI). Región de Los Lagos, Llanquihue, Volcán Calbuco, 08-II-1937, Barros 263 (SI); Peulla, 200 m, 29-X-1947, Diem 1087 (SI); PN Vicente Pérez Rosales, 273 m, 23-II-2012, Larsen 266 (SI); Valle Cayutué, 01-I-1912, Wolffhügel s.n. (SI 19950); Entre Ensenada y Petrohué, 16-II-1926, Looser 89h (SI); Lago Llanquihue, Ensenada, 07-II-1937, Barros 261 (SI); Puerto Varas, Ensenada, 50 m, 10-VI-1947, Sparre 1932 (LIL); Faldas Volcán Osorno, 19-IX-1967, Villagrán 10271 (LP). Chiloé, Queilén, 10-VII-1942, Cárdenas s.n. (SI); Chiloé, Buaúm, 30-I-1937, Barros 255 (SI). Región de Los Ríos, Valdivia, Corral, 00-XI-1929, Gunckel 806/3 (SI); Amargos, 16-III-1929, Gunckel 995.3 (SI); Fundo Venecia, Barra del Río Bueno, 11-X-1936, Hollermayer 1045 (LP); Cuyinhué, IX-1925, Werdermann 1179b (SI; LIL). Ranco, camino desde Futrono a Lago Ranco por ruta T-55, Puente Caunahué, 20-II-2012, Larsen, C. 226 (SI). Región de Aisén, Aisén, Istmo de Ofqui, 12-I-1921, Hicken s.n. (SI 16526); Isla de los Leones, sin colector s.n. (SI 16525); Ruta 7 saliendo de Puyuhuapi hacia Puerto Aysén, 26-XI-2009, Biganzoli 2226 (SI).

\section{OBSERVACIONES}

Esta especie es similar a $H$. tortuosum, la que se diferencia por los indusios oblongos, con pequeños pelos cortos en el extremo y por el margen de las frondes, dentado-ciliado y ondulado, mientras que en $\mathrm{H}$. plicatum el margen es irregular a dentado, completamente plegado (característica que le da nombre), y los indusios son elípticos con ápice agudo a cuspidado. Es una especie del subgén. Myrmecostylum.

Hymenophyllum dichotomum Cav. es una especie de las Islas Filipinas, siendo errónea la localidad del Tipo: Chile, "San Carlos de Chiloé", Née s.n. (holotipo, MA, fotografía SI!) que figura en la descripción original (Christensen 1934; Diem \& Lichtenstein 1959). Hooker (1844-1846) al observar muestras provenientes de Chile y Juan Fernández, las consideró, con dudas, similares a la especie de Islas Molucas y Java. Aquí, habiendo revisado los tipos y material adicional de ambos nombres, se excluye de la sinonimia de H. plicatum a H. dichotomum, especie del Sudeste de Asia.

Leptocionium dichotomum (Cav.) Bosch es una combinación superflua porque Van den Bosch transfiere la especie descripta por Cavanilles, pero no incluye al tipo de Filipinas sino que se refiere a material de Chile. También combina esta especie Presl, con dudas, bajo el nombre Myrmecostylum dichotomum (Cav.) C. Presl.

Hymenophyllum quadrivalve Phil. ex Reiche (Reiche 1895), es un nomen nudum, publicado sin descripción, y sin referencia a ninguna otra diagnosis. Según Looser 
(1936), se trata de H. quadrifidum, siendo quadrivalve una variante manuscrita en el herbario. Se eligió como lectotipo de $H$. quadrifidum el ejemplar con código de barras SGO000000525, por ser el ejemplar más abundante y representar mejor la variabilidad de la especie.

17. Hymenophyllum quetrihuense Diem \& J.S. Licht., Darwiniana 11(4): 661, fig. 8. 1959. TIPO: Argentina, "Neuquén: Parque Nacional Nahuel Huapi, Península Quetrihué, barranca Este del Lago Huahuan, 830 m", 14 IV-1943, J. Diem 603 (holotipo BAB00000020!; isotipos, SI000081!, LIL001948!, US00067696!). Fig. 19.

Hymenophyllum quetrihuense f. nana Diem \& J.S. Licht., Darwiniana 11(4): 663, fig. 8 px'. 1959. TIPO: Argentina, "Neuquén: Parque Nacional Nahuel-Huapí, Península Quetrihué, barranca Este del Lago Huahuan, 830 m, 14-IV1943”, J. Diem 603a (holotipo SI000082!).

Rizomas filiformes, ramificados, parduscos, de aprox. 0,4 $\mathrm{mm}$ de diám.; pelos del rizoma castaño claros a translúcidos, simples, paucicelulares, de aprox. 0,5 mm, adpresos en su base y separándose hacia el ápice, dispersos, más densos en la base del pecíolo; frondes distantes, de 3-10 cm long.; pecíolos castaño-oscuros, de 1-4 $\mathrm{cm}$ long., teretes, de aprox. $0,25 \mathrm{~mm}$ lat., alados, con escasos pelos similares a los del rizoma; lámina ovado-lanceolada, 2-pinnatífida, de 2-6 x 1-2 $\mathrm{cm}$, textura membranácea, glabras; raquis castaño oscuro, con pelos dispersos, parduscos, de aprox. 0,4 mm long., similares a los del rizoma, alado desde el primer par de pinnas, ensanchándose hacia el ápice, de margen entero; pinnas las basales más divididas, en ocasiones hacia ambos lados, las medias y apicales hasta 2-pinnatífidas con las apicales sólo con el lado acroscópico desarrollado, flabeladas, de 0,5-1 x 0,3-0,6 cm, las basales subopuestas volviéndose alternas hacia el ápice, con papilas bulbosas parduscas sobre los ejes, en el envés; segmentos oblongos, 4-5 por pinna, de aprox. 1 $\mathrm{mm}$ lat., de ápice redondo a obtuso, margen espaciadamente aserrado, con dientes notables de aprox. $0,15 \mathrm{~mm}$; soros sobre las pinnas medias y apicales, en el mismo plano de la lámina, sobre segmentos más o menos desarrollados con alas del mismo ancho o más angostas que el indusio en número de $1 \mathrm{a}$ 2 por pinna en general contiguos, subaxilares al raquis o no; involucros ovado-lanceolados a elípticos, inmersos hasta la mitad o menos en la lámina, de base aguda, engrosada, ápice agudo, margen entero, abierto más de la mitad; receptáculo cilíndrico, algo engrosado, inserto.

Distribución y eCología. Especie endémica de la Argentina, sólo se ha podido observar el material tipo de esta especie, hallado en el Parque Nacional Nahuel Huapi, que crecía terrestre en una barranca, junto con $H$. tunbrigense, $H$. tortuosum, H. darwinii y H. dentatum (Diem \& Lichtenstein 1959) (Fig. 19E).

\section{OBSERVACIONES}

Esta especie se caracteriza por presentar 1 a 4 soros por pinna sobre segmentos alados, más o menos desarrollados en ocasiones bifurcados, pinnas desarrolladas acroscópicamente, pectinadas, y soros no arqueados en la base. Es similar a $H$. pectinatum, que se diferencia por el mayor tamaño de sus frondes, y por los pelos blancuzcos presentes en el envés del raquis y nervaduras. En las características del follaje, y en las pinnas y el raquis alado se acerca a $H$. peltatum, presentando esta última especie soros subaxilares y curvados en la base. Diem \& Lichtenstein (1959) destacan a las células opacas como una característica de esta especie. Se ubica dentro del subgén. Hymenophyllum (Ebihara et al. 2006).

18. Hymenophyllum rugosum C. Chr. ex Skottsb., Nat. Hist. of Juan Fernández and Easter Isl. 2: 12, f.4 a-f. 1920. TIPO: Chile, Archipiélago Juan Fernández, Más a Tierra, "Elevated slopes of Q. Piedra Agujereada, on fern tres, 650 m", 5-IV-1917, C. Skottsberg 592 (lectotipo, aquí designado, S, foto SI!; isolectotipos K000589695!, US00067700!, UPS, GB, fotos SI!, SGO, no visto). SINTIPOS: "Cordón Centinela, dark humid forest, ca. $560 \mathrm{~m}$ ", C. Skottsberg 1140 (sintipo, S, foto SI!); the longitud, ridge, above Pangal, on tree ferns, ca. $800 \mathrm{~m}$, C. Skottsberg s.n.(sintipo, no localizado); "Quebrada Villagra, mountain spur W. of El Yunque, ca. 500 m", C. Skottsberg 630 (sintipos, S, GB, fotos SI!); "Más Afuera: Woods on the Sanchez plain, 515 m", C. Skottsberg 1137 (sintipo, GB, foto SI!); "heath of the Correspondencia Camp, in the ravines, $1100-1200$ m", $C$. Skottsberg 423 (sintipos S, UPS, GB, fotos SI!); idem., $C$. Skottsberg 1139 (sintipo, S, foto SI!); Cordón del Barril, ca. 750 m, C. Skottsberg s.n.(sintipo, no localizado); "Quebrada del Blindado, in the forest, on ferns", $440 \mathrm{~m}, 19-\mathrm{II}-1917$, C. Skottsberg 397 (sintipos K000589696!, P00622124!, P00622125!, US1055802, no visto, GB, S, BM, fotos SI!, UPS, no visto); "near the summit of Los Inocentes, ca. 1400 m”, C. Skottsberg 1138 (sintipo S, foto SI!). Hymenophyllum rugosum fma. lanceolata C. Chr. ex Skottsb., Nat. Hist. of Juan Fernández and Easter Isl. 2: 13. 1920. TIPO: Chile, "Más Afuera, at the Correspondencia Camp, in the ravine, 1160 m", C. Skottsberg 1175 (lectotipo, aquí designado, GB, foto SI!, isolectotipo S, foto SI!; UPS, no visto). Fig. 20.

Rizomas filiformes, pardo-oscuros, de 0,3-0,5 mm de diám., con escasos pelos brillosos, más densos en la inserción del pecíolo; frondes distanciadas, de $5-15 \mathrm{~cm}$ long.; pecíolos castaño oscuros, de 1,6-7 cm long., con pelos y/o papilas cortas, teretes, alados o no, cuando alados con alas dentadas de $0,1 \mathrm{~mm}$. lat.; láminas ovado-lanceoladas o linearlanceoladas, 2-3-pinnatífidas, de 3,7-9 x 1-4 cm, textura membranácea, con dientes espaciados sobre el margen, y pelos cortos o papilas sobre los ejes; raquis castaño oscuro, con pelos o papilas cortas a ambos lados, con alas planas 


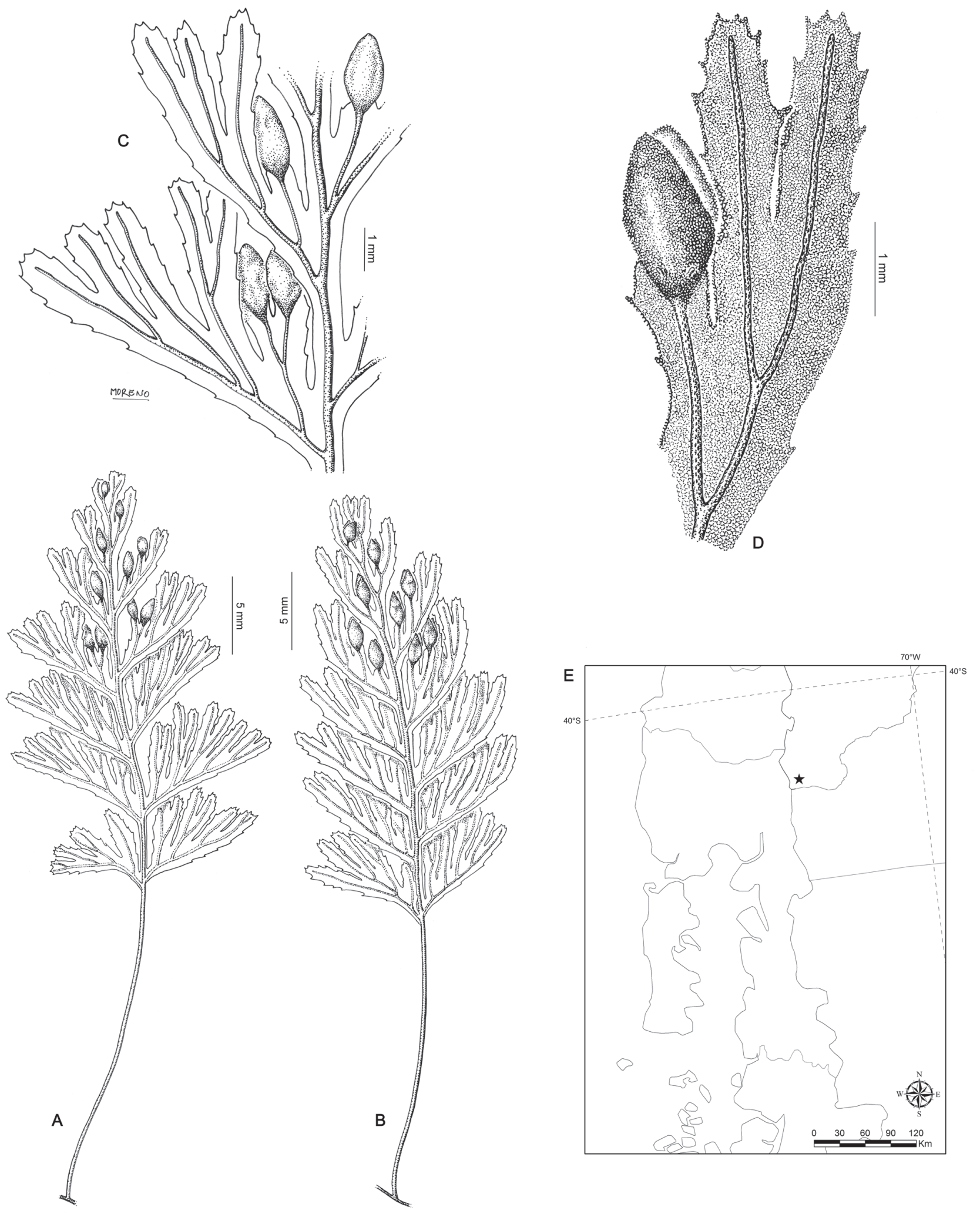

Figura 19. Hymenophyllum quetrihuense. A, B. aspecto general. C, detalle de un sector de la fronde. D, detalle de una pinna fértil. E, mapa de distribución de la especie.

Figure 19. Hymenophyllum quetrihuense. A, B, habit. C, detail of a portion of frond. D, detail of a fertile pinna. E, distribution map of the species. 


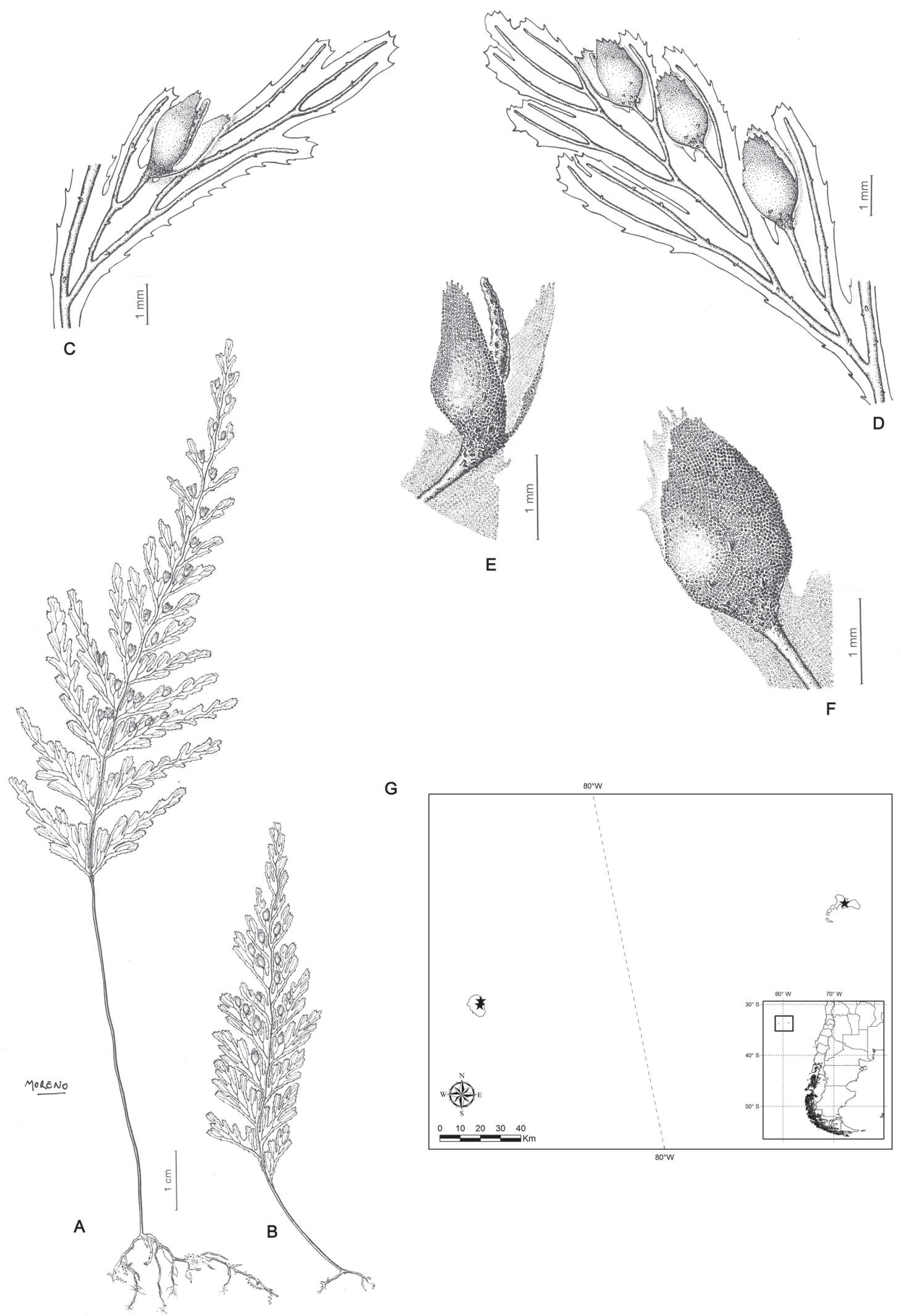

FIGURA 20. Hymenophyllum rugosum. A, B, aspecto general. C, D, vista de pinnas fértiles. E, F, detalle de indusios. G, mapa de distribución de la especie.

Figure 20. Hymenophyllum rugosum. A, B, habit. C, D, view of fertile pinnae. E, F, sorus detail. G, distribution map of the species. 
de 0,1-0,2 $\mathrm{mm}$ de ancho, de margen entero con dientes espaciados; pinnas ovado-lanceoladas, 2-pinnatífidas, de 0,5-3,4 x 0,2-0,8 cm, simétricas, alternas; segmentos oblongos, de 0,3-0,5 mm lat., de ápice redondo o trunco, de margen dentado; soros 1 a 3 por pinna, subaxilares o sobre segmentos cortos siempre adaxiales al raquis, en el mismo plano de la lámina, con su base levemente arqueada o no; involucros oblongos u ovados, no inmersos en la lámina, de base engrosada, obtusa, ápice agudo, irregularmente dentado en general, valvas abiertas más de la mitad, con pequeñas papilas sobre su superficie en la región basal; receptáculo cilíndrico, adelgazándose en la base.

Distribución y eCOlOGía. Especie endémica del Archipiélago Juan Fernández, tanto en Más a Tierra como en Más Afuera, hasta los 1400 m s.m. Terrestre o epífito, sobre los tallos de helechos arborescentes o de los árboles del bosque (Fig. 20G).

Material EXAMinado.

CHILE, Región de Valparaíso, Valparaíso, Juan Fernández: Más a Tierra, Co. Central arriba de la Q. Pangal, $650 \mathrm{~m}$, 5-III-1955, Sparre 295 (CONC); Alto Inglés, quebrada al lado S, 600 m, 28-II-1955 (CONC); Más Afuera: One-half way up the trail from mouth of Quebrada Las Vacas to Las Torres, 700 m, 2-II-1980, Stuessy et al. 5070 (CONC); On trail from mouth of Quebrada Las Vacas to Las Torres, about 2/3 up, 690 m, 2-II-1980, Stuessy et al. 5076 (CONC); Las Tres Torres, 1030 m, 4-II-1986, Stuessy 9490 (CONC).

\section{OBSERVACIONES}

Esta especie es muy particular por la presencia de pelos muy cortos o papilas sobre los ejes y nervaduras. Posee una fronde vistosa por su tamaño, lámina lanceolada, con todas sus pinnas divididas hacia ambos lados, e indusios dentados en el ápice. Presenta su mayor afinidad con H. tunbrigense, sobre todo en ejemplares pequeños, debido a sus tricomas y al margen dentado, diferenciándose ésta por sus indusios redondos, follaje verde oscuro, fronde de contorno aovado, pinnas menos divididas, y menor tamaño en general. Se ubica dentro del subgén. Hymenophyllum.

Se designa como lectotipo el ejemplar C. Skottsberg 592 depositado en $\mathrm{S}$, debido a que se consideró el material más completo y representativo de la especie.

19. Hymenophyllum secundum Hook. \& Grev., Icon. Filic. 2: tab. 133. 1831. Meringium secundum (Hook. \&. Grev.) Copel., Philip. Journ. Scien. 67(1): 44. 1938. TIPO: Argentina, Isla de los Estados, "Hab. Staten Land", $A$. Menzies s.n. (holotipo K000589698!). Fig. 21.

Hymenophyllum serra C. Presl, Hymenophyllaceae: 53, lám. 11 B. 1843. TIPO: "Habitat in Chile" H. Cuming 16 (lectotipo, aquí designado, K000589702!; isolectotipo,
K000589700!). SINTIPOS: H. Cuming 17 (K000589701); H. Cuming 19 (K000589699!).

Rizomas filiformes, ramificados, castaño-oscuros, de aprox. $0,3 \mathrm{~mm}$ de diám.; pelos del rizoma castaños a translúcidos, simples, de $0,2 \mathrm{~mm}$ long., escasos, concentrados en la base de raíces y pecíolos; frondes distantes, de 5-15(25) cm long.; pecíolos castaños oscuros, brillosos, de 2-3,5 cm long., de 0,4-0,5 mm lat., no alados, u ocasionalmente con delgadas alas caedizas en su parte apical, glabros; láminas lanceoladas a rómbicas, pinnado-2-pinnatífidas hasta 4-pinnatífidas, de 3-15 x 1-5 cm, textura membranácea, glabras; raquis castaño oscuro brillante, angostamente alado en su base ensanchándose hacia el ápice hasta $0,15 \mathrm{~mm}$, de margen entero, glabro; pinnas flabeladas las inferiores, trapeciformes las superiores, 2-3-pinnatífidas, de 1-1,5 x 0,5-1 cm, alternas, o en ocasiones las basales subopuestas, formadas por un eje principal recto que se arquea a la madurez, generando divisiones dicotómicas que originan segmentos hacia el lado acroscópico a su vez divididos dicotómicamente y reflexos a la madurez; segmentos lineares a oblongos, de 0,6-0,9 $\mathrm{mm}$ lat., de ápice redondo a trunco, margen aserrado, usualmente revoluto, con dientes pronunciados hasta de $0,15 \mathrm{~mm}$ long., distanciados aprox. $1 \mathrm{~mm}$ entre sí, por senos redondeados; soros en la porción apical de la fronde, en general 1-3 por pinna, hacia el lado acroscópico de la misma, arqueados en la base, subaxilares sobre un corto segmento apenas alado; involucros ovados, a elípticos o romboidales, globosos, no inmersos en la lámina, de base engrosada y ápice redondo a agudo, margen entero, valvas abiertas hasta más de la mitad; receptáculo cilíndrico, exerto.

DistribuCiÓn Y eCología. Especie endémica, se distribuye en toda el área de estudio tanto en la Argentina como en Chile. Es notable la cantidad de ejemplares recolectados en la parte sur del área, en Tierra del Fuego y Magallanes en Chile (Fig. 21G). Vive epífito o terrestre, en bosques y turberas, mezclado con musgos y otras especies del género.

\section{MATERIAL EXAMINADO}

ARGENTINA, Chubut, Futaleufú, Parque Los Alerces en el alerzal, extremo oeste del brazo sud del Lago Menéndez, 11-X-1953, Burkart 19099 (SI). Neuquén, Los Lagos, Puerto Blest, desembocadura del Río Bravo, 25-X-1947, Diem 1067 (SI; BAB); Río Pireco, Camino Rincón al Paso Puyehué, cascada Sta. Ana, 1100 m, 03-IV-1953, Diem 2248 (SI; BAB); Puerto Blest, Laguna Ortiz-Basualdo, 1100 m, 24-X-1947, Diem 1062 (SI; BAB). Río Negro, Bariloche, entre Puerto Blest y Puerto Alegre (Laguna Frías), 800 m, 23-X-1947, Diem 1056 (SI; BAB); Laguna Frías, 28I-1942, Pérez Moreau 104 (LIL); Lago Nahuel Huapi, Brazo Tristeza, Arroyo Lluvucó, 780 m, 04-V-1952, Diem 2144 (SI; BAB). Tierra del Fuego, Ushuaia, Puerto Cook 


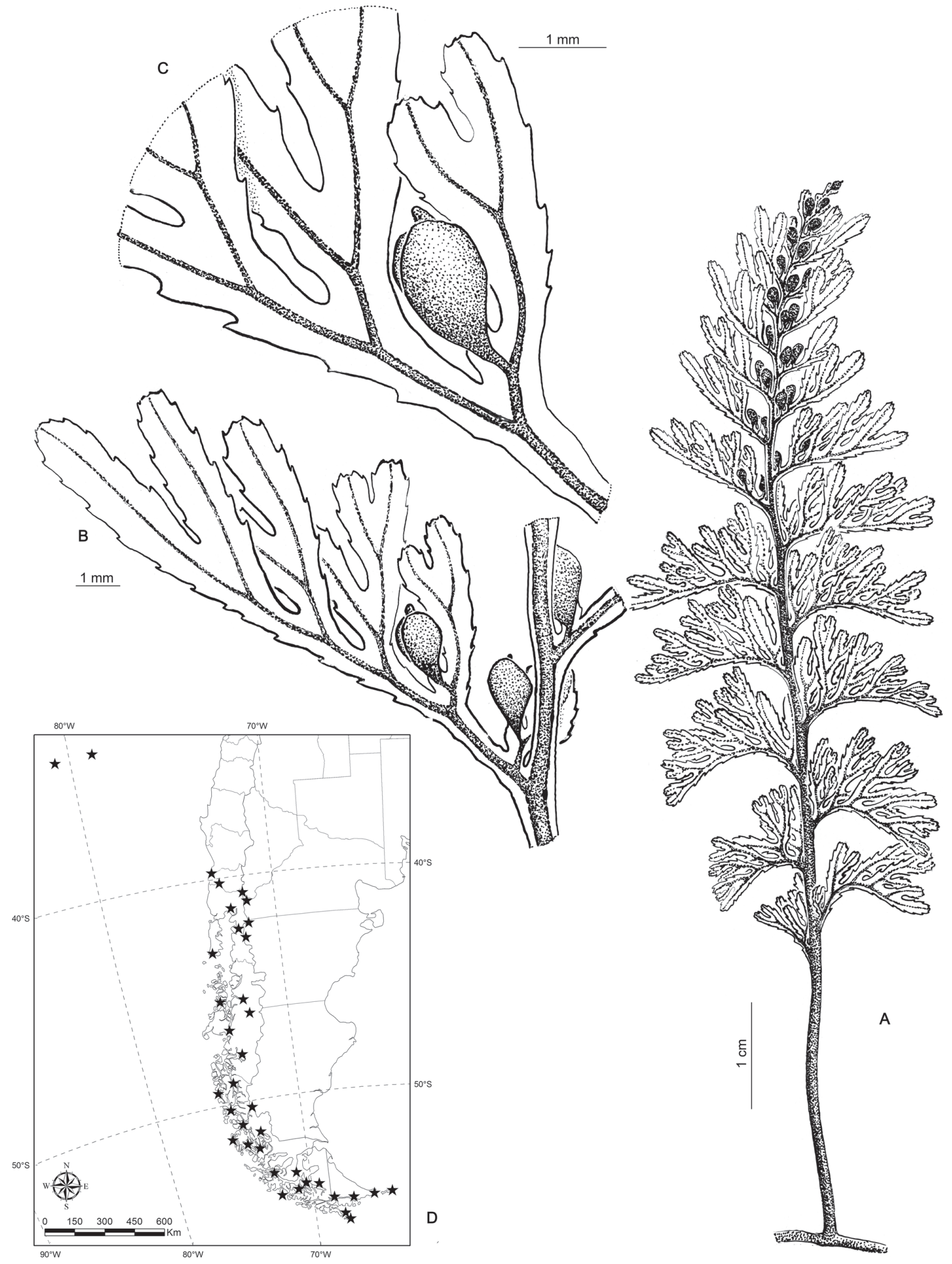

Figura 21. Hymenophyllum secundum. A, aspecto general. B, vista de una pinna fértil. C, detalle de un indusio. D, mapa de distribución de la especie.

Figure 21. Hymenophyllum secundum. A, habit. B, view of a fertile pinna. C, detail of a sorus. D, distribution map of the species. 
al E, 25-XII-1967, Torres 1116 (SI); Environs d'Ushuaia, 00-IV-1896, Alboff 904 (SI); San Juan del Salvamento (Isla de los Estados), 18-IV-1896, Alboff 918 (SI); Isla de los Estados, Puerto Roca, 21-X-1971, Dudley 704 (LP); Isla de los Estados, Puerto Parry, cerro de la laguna del chorrillo, 22-XI-1998, Biganzoli 470b (SI); Ushuaia, Bahía Thetis, 13-XI-1969, Goodall 2233 (SI; BAB); Ushuaia, thick forest near Cabo San Vicente, 15-XI-1969, Goodall 2282 (SI); Ushuaia, Fiordo Parry, Puerto Cuchillo, 14-II1971, Pisano 3151 (LP); Ushuaia, Río Tristen, 28-IV-1974, Goodall 4818 (BAB); Ushuaia, Monte Portillo, 02-IV-1972, Goodall 4248 (BAB); Ushuaia, Estancia Moat, mountain at head of Río Chico, 400 m, 26-I-1968, Moore 1641 (BAB); Ushuaia, Paso Garibaldi, 01-II-1974, Goodall 4747 (BAB); Ushuaia, Tierra Mayor Valley, 24-III-1974, Goodall 4801 (BAB); Ushuaia, Mitre Península of Isla Grande, 13-X1971, Dudley 228 (BAB). CHILE, Región de Valparaíso, Valparaíso, Más Afuera, Quebrada Mono, 800 m, Skottsberg 1135 (CONC). Región de Los Lagos, Chiloé, Pastahué, 21IX-1931, Junge 22/35 (SI). Llanquihue, Reserva Nacional Llanquihue, entrada al sendero, 526 m, 24-II-2012, Larsen 269 (SI); PN Alerce Andino, sendero hacia el Alerzal milenario, 147 m, 25-II-2012, Larsen 279 (SI). Región de Aisén, Aisén, Istmo de Ofqui, Punta Leopardo, 24-II1921, Hicken 139 (SI 16541); Puerto Chacabuco, Parque Aiken Sur, sendero del salto, 28-XI-2009, Biganzoli 2240 (SI). Región de Magallanes, Magallanes, Melville Island, 00-VI-1882, Spegazzini 304 (LP 21729); Isla Santa Inés, 13-I-1950, sin colector s.n. (SI 19923); Isla Dawson, Río San Rafael, 23-XII-1910, Benove 181 (SI). Antártica Chilena, Islas Wollaston, Isla Grevy, Pto. Caja, 05-I-1949, Vervoorst 321 (LIL); Isla Herschel, Pto. Piedrabuena, 12I-1949, Vervoorst 371 (LIL); Isla Capitán Aracena, Bahía Morris, 08-XII-1971, Moore 2781 (LP). Última Esperanza, Península Roca, Seno Resi, 22-I-1978, Pisano s.n. (TBPA 2849) (BAB); Seno Última Esperanza, Puerto Toro, W. of R. Serrano, N. of Vent. Balmaceda, 18-I-1977, Moore s.n. (TBPA 1791) (BAB; LP); Seno Unión, N. side Ancón Sin Salida, 11-I-1976, Dollenz s.n. (TBPA 948) (BAB); Isla Virtudes, Canal Elías, Puerto Virtudes, 12-II-1976, Dollenz s.n. (TBPA 1513) (BAB); Isla Rennel Norte, Canal Smyth, 23-I-1976, Dollenz s.n. (TBPA 1142) (BAB); Isla Vidal Gormaz, Seno Nantuel, Bahía María Angélica, 03-II-1976, Dollenz s.n. (TBPA 1298) (BAB); Isla Diego de Almagro, Puerto Lázaro, 09-II-1976, Dollenz s.n. (TBPA 1459) (BAB); Puerto Bueno, 26-VII-1970, Parra 168 (LP); Puerto Bella Vista, 08-XII-1979, Roig 241 (TBPA 5258) (BAB); Islas Rennel, NW, 28-I-1976, Eskuche s.n. (TBPA 745) (BAB); Puerto Bella Vista, 04-XII-1979, Roig 45 (TBPA 5048) (BAB); Isla Drummond Hay, Puerto Molyneux, 11XII-1977, Roig 149 (TBPA 2656) (LP).

\section{OBSERVACIONES}

Es una especie muy variable, que se puede distinguir por sus pinnas arqueadas y reflexas, y sus segmentos angostos divididos reiteradas veces, arqueados y de margen revoluto. En el sur del área (Región de Magallanes, Tierra del Fuego), esta especie adopta una forma más pequeña, con frondes que miden en ocasiones apenas $5 \mathrm{~cm}$ y poseen las pinnas imbricadas, los pecíolos más gruesos comparativamente con el tamaño de la fronde, con alas caedizas hacia el ápice, mientras que al norte de su área de distribución se pueden encontrar las plantas de mayor tamaño (hasta $25 \mathrm{~cm}$ ).

Presenta su mayor afinidad con $H$. peltatum (véase bajo esa especie) y con $H$. falklandicum, sobre todo en la forma que habita en el sur del área de estudio. H. falklandicum se diferencia principalmente por poseer pinnas menos divididas ( 2 ó 3 segmentos), y los pecíolos más delgados y no alados. Se ubica, al igual que sus especies afines, dentro del subgén. Hymenophyllum.

En la diagnosis original de $H$. secundum, la localidad citada por Hooker \& Greville, "Nova Zelandia", fue corregida posteriormente por Hooker (1844-1846).

Se eligió como lectotipo para el nombre $H$. serra el ejemplar con código de barras K000589702, por poseer material en estado fértil.

20. Hymenophyllum tortuosum Hook. \& Grev., Icon. Filic. 2(7): tab. 129. 1829. Myrmecostylum tortuosum (Hook. \& Grev.) C. Presl, Hymenophyllaceae 28, t. 10 f. A. 1843. Leptocionium tortuosum (Hook. \& Grev.) Bosch, Ned. Kruidk. Arch. 4 (4): 384. 1859. Meringium tortuosum (Hook. \& Grev.) Copel., Philipp. J. Sci. 67: 45. 1938. TIPO: Argentina, "Hab. Staten Land", A. Menzies 787 (holotipo, K000589705!; isotipos E00215345!, OXF, BM, fotos SI!). Fig 22.

Trichomanes beckeri Krause ex Phil., Linnaea 33:305. 1865. Hymenophyllum tortuosum var. beckeri (Krause ex Phil.) Espinosa, Revista Chil. Hist. Nat. 39: 439. 1935. TIPO: Chile, Valdivia, "Prope Corral Valdivianorum portum", $H$. Krause s.n. (holotipo, SGO000000521!).

Hymenophyllum tortuosum var. bustillosii Espinosa, Bol. Mus. Nac. Hist. Nat 15: 97, lám. 4 a y b. 1936. TIPO: Chile, "Magallanes", 1859, V. Bustillos s.n. (holotipo SGO, foto SI!).

Hymenophyllum tortuosum var. glomeratum Diem \& J. S. Licht., Darwiniana 11: 683. 1959. TIPO: Argentina, "Neuquén, Parque Nac. Nahuel Huapi, Península Panguinal, Brazo Última Esperanza", J. Diem 562 (holotipo SI!).

Hymenophyllum skottsbergii Gand., Bull. Soc. Bot. France 60: 29.1913, nom. illeg., non C. Chr. 1910. TIPO: “ins. Falkland, ad West F. Hornby Mountains", 19-121907, C. Skottsberg 861 (holotipo, LY, foto SI!; isotipo, UPS, foto SI!). 


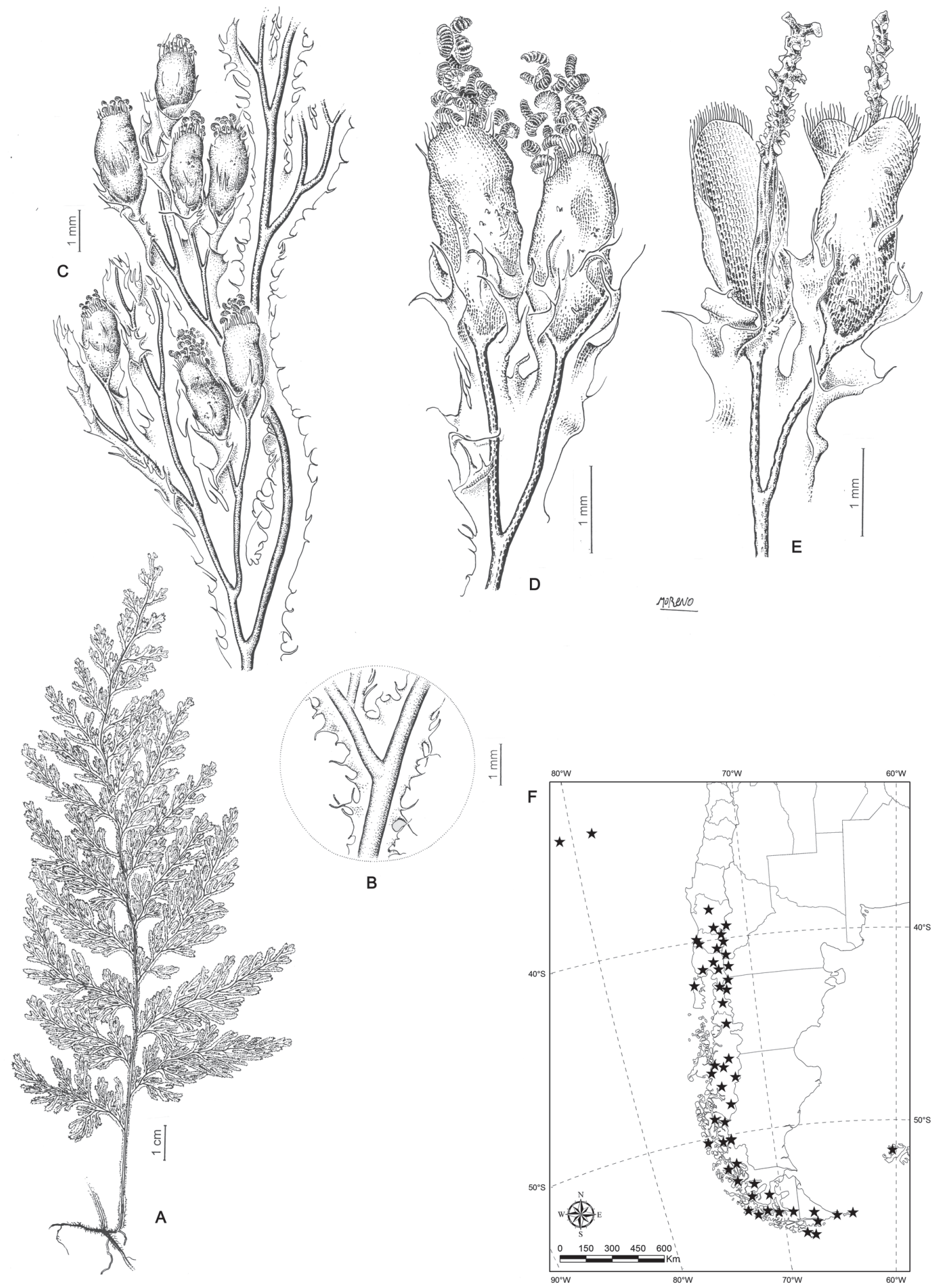

Figura 22. Hymenophyllum tortuosum. A, aspecto general. B, vista en detalle del envés del pecíolo. C, vista de parte de una fronde fértil. $\mathrm{D}$, detalle de indusios con esporangios. E, detalle de indusios, con vista completa del receptáculo. F, mapa de distribución de la especie.

Figure 22. Hymenophyllum tortuosum. A, habit. B, detailed view of the ventral side of the petiole. C, portion of a fertile frond. D, detail of sori with sporangia. E, detail of sori with full view of the receptacle. F, distribution map of the species. 
Rizomas rastreros, ramificados, castaño oscuros, de 0,3-0,6 $\mathrm{mm}$ de diám., densamente cubierto con pelos translúcidos, simples, de 6 o más células, uniseriados, ca. $2 \mathrm{~mm}$ long., algunos sobre pies ensanchados que pueden unirse formando alas, raramente en forma de $\mathrm{T}$; frondes distanciadas, erectas, hasta de $30 \mathrm{~cm}$ long.; pecíolos castaño grisáceos, de $5-15 \mathrm{~cm}$ long., del mismo diámetro o algo más grueso que el rizoma, con alas laminares en todo su largo, caedizas, fuertemente onduladas, de margen entero hasta eroso, con largos pelos pluricelulares, hasta de $1,5 \mathrm{~mm}$ long.; láminas de contorno triangular, ovado, u ovado-lanceolado, 3-4-pinnatífidas, hasta de $20 \times 10 \mathrm{~cm}$, textura membranácea, glabras; raquis terete, oscuro, con alas similares a las del pecíolo aunque menos onduladas; pinnas lanceoladas, 2-3-pinnatífidas, 8-16 por lado, hasta $8 \times 2,5 \mathrm{~cm}$, simétricas, a veces pueden ser muy desarrolladas, raquis secundario con alas de margen dentado-ciliado; pínnulas simétricas, rómbicas a flabeladas, hasta $2 \mathrm{~cm}$ de largo; segmentos lineares, simples o bifurcados, de $1 \mathrm{~mm}$ de ancho, ápice redondeado, margen dentado-ciliado, ondulado; soros distribuidos por toda la fronde, en el extremo de los segmentos, en el mismo plano de la lámina; indusios oblongos, con dientes o cilias sobre la superficie y los márgenes, valvas abiertas en el último tercio, la base aguda, el ápice redondeado, a veces apiculado, portando un cúmulo de cortos pelos pluricelulares; receptáculo cilíndrico, engrosado en su base, exerto a la madurez, con hasta 50 esporangios en su mitad superior.

Distribución Y eCología. Especie endémica, en Chile se encuentra desde Temuco, en la Región de la Araucanía hasta la Región de Magallanes y la Antártica Chilena, y en las Islas Juan Fernández. En Argentina se distribuye desde Neuquén hasta Tierra del Fuego, Islas de los Estados y las Islas Malvinas (Fig. 22F). Epífito y terrestre en sotobosque, asociado a musgos y otras especies, como $H$. caespitosum, H. pectinatum y H. peltatum.

\section{Material eXAminado}

ARGENTINA, Chubut, Futaleufú, Parque Los Alerces en el alerzal, extremo oeste del brazo sud del Lago Menéndez, 11-X-1953, Burkart 19096 (SI). Neuquén, Lácar, Huahum, cascada Chachín, 750 m, 31-III-1952, Diem 2117 (SI); Los Lagos, Nahuel Huapi, Península Panguinal, Brazo de Última Esperanza, 09-XI-1941, Diem 565 (SI); Quetrihué, 12-V-1945, Diem 945b (SI); Nahuel Huapi, Quetrihué, Lag. Patahua, 800 m, 09-III-1959, de la Sota 2162 (LIL); Parque Nac. Nahuel Huapi, Isla Victoria, punta Norte, 06-II-1952, Boelcke 6302 (SI); Correntoso, 05-II-1934 Burkart 6317 (SI); Puerto Blest, Laguna Ortiz-Basualdo, 24-X-1947, Diem 1060 (SI); Brazo Blest, Arroyo Bravo, 09-II-1938, Capurro s.n. (LIL 18375); Puerto Blest, camino a cascada Los Cántaros, 23-II-2011, Larsen 172 (SI). Río Negro, Bariloche, camino entre Laguna y Ventisquero
Frías, 31-X-1947, Diem 1102 (SI); Puerto Blest, 00-XII1897, Spegazzini 337 (SI); Lago Frías, subida Paso de las Nubes, 29-I-1942, Pérez Moreau 201 (LIL); Bognete Pérez Rosales, 28-I-1942, Pérez Moreau 207 (LIL). Santa Cruz, Territorio de Santa Cruz, 220 m, 18-III-1901, Hogberg s.n. (SI 16055). Lago Argentino, Brazo Spegazzini, frente glaciar que baja del Cerro Heim hacia el SE, 220 m, 22-III1953, Vervoorst 4724 (LIL). Tierra del Fuego, Ushuaia, Isla de los Estados, Puerto Vancouver subida al Lago Capitán Fernández, cascada, 01-XII-1967, Nicora 7312 (SI); San Juan del Salvamento (Isla de los Estados), 18-IV-1896, Alboff s.n. (SI 16056); Isla de los Estados, Primera Bahía, 30-X-1971, Dudley 1097 (LP); Ushuaia Mitre Península of Isla Grande, 13-X-1971, Dudley 258 (BAB); Isla de los Estados, Puerto San Juan, 28-XII-1933, Castellanos, s.n. (LIL 18369); Ushuaia, Bahía Thetis, 13-XI-1969, Goodall 2232 (SI; BAB); Ushuaia, Isla de los Estados, Puerto Parry, cerro de la laguna del chorrillo, 22-XI-1998, Biganzoli 470a (SI); Islas Malvinas, West Falkland, Horny Mts., Skottsberg 861, 19-XII-1907 (BA). CHILE, Región de Los Ríos, Valdivia, camino Paso Carririñe y Liquiñe, 900 m, 1976, Marticorena 675 (CONC); Cueva La Aguada, 16-III-1929, Gunckel 972pp (SI). Región de Los Lagos, Llanquihue, Valle Callutue (Lago Esmeralda), 00-I-1912, Wolffhügel s.n. (SI 19952); Bosque límite con vegas altoandinas, bajando el volcán Osorno, 1056 m, 23-II-2012, Larsen 260 (SI). Osorno, Volcán Osorno, La Picada, 950-1500 m, 29XI-1939, Gunckel 8968 (LIL). Región de Aisén, Aisén, San Rafael, 18-I-1921, Hicken 70bis (SI); Leopardo, 12I-1921, Hicken 83 (SI 16611); Istmo de Ofqui, playita, 04-II-1921, Hicken s.n. (SI 16609); Entre el Lago León y el río Fiero (región del Lago Buenos Aires), 550 m, 09II-1939, Rentzell 6250 (SI). Coihaique, Ruta de Puerto Tranquilo al Ventisquero Río Exploradores, km 24, 320 m, 29-XI-2009, Biganzoli 2262 (SI); Ruta de Puerto Tranquilo al Ventisquero Río Exploradores, km 34, 213 m, 29-XI2009, Biganzoli 2256 (SI). Región de Magallanes, Última Esperanza, Seno Última Esperanza; Puerto Bella Vista, S. shore, 11-I-1977, Moore s.n. (TBPA 1644) (LP); Isla Piazzi, Caleta Ocasión, Abra Leackey's Retreat, 150 m, 16-I-1976, Dollenz s.n. (TBPA 1018) (BAB). Magallanes, Skyring water, 01-III-1917, Bonarelli 26bis (SI); Isla Santa Inés, 00I-1950, sin colector s.n. (SI 19922); Isla Dawson, al E de la Bahía Loma, 22-XII-1910, Benove 3a (SI); Bahía Morris, Isla Capitán Aracena, 13-XII-1971, Pisano 3349 (LP); Río Santa María, a 60 km camino sur, 10-II-1972, Pisano 3515 (LP); Península Brunswick, Bahía San Nicolás, N. of Cabo Forward, 08-XII-1971, Moore 2717 (BAB). Antártica Chilena, Pernius Harvey, isla Packsaddle, 01-I-1949, Vervoorst 268 (LIL); Islas Wollaston: Bahía Hately, 80 m, 10-I-1949, Vervoorst 346 (LIL).

\section{OBSERVACIONES}

Esta especie es muy característica por su follaje levemente 
a muy ondulado y por sus indusios con ápice redondeado a trunco con numerosos pelos muy delgados. La especie más afín es $H$. magellanicum (véanse observaciones bajo esta especie), ambas se ubican en el subgénero Myrmecostylum.

21. Hymenophyllum tunbrigense (L.) Sm., Mém. Acad. Roy. Sci. (Turín) 5(1790-1791): 418. 1793. Trichomanes tunbrigense L., Sp. Pl. 2: 1098. 1753. TIPO: Inglaterra, “Anglia", sin colector s.n. (LINN 1253.4 y 1253.5, foto!). Fig. 23.

Hymenophyllum tunbrigense (L.) Sm. var. asperulum (Kunze) Diem \& J. S. Licht., Darwiniana 11: 717. 1959. Hymenophyllum asperulum Kunze, Linnaea 9: 109. 1834. TIPO: Chile, "Obtegit praerupta humida argillosa ad Talcahuano flor. Chilens.”, Diar. 148, Herb. Poepp. Kze (isotipo, BR0000006965808!, posible isotipo P00622168!).

Rizomas filiformes, ramificados, castaños, de 0,3-0,4 mm de diám.; pelos del rizoma ferrugíneos, de 0,25-0,65 mm long., escasos; frondes distantes a aprox. $1 \mathrm{~cm}$, de 1,7-8,5 cm long; pecíolos castaños, de $0,6-3,5 \mathrm{~cm}$ long., no alados, con cortos pelos simples, escasos; láminas ovadas, hasta lineares, pinnado-pinnatífidas, hasta 2-3-pinnatífidas, textura membranácea, en ocasiones con pelos ferrugíneos sobre las nervaduras y en la base de los indusios, de hasta 4 células; raquis castaño oscuro, recto o en zig-zag, alado en toda su longitud, con las alas más anchas hacia el ápice, o sólo alado en el ápice, piloso o no; pinnas ovadas, elípticas o rómbicas, 2-pinnatífidas de 0,5-1,2 x 0,3-0,8 cm, con divisiones hacia ambos lados, al menos las basales, imbricadas a algo distanciadas; segmentos lineares u oblongos, de 1-1,2 mm lat., ápice redondo a trunco, margen con dientes pluricelulares; soros uno por pinna, subaxilares, sobre el lado acroscópico de la pinna, sobre un corto segmento angostamente alado y recurvado, perpendiculares con respecto al plano de la lámina en la madurez; involucros redondos, romboidales, con la base aguda algo inmersa en el segmento, el ápice redondeado, en general irregularmente dentado o entero, ocasionalmente con pelos ferrugíneos en la base, valvas abiertas a la madurez, hasta la mitad o más; receptáculo cilíndrico inserto, no supera la long. de los indusios.

Distribución y eCología. Especie de América, Europa y Oceanía. En los bosques subantárticos de Argentina se halla principalmente en la parte norte, siendo muy frecuente en el Parque Nahuel Huapi. En Chile se encuentra desde Concepción hasta Peulla, con escasas colecciones en Islas Juan Fernández (Diem \& Lichtenstein 1959) (Fig. 23G). Es una especie terrestre, crece entre las raíces y las bases de los troncos en bosques húmedos, o cerca de cursos de agua, mezclado con musgos.

\section{MATERIAL EXAMINADO}

ARGENTINA, Chubut, Cushamen, Parque Nacional Lago Puelo, sendero a Gendarmería, 270 m, 07-XII-2009, Biganzoli 2421 (SI). Neuquén, Lácar, Huahum, cascada Chachín, 750 m, 31-III-1952, Diem 2119 (SI). Los Lagos, Península Quetrihué, lago Huahuan, 14-IV-1943, Diem 603a (SI); Brazo Rincón, Península Panguinal, cerca del camping, cruzando el río Totoral, orilla del lago, 21-II-2011, Larsen 164 (SI); arroyo Colorado, desembocadura, 12-V1940, Diem 572 (BAB); Lago Nahuel Huapi, Brazo Última Esperanza, cerca Puerto Barata, 770 m, 18-I-1948, Diem 1112 (SI; BAB); Lago Nahuel Huapi, Isla Victoria, Puerto Pampa, cerca del desagüe de un arroyo, 28-VIII-1942, Diem 395 (SI; BAB). Río Negro, Bariloche, Puerto Blest, costa del Nahuel Huapi, 29-IV-1942, Diem 573a (SI); Puerto Blest, costa sur de la Bahía, 780 m, 22-X-1947, Diem 1055 (SI; BAB). Santa Cruz, Lago Argentino: Brazo Onelli, 10II-1955, Pérez Moreau s.n. (BA 56648). CHILE, Región del Biobío, Concepción, Parque Hualpén, 21-IV-1970, De la Sota 6033 (LP); In the woodland along the unused road leading to Estero Bellavista, $8 \mathrm{~km} \mathrm{~N}$ of Lirquén, then 5 km east, 03-I-1966, Meyer 9748 (LP); Chiguayante, Cerro Manquimávida, 01-X-1938, Barros 2238 (SI); Concepción, 25-X-1938, Barros 2239 (SI). Región de Los Ríos, Valdivia, Corral, cueva La Aguada, 00-IX-1929, Gunckel 1171.4 (SI). Región de Los Lagos, Llanquihue, Lago Todos los Santos, 00-II-1910, Hauman 7 (LIL 40862); Peulla, cascada de los helechos, 250 m, 28-X-1947, Diem 1083 (SI; BAB); Llanquihue, 100 m, 1961, Kubitzki 2 (CONC).

\section{OBSERVACIONES}

Especie afín a $H$. peltatum y $H$. falklandicum, las que se diferencian por presentar todas sus pinnas desarrolladas acroscópicamente, sus ejes sin pelos, y el ápice de los indusios entero. Todas ellas pertenecen al subgén. Hymenophyllum.

En las Pteridofitas de México (Mickel \& Smith 2004) toman a la especie $H$. tunbrigense en sentido amplio, tanto por su morfología como por su distribución geográfica. La especie $H$. tunbrigense de los bosques andino-patagónicos, es una entidad de distribución restringida a algunas áreas como el lago Nahuel Huapi, y en Chile desde Concepción hasta Chiloé (Rodríguez 1995). De este modo, la especie del sur de Argentina y Chile se encuentra considerablemente aislada del taxón neotropical y del holártico.

Se excluyen de la sinonimia de $H$. tunbrigense propuesta por Diem \& Lichtenstein (1959) a: Hymenophyllum antarticum C. Presl. [Australia, "Habitat in Nova Hollandia ad Port Jackson", F. Sieber s.n. (probable isotipo US00134545!)] en la actualidad sinónimo de $H$. cupressiforme Labill. de Australia (McCarthy 1998). Hymenophyllum minimum A. Rich. ["Crescit in NovaZeelandia", Urville'd, s.n. (P00623489!)], por presentar caracteres diferentes a $H$. tunbrigense, como pinnas simples, 


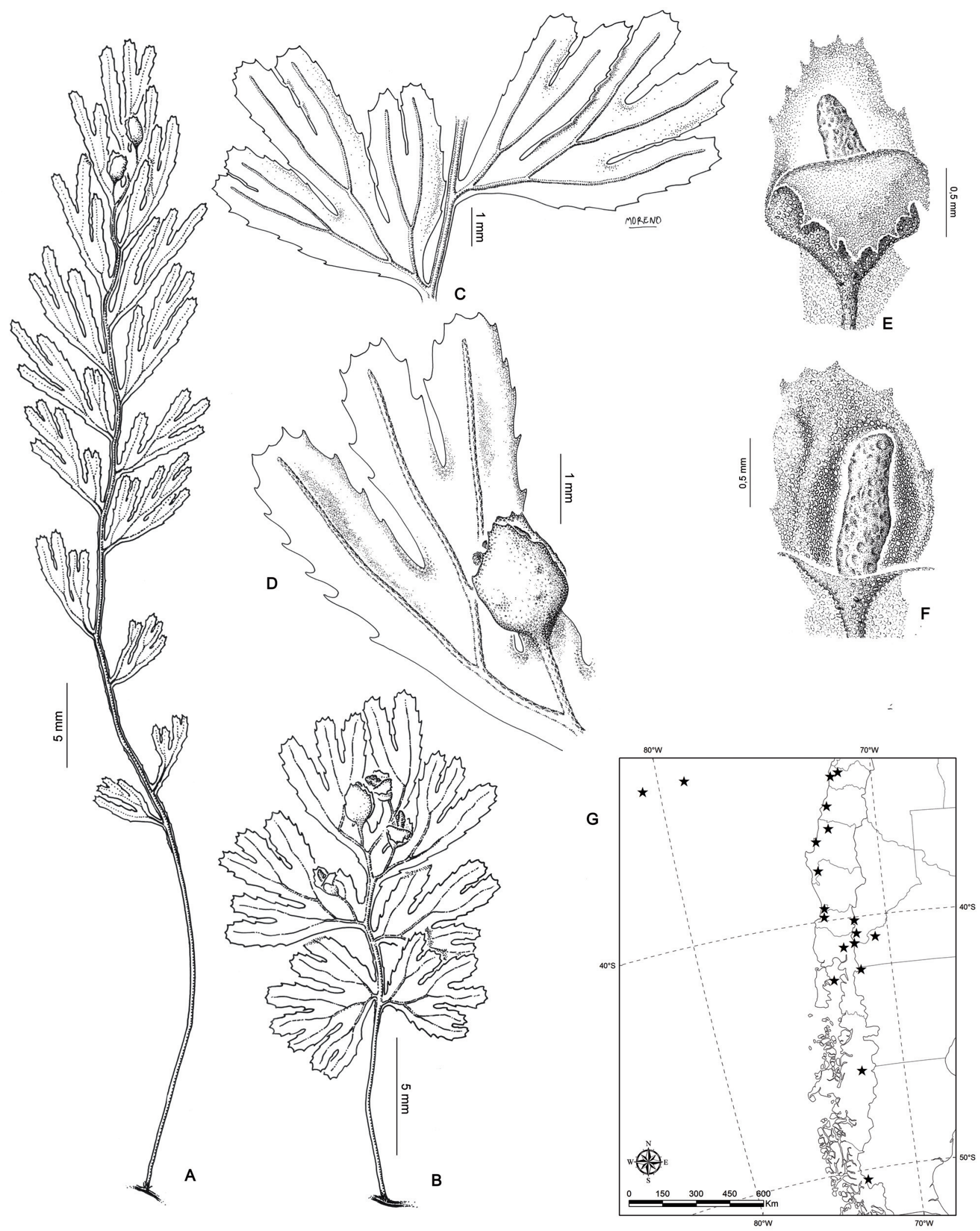

FIGURA 23. Hymenophyllum tunbrigense. A-B, aspecto general. C, detalle de las pinnas basales. D, detalle de una pinna fértil. E, detalle de un indusio. F, detalle de un receptáculo. G, mapa de distribución de la especie.

FIGURE 23. Hymenophyllum tunbrigense. A-B, habit. C, detail of basal pinnae. D, detail of a fertile pinna. E, detail of a sorus. F, detail of a receptacle. $\mathrm{G}$, distribution map of the species. 
plegadas e indusios terminales en la fronde. Hymenophyllum revolutum Colenso e Hymenophyllum zeelandicum Bosch, que corresponden a especies de Nueva Zelanda, aunque no se ha podido estudiar los tipos, y a Hymenophyllum thunbergii Eckl. in C. Presl, Hym. 32. 1843. nom. nud. citado sin descripción.

22. Hymenophyllum umbratile Diem \& J.S. Licht., Darwiniana 11:664, fig. 9.1959. TIPO:Argentina, "Neuquén. Parque Nacional Nahuel Huapi, Península Quetrihué, arroyo de la Lophosoria", 780 m, 15-II-1941 J. Diem 370 (P. 120) (holotipo SI000083!; isotipos BAB00000022!, BAB00000023! US00067708!, LIL001949!). Fig. 24.

Rizomas filiformes, ramificados, parduscos, de $0,2 \mathrm{~mm}$ de diám.; pelos del rizoma castaños, simples, paucicelulares, de aprox. 0,3 mm long., muy dispersos; frondes de 5-10 cm long., distantes; pecíolos castaño-oscuros, de 0,2-2,5 cm long., teretes, de aprox. 0,3 mm diám., no alados, glabros; láminas ovado-lanceoladas, 2-pinnatífidas, de 4-9 x 1-2,5 $\mathrm{cm}$, textura membranácea, glabras; raquis castaño oscuro, terete, de 0,1-0,3 mm lat., angostamente alado en todo su largo, glabro; pinnas flabeladas a falcadas, pinnatífidas, de $1-1,5 \times 0,2-0,6 \mathrm{~cm}$, todas dividas hacia el lado acroscópico, alternas u opuestas, con la costa continuándose en un segmento estéril, oblicuo a vertical, notablemente más ancho que el resto; segmentos oblongos, de hasta $1,5 \mathrm{~mm}$ lat., de ápice redondo o truncado, margen aserrado con dientes desde muy pequeños hasta $0,15 \mathrm{~mm}$, marcadamente acroscópicos, distanciados aprox. $0.5 \mathrm{~mm}$ entre sí; soros sobre todas las pinnas, a excepción de las más basales, de 1-4 por pinna, algo arqueados en la base, de manera que se orientan en un plano algo oblicuo con respecto al plano de la lámina, sobre un segmento corto, o de largo variable, con alas de casi el mismo ancho que el indusio o más angostas, raramente más anchas, lobuladas; involucros ovados a rómbicos, no inmersos en la lámina, de base engrosada, aguda, y ápice redondo, de margen entero a irregularmente dentado, valvas abiertas casi hasta la base; receptáculo filiforme, algo más grueso que la nervadura que lo porta, de 0,2 mm diám., inserto, tan largo como las valvas.

Distribución y eCología. Especie endémica, en la Argentina se halla en Neuquén en la península de Quetrihué. En Chile fue recolectada en la isla de Chiloé, en la Región de Los Lagos y en la Región de Aisén (Fig. 24G). Terrestre y epífita, crece en barrancas y en sotobosques húmedos.

\section{Material EXAMINADO}

ARGENTINA, Neuquén, Los Lagos, Quetrihué, Arroyo de la Lophosoria, 15-II-1941, Diem 370 (SI). CHILE, Región de Los Lagos, Chiloé, Isla Grande de Chiloé, Abtao, 300 m, 1984, Villagrán 5599 (CONC). Osorno, Río Nauto, 21II-2012, Larsen 247 (SI). Palena, Ruta 231 entre Futaleufú y Puerto Ramírez, 165 m, 26/11/2009, Biganzoli 2210 (SI). Región de Aisén, Aisén, Ruta 7 entre La Junta y Puyuhuapi, 190 m, 26/11/2009, Biganzoli 2223 (SI).

\section{OBSERVACIONES}

Diem \& Lichtenstein (1959) describen los indusios de esta especie como no arqueados en la base, lo que la acerca al grupo de $H$. pectinatum y $H$. quetrihuense. Sin embargo, en el tipo de la especie y el material examinado se observan los soros levemente arqueados en la base, a pesar que los indusios pueden orientarse en el mismo plano que la lámina. Este carácter aproxima a $H$. umbratile al grupo de $H$. peltatum, diferenciándose esta última especie principalmente porque posee los indusios con el margen entero, dispuestos sobre segmentos cortos y angostamente alados.

En las frondes estériles se observan claramente las nervaduras terminando a una distancia de aprox. $1 \mathrm{~mm}$ del margen de la fronde (Diem \& Lichtenstein 1959). El ancho de los segmentos en general aumenta hacia el ápice, alcanza su valor máximo cerca del ápice tomando una forma obovada característica, que contrasta con el ancho de las alas del raquis, mucho más delgadas. En los ejemplares de herbario frecuentemente se observa la lámina revoluta, obedeciendo este carácter a la curvatura de la costa hacia el extremo. Se ha observado también una forma característica de las pinnas fértiles, reflexas, con 4 ó 5 indusios sobre segmentos de longitud variable, algo arqueados en su base (ocasionalmente de ápice entero), y con 2 segmentos algo obovados en el extremo de la pinna, que es considerado una forma intermedia de esta especie con $H$. peltatum.

\section{CONCLUSIONES}

En la región austral-templada de Chile y Argentina se encuentran 22 especies de Hymenophyllum. Se incluyeron las variedades y formas de $H$. caespitosum, $H$. caudiculatum, $H$. cuneatum e $H$. peltatum dentro del rango específico de cada uno de estos taxones.

Se ubica nuevamente a Hymenophyllum bibraianum en la sinonimia de $H$. krauseanum.

No se encontraron evidencias morfológicas para separar a las especies $H$. caudiculatum e $H$. magellanicum presentes en las áreas disyuntas Bosque subantártico-Bosque atlántico.

Se excluyen del área estudiada a los siguientes taxones citados en Diem \& Lichtenstein (1959): Hymenophyllum antarticum de Australia, H. dichotomum Cav., de Filipinas, $H$. dilatatum (G.Forst.) Sw. de Nueva Zelanda, $H$. polyanthos (Sw.) Sw. del Neotrópico, H. rarum $\mathrm{R}$. Br., de Australia y Tasmania, H. abruptum Hook., de Jamaica, $H$. brevifrons Kunze $[=H$. abruptum var. brevifrons (Kunze.) Franch.] de Centroamérica, $H$. franklinianum Colenso de Nueva Zelanda, Hymenophyllum megachilum C. Presl de Brasil e H. wrightii Bosch, especie de China y Japón. 

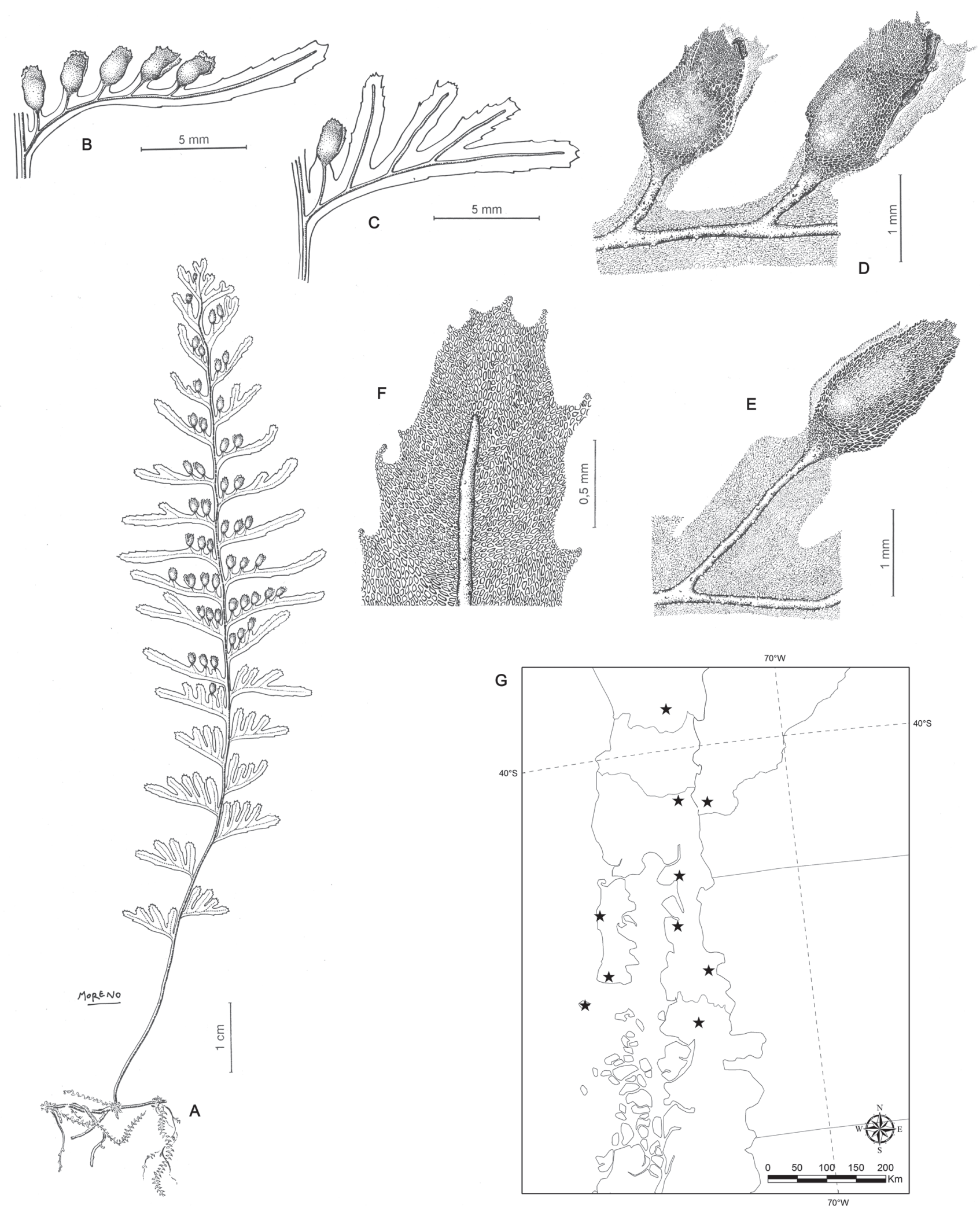

Figura 24. Hymenophyllum umbratile. A, aspecto general. B, C, vista de pinnas fértiles. D, E, detalle de indusios. F, detalle del ápice de un segmento. G, mapa de distribución de la especie.

Figure 24. Hymenophyllum umbratile. A, habit. B, C, view of fertile pinnae. D, E, sori detail. F, detail of apex of a segment. G, distribution map of the species. 


\section{AGRADECIMIENTOS}

Se agradece a Fernando Zuloaga y Marieta Múlgura por su dirección y apoyo profesional, y a Francisco Rojas, Alan Larsen, Marcelo Moreno y Jennifer Castelo por los dibujos que ilustran este trabajo. Al personal de los herbarios consultados por su atención en la búsqueda y envío de las imágenes de materiales tipo y adicionales. A los compañeros de campañas del primer autor, Fernando Biganzoli, Diego Degennaro, Christian Zanotti y Federico Beaudoin. A María Vallejos por su ayuda en la confección de los mapas.

\section{BIBLIOGRAFÍA}

Baksh-Comeau, Y.S. 2000. Checklist of the pteridophyte of Trinidad \& Tobago. Fern Gazette 16: 11-122.

Cabrera, A.L. \& A. Willink. 1973. Biogeografía de América Latina. Programa Regional de Desarrollo Científico y Tecnológico, Departamento de Asuntos Científicos, Secretaría General de la Organización de los Estados Americanos, Washington, District of Columbia. $120 \mathrm{pp}$.

Cassá de Pasos, L.A., F.F. Vidoz, G.E. Giudice, J.P. Ramos Giacosa, M.L. Luna \& E.R. de la Sota. 2010. Diversidad de helechos y licofitas del Parque Nacional Lago Puelo (Chubut-Argentina). Boletín de la Sociedad Argentina de Botánica 45(3-4): 383-403.

Christensen, C. 1905-1906. Index Filicum. Hagerup, Copenhagen. $744 \mathrm{pp}$.

Christensen, C. 1910. On some species of ferns, collected by Dr. Carl Skottsberg in Temperate South America. Arkiv för Botanik 10(2): 1-32.

Christensen, C. 1934. Index Filicum, Supplementum tertium, pro annis 1917-1933. $220 \mathrm{pp}$.

Christensen, C. 1938. Filicinae. In: F. Verdoorn (ed.), Manual of Pteridology. The Hague: Nijhoff, pp. 522-550.

Copeland, E.B. 1938. Genera Hymenophyllacearum. The Philippine Journal of Science 67: 1-110.

Copeland, E.B. 1947. Genera Filicum. Waltham, Massachusetts. $247 \mathrm{pp}$.

De la Sota, E.R. 1977. Pteridofitas. En: A. L. Cabrera (ed.), Flora de la Provincia de Jujuy. Colección Científica del Instituto Nacional de Tecnología Agropecuaria, Tomo 13, Parte 2, $275 \mathrm{pp}$.

De la Sota, E.R., M. Ponce, M. Morbelli \& L. Cassá de Pazos. 1998. Pteridofitas. En: M.N. Correa (ed.), Flora Patagónica. Colección Científica del Instituto Nacional de Tecnología Agropecuaria 8(1), pp. 282-369.

Diem, J. \& J.S. DE Lichtenstein. 1959. Las Himenofiláceas del área argentino-chilena del sud. Darwiniana 11: 611-760.

Doyle, J. J. \& J. L. Doyle. 1987. A rapid DNA isolation procedure for small quantities of fresh leaf tissue. Phytochemical Bulletin 19: 11-15.

Ebihara, A., J.-Y. Dubuisson, K. Inatsuki, S. Hennequin \& M. ITo. 2006. A taxonomic revision of Hymenophyllaceae. Blumea 51: 221-280.

Gastony, G.J. \& D.R. Rollo. 1995. Phylogeny and generic circumscriptions of cheilanthoid ferns (Pteridaceae:
Cheilanthoideae) inferred from $r b c L$ nucleotide sequences. American Fern Journal 85: 341-360.

Goloboff, P.A., J.S. Farris \& K. Nixon. 2008. TNT, a free program for phylogenetic analysis. Cladistics 24: 774-786.

Hariot, P., P. Petit, J. Muller D’argovie, E. Bescherelle, C. Massalongo \& A. Franchet. 1889. Mission Scientifique Cap Horn 1882-1883. Tome V, Botanique. GauthierVillars et Fils, Imprimeurs-Libraries, Paris. 512 pp.

Hennequin, S. 2003. Phylogenetic relationships within the fern genus Hymenophyllum s.l. (Hymenophyllaceae, Filicopsida): contribution of morphology and cytology. Comptes Rendus Biologies 326: 599-611.

Hennequin, S. 2004. Le genre Hymenophyllum Sm. (Hymenophyllaceae, Filicopsida): systématique phylogénétique, évolution morphologique et histoire biogéographique. Thèse de doctorat de l'Université Pierre et Marie Curie. 266 pp.

Hennequin, S., A. Ebihara, M. Ito, K. Imatsuki \& J.-Y. Dubuisson. 2006a. Phylogenetic systematics and evolution of the genus Hymenophyllum (Hymenophyllaceae: Pteridophyta). Fern Gazette 17: 247-257.

Hennequin, S., A. Ebihara, M. Ito, K. Iwatsuki \& J.-Y. Dubuisson. 2006b. New insights into the phylogeny of the genus Hymenophyllum s.l. (Hymenophyllaceae): revealing the polyphyly of Mecodium. Systematic Botany 31: 271-284.

Hennequin, S., A. Ebihara, J.-Y. Dubuisson \& H. Schneider. 2010. Chromosome number evolution in Hymenophyllum (Hymenophyllaceae), with special reference to the subgenus Hymenophyllum. Molecular Phylogenetic and Evolution 55: 47-59.

Hooker, W.J. 1844-1846. Species Filicum, vol. 1. Pamplin, London. Plates I-LXX.

Hooker, W.J. \& J.G. BaKer. 1868. Synopsis Filicum. Robert Hardwicke, London. 482 pp.

IWATSUKI, K. 1984. Studies in the systematics of filmy ferns: VII. A scheme of classification based chiefly on the Asiatic species. Acta Phytotaxonomica et Geobotanica 35: 165179.

Iwatsuki, K. 1990. Hymenophyllaceae. In: U.K. Kubitzki \& P.S. Green (eds.), the Families and Genera of Vascular Plants, Vol. 1: Pteridophytes and Gymnosperms. Springer-Verlag. Berlin. pp. 157-163.

Kramer, K.U. 1978. The pteridophytes of Suriname: An enumeration with keys of the ferns and fern-allies. Natuurwetenschappelijke Studiekring voor Suriname de Nederlandse Antillen, Utrecht. 197 pp.

Lellinger, D.B. 1989. The ferns and fern-allies of Costa Rica, Panama and the Chocó (Part 1: Psilotaceae to Dicksoniaceae) Pteridologia 2A: 1-364.

Lellinger, D.B. 2002. A Modern Multilingual Glossary for Taxonomic Pteridology. Pteridologia 3: The American Fern Society, Inc., 263 pp.

Looser, G. 1936. Identificación de algunas pteridofitas chilenas descritas por el Dr. R.A. Philippi.

McCARthy, P.M. 1998. Flora of Australia. Volume 48: Ferns, Gimnosperms and Allied Groups. Melbourne ABRS/ CSIRO. 766 pp.

Mickel, J.T. \& A.R. Sмith. 2004. The Pteridophytes of Mexico. Memoirs of the New York Botanical Garden 88. 1054 pp.

Morton, C.V. 1968. The genera, subgenera and sections of the 
Hymenophyllaceae. Contributions from the United States National Herbarium 38: 153-214.

Pacheco, L. 1995. Hymenophyllaceae. En: G. Davidse, M. Sousa \& A.S. Knapp (eds.), Flora Mesoamericana 1: Psilotaceae a Salviniaceae. pp. 62-83. Universidad Nacional Autónoma de México, Instituto de Biología, México, D.F.

Pichi Sermolli, R.E.G. 1977. Tentamen pteridophytorum genera in taxonomicum ordinem redigendi. Webbia 31: 315-512.

Proctor, G.R. 1985. Ferns of Jamaica: A guide to the pteridophytes. British Museum (Natural History). London. 631 pp.

Proctor, G.R. 1989. Ferns of Puerto Rico and the Virgin Islands. Memoirs of the New York Botanical Garden 53: 1-389.

Pryer, K.M., A.R. Smith, J.S. Hunt \& J.-Y. Dubuisson. 2001. $r b c L$ data reveal two monophyletic groups of filmy ferns (Filicopsida: Hymenophyllaceae). American Journal of Botany 88: 1118-1130.

ReICHE, C. 1895. Informe del señor doctor Karl Reiche, naturalista de la expedición. En: H. Steffen (ed.), Memoria jeneral sobre la espedicion esploradora del rio Palena. (Diciembre 1893-Marzo 1894). Anales Universidad de Chile 90: 715747.
Rodríguez, R.R. 1995. Pteridophyta. En C. Marticorena \& R. Rodríguez (eds.), Flora de Chile, Vol.1. Universidad de Concepción, Chile. pp. 119-309.

SADEBECK, R. 1902. Pteridophyta. In: H.G.A. Engler \& K.A.E. Prantl (eds.), Die Näturlichen Pflanzenfamilien, Teil 1, Abt. 4.880 pp.

SÁnchez, C. 2000. Hymenophyllaceae. En: W. Greuter (ed.), Flora de la República de Cuba, Fasc. 4. iv + 96 pp. Koeltz Scientific Books, Königstein.

STURM, J.W. 1858. Enumeratio plantarum vascularium cryptogamicarum Chilensium. Abhandlungen der Naturhistorischen Gesellschaft zu Nürnberg 1: 151-202.

Thiers, B. (continuously updated). Index Herbariorum: A global directory of public herbaria and associated staff. New York Botanical Garden's Virtual Herbarium. http://sweetgum. nybg.org/ih/

Tryon, R.M. \& R.G. Stolze. 1989. Pteridophyta of Peru, Part I. Fieldiana Botany 20: 1-145.

Vidoz, F.F., L.A. Cassá de Pazos \& E.R. de la Sota. 1999. Paso Puelo, Chubut, Argentina: vía de ingreso de helechos valdivianos. Parodiana 11(1-2): 43-48.

\begin{abstract}
APÉNDICE
H. apiculatum Mett. ex Kuhn AF275642 (Pryer et al. 2001); H. australe Willd. AB191439 (Hennequin et al.2006b); H. badium Hook \& Grev. AB191440 (Hennequin et al. 2006b); H. caespitosum Gaudich. (= Serpyllopsis caespitosa (Gaudich.) C. Chr.) AF275649 (Pryer et al. 2001); H. capurroi de la Sota, C. Larsen 108 (SI) new; H. caudiculatum Mart. var. productum (C. Presl) C. Chr. AB191442 (Hennequin et al. 2006b); H. cruentum Cav. (= Hymenoglossum cruentum (Cav.) C. Presl) AY095107 (Hennequin et al. 2003); H. cuneatum Kunze AY775401 (Hennequin et al. 2006b); H. darwinii Hook. f. ex Bosch, F. Biganzoli 2253 (SI) new; H. demissum (G. Forst.) Sw. AY775402 (Hennequin et al. 2006b); H. dentatum Cav. AB496563 (Hennequin et al. 2010); H. dicranotrichum (C. Presl.) Sadeb. AB496562 (Hennequin et al. 2010); H. dilatatum (G. Forst.) Sw. AY095111 (Hennequin et al. 2003); H. falklandicum Baker, Biganzoli 2254 (SI) new, C. Larsen 178 (SI) new; H. ferrugineum Colla AF275644 (Pryer et al. 2001); H. flexuosum A. Cunn.AB217850 (Hennequin et al. 2006b); H. fuciforme Sw. AB191446 (Hennequin et al. 2006b); H. fucoides (Sw.) Sw. U20933 (Hasebe et al. 1995); H. heimii Tardieu AY775404 (Hennequin et al. 2006b); H. hirsutum (L.) Sw. AY775407 (Hennequin et al. 2006b); H. imbricatum Blume AB496566 (Hennequin et al. 2010); H. inaequale (Poir.) Desv. AY095112 (Hennequin et al. 2003); H. krauseanum Phil., F. Biganzoli 2228 (SI) new; H. magellanicum Willd. ex Kunze (= H. seselifolium C. Presl), C. Larsen 190 (SI) new; H. multifidum (G. Forst.) Sw. GU200664 (Hennequin et al. 2010 ); H. pectinatum Cav. AY095115 (Hennequin et al. 2003); H. peltatum (Poir.) Desv. GU200665 (Hennequin et al. 2010), AB496559 (Hennequin et al. 2010), AB496564 (Hennequin et al. 2010), F. Biganzoli 2236 (SI) new, F. Biganzoli 2247 (SI) new; H. plicatum Kaulf. AB496561 (Hennequin et al. 2010); H. polyanthos (Sw.) Sw. AB064295 (Ebihara et al. 2002), AF275647 (Pryer et al. 2001 ), AY775406 (Hennequin et al. 2006b), AY775405 (Hennequin et al. 2006b); H. pulcherrimum Colenso AB191451 (Hennequin et al. 2006b); H. rarum R. Br. AB217845 (Hennequin et al. 2006b); H. rugosum C. Chr. \& Skottsb.GU200667 (Hennequin et al. 2010); H. secundum Hook. \& Grev. AF275648 (Pryer et al. 2001); H. tortuosum Hook. \& Grev. GU200668 (Hennequin et al. 2010); H. tunbrigense (L.) Sm. AB496579 (Hennequin et al. 2010), GU200670 (Hennequin et al. 2010), GU200671 (Hennequin et al. 2010); H. umbratile Diem \& J. S. Licht., F. Biganzoli 2223 (SI) new; H. villosum Colenso AB191454 (Hennequin et al. 2006b); H. wilsonii Hook. GU200669 (Hennequin et al. 2010 ); Trichomanes rigidum Sw. AY095108 (Hennequin et al. 2003).
\end{abstract}

Recibido: 27.12.12

Aceptado: 09.08 .13 